Portland State University

PDXScholar

10-16-1980

\title{
A Cross-Cultural Study of Role Behaviors Pertaining to the Roles of Student and Professor
}

Kathryne Jeanne Nadal

Portland State University

Follow this and additional works at: https://pdxscholar.library.pdx.edu/open_access_etds

Part of the Communication Commons, and the Education Commons

Let us know how access to this document benefits you.

\section{Recommended Citation}

Nadal, Kathryne Jeanne, "A Cross-Cultural Study of Role Behaviors Pertaining to the Roles of Student and Professor" (1980). Dissertations and Theses. Paper 863.

https://doi.org/10.15760/etd.863

This Thesis is brought to you for free and open access. It has been accepted for inclusion in Dissertations and Theses by an authorized administrator of PDXScholar. Please contact us if we can make this document more accessible: pdxscholar@pdx.edu. 


\title{
A CROSS-CULTURAL STUDY OF ROLE BEHAVIORS \\ PERTAINING TO THE ROLES OF \\ STUDENT AND PROFESSOR
}

by

KATHRYNE JEANNE NADAL

A thesis submitted in partial fulfillment of the requirements for the degree of

\author{
MASTER OF ARTS \\ in \\ SPEECH COMMUNICATION
}

Portland State University

1980 
TO THE OFFICE OF GRADUATE STUDIES AND RESEARCH:

The members of the committee approve the thesis of

Kathryne Jeanne Nadal presented October 16, 1980.

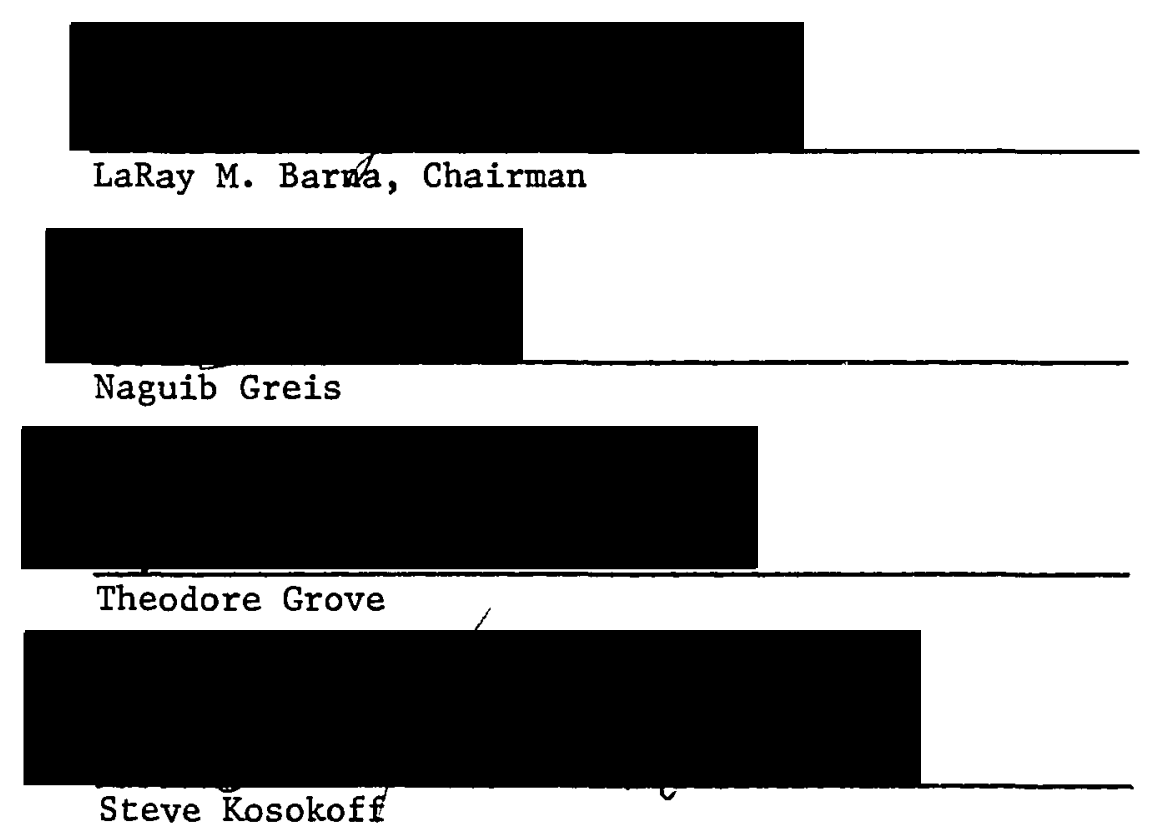

APPROVED :

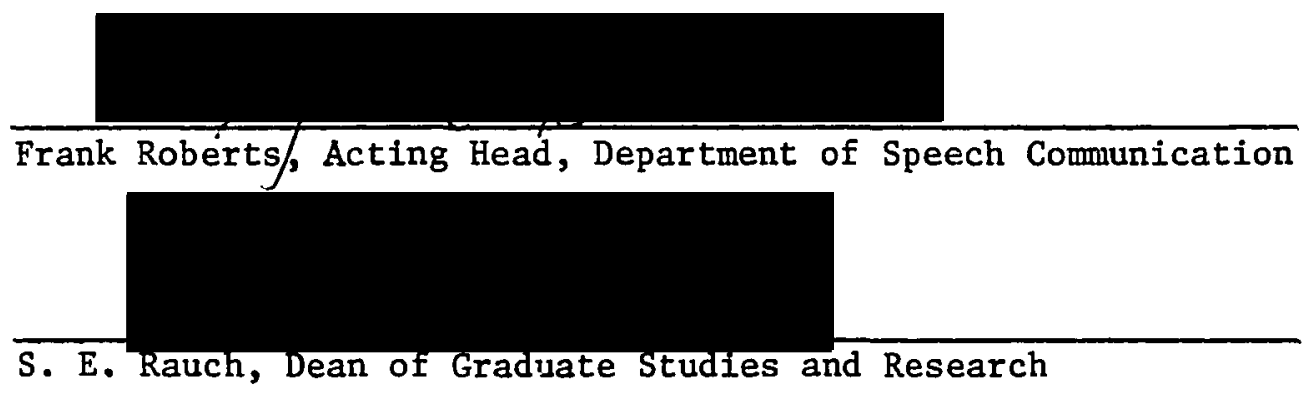


AN ABSTRACT OF THE THESIS OF Kathryne Jeanne Nadal for the Master of Arts in Speech Communication presented October 16, 1980.

Title: A Cross-Cultural Study of Role Behaviors Pertaining to the Roles of Student and Professor.

APPROVED BY MEMBERS OF THE THESIS COMMITTEE:

LaRay M. Barnal Chairman

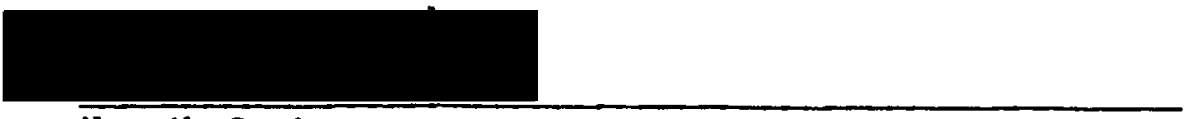

Naguib Greis

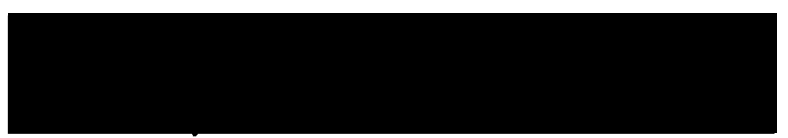

Theodore Grove

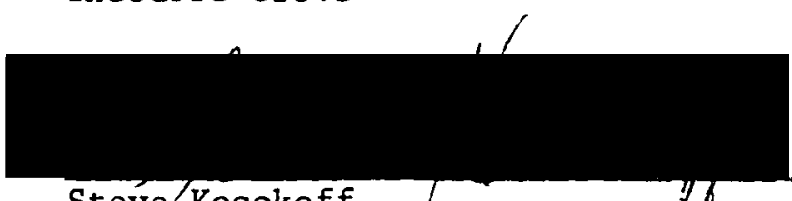

Steve/Kosokoff /

Communication theory involving the role concept has shown that role expectations and differing evaluations of role behavior can lead to communication breakdowns between persons. Literature pertaining to relations between professors and international students indicates the presence of unfulfilled expectations between them as to how they perform their respective roles. It was therefore hypothesized that some difficulties international students face in the academic world may be due to factors such as differing role expectations. As the literature provided no methodologically based cross-cultural research in 
this area, the researcher undertook to discover if professors and students evaluate the roles of student and professor differently crossculturally. The researcher was also interested to learn of other factors that might affect role behavior evaluation such as status, sex, country of origin, and time in country.

The purpose of the research was to: 1) definitively explore the current status of cross-cultural research on the roles of professor and student; 2) develop and administer a questionnaire that would allow a cross-cultural exploration of the role behaviors associated with the roles of student and professor; and 3) analyze the results.

Role behaviors associated with student and professor roles were obtained from a multi-cultural sample and from them a prototype questionnaire was composed of 118 selected role behavior items. This was given to a sample of thirty-four subjects at two week intervals. Fortyfive items evaluated at a significance level of .65 or above were termed reliable and included in a final questionnaire that was completed by a cross-cultural sample of 501 professors and students at a large urban university.

The results indicated that culture-and status both affect how a role behavior is evaluated, but that culture is the more significant factor. When the evaluations of international students and American students were compared, using the t-Test for comparison of independent sample means, they differed significantly in the evaluation of seventeen items. International students and American professors differed in their evaluation of twenty-three of the forty-five items, whereas when American students' evaluations of the items were compared to those of 
American professors' there were only five items evaluated differently. These results can be interpreted to mean that American students and American professors perceive these roles more similarly than do international students and American professors.

Using an "etic-emic" classificatory schema there were nineteen "etic" and twenty-six "emic" role behaviors. Of the "emic" role behaviors, culture was determined to be the significant variable for the differing evaluations of sixteen items, status for five items, and both status and culture for one item. For four items is was not possible to determine the primary factor responsible.

Further analysis of the data indicated that sex, status as an undergraduate, graduate, or professor, and cultural background or country of origin are other variables that can be isolated out as affecting how a role behavior is evaluated.

The significance of the results and suggestions for improving communication between professors and students is addressed and directions for further research suggested. 
The soul of wit may become the very body of untruth. However elegant and memorable, brevity can never, in the nature of things, do justice to all the facts of a complex situation. On such a theme one can be brief only by omission and simplification. Omission and simplification help us to understand--but help us, in many cases, to understand the wrong things; for our comprehension may be only the abbreviator's neatly formulated notions, not of the vast, ramifying reality from which these notions have been so arbitrarily abstracted. But life is short and information endless: nobody has time for everything. In practice we are generally forced to choose between an unduly brief exposition and no exposition at all.

Aldous Huxley

Brave New World Revisited 
The belief in an idea or concept provides one with the momentum to undertake its exploration and the determination to see that exploration through; but, it is the encouragement, inspiration, careful criticism, direction, cooperation, and help from others that enable that idea or concept to grow and mature as it should. During the past seven years, many, many individuals--whether geographically near or far from me--have given me one or all of these. So, it is you who have given to me--family, friends, mentors, members of the thesis committee, friends and colleagues in both the Speech Communication Department and the Center for English as a Second Language, and participants in the study--that I thank and with whom I share my happiness in the completion of this thesis and a hope that its ideas and concepts may provide something interesting, useful, and helpful to others. 
TABLE OF CONTENTS

PAGE

EPIGRAPH ..........................

ACKNOWLEDGMENTS . . . . . . . . . . . . . . .

iv

LIST OF TABLES . . . . . . . . . . . . . . . . .

ix

CHAPTER

I INTRODUCTION . . . . . . . . . . . . . . . . I

Background . . . . . . . . . . . 1

Justification ............ . . . 4 4

Purpose ................ . . . 6

II REVIEW OF THE LITERATURE . . . . . . . . . . . . 7

Introduction . . . . . . . . . . . . 7

Role Defined . . . . . . . . . . . 8

Role Theory .............. . . 10

Role and Communication Theory . . . . . . 12

Patterning of Behavior . . . . . . . . 15

Studying Roles Cross-Culturally . . . . . 18

Cross-Cultural Studies.......... . 23

Perceptions of Student Behavior ....... 26

Perceptions of Professorial Behavior..... 36

Concluding Remarks ............ . . 42

III BASIS OF THE STUDY . . . . . . . . . . . 44

Introduction . . . . . . . . . . 44 
III (continued)

The Research Questions ............ 44

Research Hypotheses . . . . . . . . . 45

Definitions . . . . . . . . . . . 45

Criteria of Hypothesis Assessment . . . . . . 46

IV RESEARCH DESIGN AND METHODOLOGY . . . . . . . . . 48

Int roduction . . . . . . . . . . . . 48

Development of Behavior Lists . . . . . . . 48

Questionnaire Development . . . . . . . 50

Conclusion and Resulting Questionnaire ..... 53

V TEST ADMINISTRATION . . . . . . . . . . 55

Introduction ............. . . . 55

Subject Representation .......... . . 55

Questionnaire Administration . . . . . . 56

Summary . . . . . . . . . . . . 60

VI LIMITATIONS AND ASSUMPTIONS . . . . . . . . . 61

VII HYPOTHESES TESTING: DISCUSSION AND RESULTS . . . . 65

Int roduction . . . . . . . . . . . 65

Hypothes is I: Results ............ 65

Hypothesis II: Results . . . . . . . . . 67

Hypothesis III: Results . . . . . . . . 69

Discussion: "Etic"/"Emic" Distinction and... . 70 Determination of Normative Structures of Role Behaviors 
CHAPTER

VII (continued)

Discussion: Etic Role Behaviors . . . . . . 73

Discussion: Emic Role Behaviors . . . . . . 76

Suma ry . . . . . . . . . . . . . . 83

VIII OTHER RESULTS, AND SUGGESTIONS FOR FURTHER . . . . . 85 RESEARCH

Variable: Culture Area/Country . . . . . 86

Variable: University Status . . . . . . . 89

Variable: Sex.............. 89

Conclusion and Further Suggestions for . . . . 95 Research

IX SOME PRACTICAL IMPLICATIONS AND CONCLUDING . . . . 96 REMARKS

Practical Implications . . . . . . . . 96

Concluding Remarks . . . . . . . . . 102

REFERENCES CITED . . . . . . . . . . . . . . . . 103

APPENDIX

A Key to Item Numbers, Item Code Names, and Item Descriptions ............. . 110

B Field Test Edition of Questionnaire Regarding International Student Behaviors Given to Professors During the Fall of 1979 . . . . . .

C Cover Letter, Instructions, Reliability of Role Behavior Questionnaire Forms, and Demographic Information Sheets . . . . . . . 
APPENDIX

D Faculty Cover Letter, General Cover Letter and Instructions, Final Questionnaire on Role Behaviors of Students and Professors, Demographic Information Sheet, and Follow-up Letter to Professors Personally Contacted . . . .

E Problem Oriented Professor and Student Behavior Lists Compiled From Personal Interviews and the Literature . . . . . . . . . . . 140

F Open-ended Questionnaire Form on Characteristics of Students and Professors, Professor and Student Behavior Lists compiled From Openended Questionnaires .............

G Statistical Tables: VII, VIII, IX, X, XI, XII,

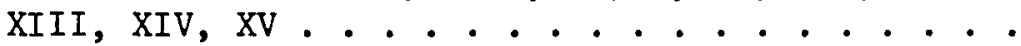


LIST OF TABLES

TABLE

PAGE

I Distribution of Subject Populations by Academic Major/Field ................

II "Etic" Role Behaviors and Their Normative Structures . . . . . . . . . . . . .

III Classification of "Emic" Role Behaviors by Variable Responsible for Difference in Evaluation ................

IV Results of T-Test Comparison of American Professor with All Culture Area/Country Groups . . . .

V Results of T-Test Comparison of Groups Defined By University Status and Culture . . . . . . .

VI Results of T-Test Comparison of Groups: Male and Female International Students with Male and Female American Professors . . . . . . . . .

VII Results of Reliability Testing of Behavior Items: Student--High Grades and Passing . . . . . . . .

VIII Results of Reliability Testing of Behavior Items: Student--Understanding and Learning . . . . .

IX Results of Reliability Testing of Behavior Items: Professor ................

X Condensed Results of T-Tests for Comparison of Independent Samples: Significance Level and Difference Between the Means of Compared Subject Groups . . . . . . . . . . . . . . .

XI T-Test Results for Comparison of Groups: International Students with American Students ....

XII T-Test Results for Comparison of Groups: International Students with American Professors.... 
XIII T-Test Results for Comparison of Groups: American Students with American Professors . . . . . . . 184

XIV Normative Structures of Role Behavior Items: Subject Groups' Collapsed Evaluation Ratings of Each Item . . . . . . . . . . . . . .

XV Breakdown of Countries Represented by Culture Area Designation . . . . . . . . . . . . 
CHAPTER I

\section{INTRODUCTION}

\section{Background}

Visiting or attending an institution of higher education today often gives rise to comments on the presence of large numbers of students from other countries. Today, in actual count there are more than 250,000 international students enrolled in colleges and universities in the United States as compared to about 60,000 in the early 1960 's. In some universities international students make up as much as $13 \%$ of the enrollment.

Until the 1960 's the international student was a relative rarity in the American university classroom. He or she was generally from Europe and usually "... on his own financial resources for his own special purposes" (NAFSA, 1974, p.5). Most often they were accorded a certain amount of status by the university professors and students, and were admired for their ability to do well in a foreign country. Naturally, some had difficulties. Yet, as they were fewer in number, it was possible for individual professors and other university personnel to attend to their needs. They created little impact on the overall university system and thus there was little reason to consider them a problem (NAFSA, 1974, pp.1-8).

Today, however, with increased numbers of students from literally every part of the world coming to the United States for higher education, 
the international student is no longer the rarity in the classroom. And, the "typical" international student has changed. Two-thirds of today's international students are from developing countries and have further to go in order to adjust to the American university than his/her predecessors did (Spaulding et al., 1976, p.19).

Language is most often cited as being the prime factor giving students difficulties and language proficiency has been frequently correlated with academic success (Spaulding et al., 1976, pp. vi, 39,41). It has also been observed that students who do not have good English skills are not prevented from doing well in the classroom (Chapman and Forman, 1978, pp.12,13). Language is definitely a visible and easilytargetted problem; yet it should be remembered that good language ability will not guarantee academic or interpersonal success in a foreign culture anymore than it will in one's own culture.

Factors outside of language are also beginning to be recognized as significant in affecting a student's academic adjustment and his/her possibilities for success in an American university. At Portland State University, where this study is being done, the faculty has been approach 1 at least twice during the previous two years for their comments and opinions regarding the international students in their classes.

In the spring of 1978 the director of the Center for English as a Second Language, Dr. Naguib Greis, queried the Portland State University faculty about the language problems of international students in their courses. He was particularly interested to know the degree of 
the language problem and to discover which language component--reading, writing, listening, or speaking--seemed to be at the root of international students' difficulties in their courses. One item of the questionnaire is observed to be noteworthy because of the responses it elicited from the faculty. It asked the faculty member to rank four of foreign students' basic language problems (speaking, grammar, idioms, and communication) and provided a space for "other" problems to be added.

The responses to the choice "other" are noteworthy because they are largely cultural in orientation, not linguistic. Greis (1979) summarized them into two areas of concern:

Culture orientation: cultural adjustment, culture shock, missing cultural meanings, culturally related aspects of the subject, no grasp of the assumptions in U.S. education and of basic American institutions, poor attitude towards women (one instructor complained that student behavior often openly displayed that women's status was inferior).

Attitude towards learning: poor study habits, use of memorization, lack of independent analysis and use of reasoning and inference, not asking when they don't understand, reluctance to communicate with the instructor, absenteeism and not finding out what they missed, tardism, not taking notes in class, expectation of special treatment, lack of confidence, defensive behaviors, not following instructions, playing on their communication "problem" to their advantage. (p.7)

The same year the Foreign Student Advisor polled the faculty in order to solicit information on student-professor interaction. Even though English ability was labelled the major problem in the findings of this study, non-linguistic factors were also mentioned as problems which might contribute to an international student's difficulty in the classroom. Factors cited were: "1. Poor educational background; 
2. Lack of understanding of the U.S. educational system; 3 . Insufficient academic preparation in major field; 4. Low motivation" (Martinez and Akpan, 1978, p.14).

It is apparent from the questionnaire results that at least some international students are not meeting the expectations professors have for them as students. This leads one to speculate that some of the academic problems international students have are due to nonlinguistic factors such as culture as well as to linguistic ones. Triandis (1972) found through his research on Greek and American role-sets that communication breakdowns can occur between persons from different cultures by virtue of the way in which the communicators define and evaulate roles and role behaviors. In the United States university setting it is therefore likely that misunderstandings and subsequent breakdowns in communication between international students and their professors can arise due to their having different expectations of one another in their respective roles as professor or student.

Justification

Most research involving international students centers around topics of adjustment, the relationship of language to academic success, and attitudes international students hold towards the United States (Spaulding et al., 1976). Often, in adjustment studies, the academic milieu is alluded to, but only in the most general sense (e.g. students are asked to rank academic problems along with other problem areas or students are asked about the quality of teaching and if 
profesșors are available to them). No research can be found that compares professors' and students' perceptions of their roles cross-culturally. This gap needs to be filled.

If potential areas and or causes of conflict and misunderstanding as they pertain to the academic environment between professors and international students can be found there are several groups that could make use of the information. English as a Second Language (ESL) programs trying to prepare their students for entry into the university could use it in the cross-cultural component of the curriculum. Foreign Student Advisors would be benefitted in that this information could potentially improve their counselling of students with academic difficulties. It would also provide them with more information when serving as a resource for concerned faculty. Additionally, Foreign Student Advisors could incorporate such information into orientation programs for those students who do not receive it in an ESL program. In a more abstract manner, each of us could potentially benefit from this information. According to Davis ([1975?]):

Students from developing countries typically come with high aspirations for themselves and their nations, and expect the American experience to help them achieve their goals.... The more congruence between their aspirations and their self-perceived progress in reaching them...the more favorable they will be towards aspects of education and other aspects of life in the host country. ( $p .2$ )

He also suggests that though most international students go abroad for formal educations, that there are those who mainly seek cross-cultural experience and its accompanying contacts with members of the host culture. As good professor-student relaitonships are assets to effective 
and satisfying learning experiences, students are concerned with their relationships with their professors. It is the researcher's and others' belief that the outcome of the communication and subsequent relationship between a professor and a student has a strong bearing on how well a student will do in his/her studies (Cable, 1974, p.41). This being so, effective communication will lead not only to more effective learning, but to a student who returns home satisfied with his/her stay in the United States (Davis, [1975?], p.2). The long range implications of a student's satisfaction or dissatisfaction with his/her U.S. stay can potentially affect international relations.

Lastly, there is the need to add to the general information, theory, and research currently available in the rapidly-growing field of Intercultural Communication, a field dedicated to increasing effective communication between persons of different cultures and backgrounds.

\section{Purpose}

The purpose of the research which follows is: 1) to definitively explore the current status of cross-cultural research on the roles of professor and student; 2) to develop and administer a questionnaire that will allow a cross-cultural exploration of the role behaviors associated with the roles of student and professor; and 3) to analyze the results of the developed questionnaire completed by a cross-cultural sample of students and professors. 
CHAPTER II

REVIEW OF THE LITERATURE

\section{Introduction}

This study concerns itself with how students and professors evaluate the behaviors associated with their roles, with particular emphasis given to the role of culture in affecting the evaluative tendencies of an individual.

First the current definitions of role will be briefly reviewed and the notion of the existence and usefulness of Role Theory as a concept stated. Then roles and role behaviors will be examined in the context of communication theory, particularly how roles and role behaviors are learned through interaction with one's social group and the existence of patterning of behavior in interactive communication. Following that, the current status of thought on role as it fits into theories of subjective culture and the usefulness of studying roles and role behavior cross-culturally will be discussed.

The last section of this chapter will recount the current status of research on the role behaviors of university students and professors cross-culturally and outline the present information available regarding the observations and perceptions of international student and professor behaviors and characteristics. 
Role Defined

Role can be variously defined. Though no such classification has previously been attempted, a review of the litersture indicates that definitions of role fall into five categories. Role is most often defined in terms of performance, in terms of expectation and behavior (variously referred to as overt and covert behavior), or in terms of its social function. Other definitions of role concern its communicative function or view role as a communicative process and patterning.

A long standing definition of role has been one that focusses on performance. Young (1942, p.383) writes that role is simply what one does. Kupferer and Fitzgerald (1971) state that role "... is the dynamic aspect of status. The way we carry out duties and responsibilities" (p.19). They go on to say that not all people in a given role behave alike, but that there are boundaries beyond which one may not pass and still find approval. Rich (1974), too, supports this view of performance when she states that role "...is a set of behaviors that is enacted" (p.65).

Others accept the performance view of role, but express the importance of expectations as a part of role and would define role as both overt and covert behavior. One of these authors says that role is a concept including patterns of behavior associated with a position and also patterns of expectations held by the role occupant as well as those expected by members of society (Hoyle, 1969, p.36). According to Sereno and Bodaken (1975) "...the role we occupy is formed by the expectations others have of us--and those we have of ourselves" (p.222). Broom and Selznik (1968, p.18) enlarge on this statement when they discuss the 
nature of an ideal role. According to them, an ideal role prescribes the rights and duties of a social position and tells the individual in the role what is expected of him in that role as well as upon whom he or she has a rightful claim. Society Today (1971, p.117) adds the additional idea that these expectations are normatively prescribed and have a predictive (s/he will do) as well as a normative (s/he should do) character.

Another group of authors stress the social function of role in a particular society. Sociologists are the major advocates of this definition and tend to look at role more within the context of society. Oesar and Harary (1966, p.94) say that role applies to positions within a structural system that includes persons, positions, and tasks. Gergen (1969) sees the major feature of roles in their functional value: "...they play a crucial part in maintaining the existence of a group. In order to maintain itself a society requires differentiation into various roles, so that various subgroups each make a contribution to the whole (p.83). Linnton (1949, pp.211-223) in discussing ascribed and achieved roles in different societies points out that ascribed roles provide for the continued smooth functioning of a society that is not experiencing dramatic cultural changes. Edward Stewart (1972, p.59) notes that roles are provided by every culture in order to integrate its members into each society as functioning and contributing members.

Persons interested in communication process among members of a society view role in terms of its function in determining the nature of the communicative act. Ruesch (1974) represents this view: 
Used in connection with communication, the term "role" refers to nothing but the code which is used to interpret the flow of messages. For example, the statements of a person who wishes to see an automobile are going to be interpreted in a sense quite different from that which they would have if the person were to make the same statement in the role of an automobile buyer. Awareness of a person's role in a social situation enables others to gauge correctly the meaning of his statements and actions. (p.160)

All of the above emphasize that role can be many things. Biddle and Thomas (1966, p.3) combine the above definitions when they state that role consists of 1) patterned forms of behavior such as seen in social positions, aggregates, specializations, and divisions of labor; and 2) processes such as communication, learning, socialization, sanctioning and conformity, and interdependence.

In studying roles cross-culturally, the intercultural communication researcher is interested in their communicative function and in discovering the patterns and meanings of role behaviors as well as how they are learned and evaluated in a particular culture.

Two other important aspects of role mentioned in the literature are that roles are of two kinds--ascribed and achieved--and that any individual will simultaneously hold several different roles as part of his/her "role-repertoire."

This study will attempt to establish how the subjects' evaluations of role behaviors are affected by their achieved roles of student or professor and by their ascribed role as a member of a particular culture.

Role Theory

The concept of role has been discussed for many years; however, 
its use in the context of the field of study called Role Theory is relatively new. Biddle and Thomas, in Role Theory: Concepts and Research (1966), pioneered the effort to recognize the potential of role theory and to articulate its domain, perspective, status, theories, and methods of inquiry.

In their seminal work they suggest that although new, the field of role theory is similar to other specializations in the social sciences in that it "...aspires to understand, predict and control the particular phenomena in its domain" (Biddle and Thomas, 1966, p.3). They describe this domain as the study of real life behavior as displayed in on-going social situations $(p .17)$.

Nevertheless, the question of whether or not role theory really exists at the level of bona fide theory persists. Some view it more as a useful metaphor. In the words of Swenson (1973) "...role theory is a metaphor--that is, a way of looking at the interaction between people-which has been borrowed from the theatre" (376).

Others say that role theory is worthy of study because it provides a conceptual framework around which other ideas--concepts which show a regularity that can be hypothesized and stidied--can be grouped. Swenson agrees and states:

Thus role theory is structured on the observable fact that there are certain kinds of transactions that are prescribed for certain kinds of relationships... It is this regularity...that provides the rationale for the application of the concept of role to the study of interaction between people. (pp.274-5)

Dance and Larson (1972) see role more as an idea than as a theory, but as a useful one which "...has spawned a number of anciliary concepts 
which extend the usefulness of the original idea" (p.106-7). They go on to state that these concepts give one a way to interpret human behavior and that "...since such an interpretation exhibits a certain consistency of viewpoint, it has come to be called role theory" (p.107).

Thus, it appears that role theory can not be considered a theory in the traditional sense. However, it is made up of useful concepts that have been the subject of much study and are worthy of further investigation.

Role and Communication Theory

It is useful to understand the relationship of the role concept to overall communication principles. Berlo's (1974, pp.285-287) model of communication can serve as a framework to illustrate this point. In his model of communication, the source, governed by attitudes, knowledge, a social system, a culture, and communication skills encodes a message. This message is transmitted through a channel to a receiver who decodes and responds to the message based on and governed by his/her unique attributes. Among such attributes are the roles in wich the source and receiver find themselves.

In communication theory, the sender's and receiver's attributes are the major variables. As these are not the same or constant from person to person they can be a source of miscommunication. In intercultural communication--which occurs "... whenever a message sender is of one culture and the message receiver is of another..."--culture 1

1 Porter (1972) defines culture as "...the cumulative deposit of knowledge, experience, meaning, beliefs, values, religions, concepts of 
becomes the significant variable (Porter, 1972,p.3).

Role expectations, as a part of one's learned culture, influence one's behavior as well as how one will evaluate the behavior of another and in turn respond to it. If two people share the same role expectations and coding system they will probably succeed in communicating their intended messages to one another (Smith, A.L., 1973, pp.28,115). If not, it is probable that miscommunication, misunderstanding, and conflict will occur (Society Today, 1971, p.121).

Roles are one of many things a person learns during socialization. "From almost the time we're born, each of us is indirectly taught a whole set of roles that we'11 be expected to play" (Adler and Towne, 1975, p.132). Usually, the other menbers of one's group are anxious that $\mathrm{s} /$ he learns his/her role quickly and "...they informally and repeatedly depict it for him in their conversation and overt behavior" (Wilson and Kolb, 1949, p.208). "We learn to view phenomena as others in our group have done; we tend to behave in situations as we have learned from others to behave" (Smith, A.L., 1973, p.28). Condon and Yousef (1975, p.4) agree and add their opinion that it is because we learn these culturally determined roles informally from persons around us who follow the same rules that one tends to believe that role behaviors and expectations as $s /$ he knows them are universal. Thus, no

self, the universe, and self-universe relationships, heirarchies of status, role expectations, spatial relations, and time concepts acquired by a large group of people in the course of generations through individual and group striving. Culture manifests itself both in patterns of language and thought and in forms of activity and behavior." (p.5) 
matter in what way a role with its accompanying patterns of behaviors and expectations is learned, one must keep in mind that these behaviors and expectations are culturally determined and not necessarily common to other cultural groups.

Learning a role involves more than acquiring external behaviors, even though recognizing and learning to enact the behaviors associated with a particular role is important. It also involves one's learning the internal states--feelings, expectations, meanings--of a role. Berlo (1974, pp.285.-29l) discusses two ways of acquiring the internal states of a role. One is through practicing empathy; the other is through roletaking and inference making.

Berlo defines empathy as "...the process through which we arrive at the expectations, anticipations of the internal psychological states of man" (p.287). This theory argues that man observes his own behavior which he then relates symbolically to his own internal states. After developing interpretations and meanings for his own behavior he can then observe others' behaviors and infer their internal states. Inferences in this case are based on similarities and on the assumption that people express given internal states by acting in the same ways. Berlo (pp.285-291) continues that another way of learning a role is by a continual process of imitation and inference. There are three steps in this learning process as he outlines it. In step number one an individual notes and imitates the behaviors of another and retains a behavior if it is rewarded. Slowly, one learns the symbols for which people share meanings and begins to understand the behaviors and the role the behaviors define. Step two involves playing the role with understanding. Step three involves hypothesizing what it would be like 
to behave as others do. At this point one begins to infer the role and to put oneself into others' shoes symbolically and to develop expectations for one's own behavior.

It is important to realize that the patterns of behavior that one links with a particular role exist and operate largely outside of one's awareness. Usually, only when the pattern is broken does one become aware of them at all. In the following section the patterning of behavior will be explained more fully.

\section{Patterning of Behavior}

To examine role behavior one must first become aware of what behaviors constitute a role; then one must determine what those behaviors mean, whom the behaviors are communicated to, when they are communicated, and in what style they are communicated (Ruhly, 1976,p.19). This leads into the determination and understanding of the patterns of interaction that belong to a particular role or role set. Hall (1977, p.152) labels these patterns "action chains" and believes that it is due to the breaking of action chains that the communicative act is broken or that there is misunderstanding. Hall states that his studies of action chains go more deeply into the stylistics of non-verbal communication patterns than others might like or feel necessary, but, he goes on to say, he believes that to resolve difficulties of communication, particularly cross-culturally, one must study non-verbal patterns such as synchrony.

Hall (pp.74-79) has discovered that people innately work towards moving in synchronization with other persons. He says that people 
become habituated to the rhythms of their own language and culture and that bonds between people are due to shared organizational forms. "This means humans are tied to each other by hierarchies of rhythms that are culture specific and expressed through language and body movement" (p.74). He states that if people are together enough, they begin to interact with one another in synchrony. Synchrony provides an index of how things are going along and a lack of synchrony usually serves as an unconscious source of tension which interferes with work and group activity.

It is worth a brief digression to illustrate this point. McDermott (1974) supports Hall's idea when he states that "...interacting with a person with a slightly different code of rhythm can be a fatiguing and upsetting experience" (p. 105). McDermott, in looking at classroom behaviors of black and white children reports that:

Punctuation breakdowns are the stuff of self-fulfilling prophecies.... The child moves or speaks in the wrong way at the wrong time according to the teacher's code, and he will be branded hyperactive, out-of-control, or stupid. The teacher will appear equally disoriented according to the child's code and may well be branded cold and unfair. Slight differences in time and space do not have to result in a disaster, but they often do. (p.109)

He cites a study involving four year old girls--two black and two white--interacting with a teacher considered to be unbiased. Analysis of the video-taped sequence revealed that though the teacher looked equally at the students, the black children looked at the teacher three times as often as the white children did, but that the white children established eye contact with the teacher twice as often. It was noted that the white girls seemed to know just when to look at the teacher to 
get her messages, but that the black girls didn't and seemed to be working from a slightly different interaction rhythm. Looking at the behaviors of the four girls McDermott postulates anxiety or hyperactivity in the two black children, and that their being unable to obtain the reinforcement needed, the girls indeed did become anxicus.

It is evident from the work of Hall (1977) and the above classroom study that patterns of behavior do exist and that they affect the outcome of interaction as well as the interpretations made of an interaction sequence. Thus while synchrony is only one aspect of interactive behavior, as an example it indicates the usefulness of studying the context, nature, and the pattern of behaviors associated with a particular role or role-set.

In view of the above, one can understand how there is an increased probability for successful communication when two people share a similar cultural background. Shared cultural influences, experiences, coding systems, meanings for acts (e.g., smiling, glancing, bowing), behavioral characteristics, and patterns make interaction more predictable and successful (Smith, A.L., 1973, pp.23,78,79). A. L. Smith (1973) says:

Each person's initial reaction is to measure the other person by attitudes, values, and behaviors present within himself. The closer the person we are trying to communicate with comes to our own view of ourselves, the easier it is to have meaningful interaction. (p.115)

Breakdowns and conflict in a cross-cultural context are proportionate to the cultural distance between two people. Miscommunication across cultures is also due to the tendency of people to be ethnocentric and unaware of the impact culture has on their interpretation of the world. Berlo states that breakdowns in communication are due to the 
fact that we "...often assume that another person attaches the same meaning to a word...a smile..." and that we assume "...that other people see the world in the same way we do--just because they perform many of the physical behaviors we perform" (p.288).

Thus, one enters into an interaction as an individual personality within the confines of a particular role and culture. Expectations for his/her own behavior in that role are based on what s/he has learned from the parent society. For example, a brother in a particular culture interacting with his sister knows that he may tease and tickle her, but that he shouldn't spank her. The same individual has expectations for himself as a student. He knows, perhaps, that he must go to school every day, that he must read books assigned by his teacher, that he must listen to lectures, and that he will erase the blackboard after his teacher has left the classroom. The teacher, on the other hand, expects these behaviors from the student and knows that $s /$ he is expected to assign homework, give lessons, and feel insulted if the blackboard is not erased before his/her return to the classroom after an intermission. Interaction and communication flow smoothly when the expectations about a role, or roles, are shared and enacted as expected. When the expectations are not shared and thus not fulfilled during interaction--as is often the case in intercultural communication situations--communication breaks down.

\section{Studying Roles Cross-Culturally}

The field of Intercultural Comnunication studies the nature of communication processes between people of different cultures. By 
definition intercultural communication is a two-way process that involves a communicator of one culture and an audience of another. Each communicator acts as a single member of a culture rather than as the representative of a nation and is influenced by what his/her culture has taught him/her (Sitaram, 1972,p.21). In intercultural communication theory culture is designated the prime variable affecting the communicative process and differences in cuiture are primarily responsible for difficulties in communicating. Singer (1977) says this is because: ...each of the groups to which we belong teaches us its own attitudes and values as well as its own accepted modes of behavior. It is precisely because each of these groups teaches all of its members how to order, evaluate, and react to external stimuli that we become a group. Each group teaches us a common "language" (in its broadest sense) thus making it easiest to communicate effectively with other members of the same groups, and more difficult to communicate with people who are not. (p.38)

Intercultural Comminication as an academic field studies not only the art and process of communication between cultures but also the many cultural factors that shape the art and affect its process (Sitaram, 1972, p.23). It is based on the assumption that one's beliefs, attitudes, values, and assumptions are culturally based and out-of-awareness, and that they influence the way in which we assign meaning to verbal and non-verbal symbols and the way in which we behave (Ruhly, 1976, p.7).

The intercultural communicator ideally tries to "...be aware a) of the possibility of alternative interpretations, and $b$ ) that the other person holds meanings that are legitimate for him or her" (Ruhly, 1976, p.7). As the communicator comes into contact with someone of another culture s/he should try to keep in mind that both participants 
are products of what each has learned through socialization in their own cultures. Condon and Yousef (1975) state the implications of this directly:

Your background--culturally, as a foreigner, and personally as you--will influence everything you expect, a great deal of what you do and do not do, and most of how you later think about what has happened. (p.33)

The intercultural communication researcher, on the other hand, tries to discover the particulars that affect intercultural communication and how they affect perception and interpretation, meaning, and behavior. S/he recognizes that though the function of communication is universal (e.g. to argue, to propose, to get to know someone), the form and style across cultures is contrastive and that "...across cultures and languages it takes time to learn the functional equivalents..." (Condon and Yousef, 1975, pp.19,30). A. G. Smith (1977) enlarges on this theme, stating that "...intercultural communication is much more complex than one would think. It involves differences in languages, in non-verbal codes, and billions of bits of information. Many times what seems to be insignificant becomes very significant in determining intercultural understanding" (p.5).

The study of the complexity of communication between persons from different cultures in order to attempt to understand how these "billions of bits of information"--of which the concept of role is a part--are related to one another within a particular culture has necessitated probing into the non-tangible aspects of behavior. These intangibles have been described in various ways. Sometimes they are referred to as one's point of view. Adler and Towne (1975) say, "Every culture has its own view, its own way of looking at the world, 
which is unique...it's easy to forget that people everywhere don't see things as we do" (p.136). Szalay and Fisher (1979) term this intangible aspect of culture one's "frame of reference" and write:

People in every country of the world develop their own particular interests, perceptions, attitudes, and beliefs--that is, a characteristic frame of reference within which they organize and interpret their life experiences. How much people in a particular country differ from Americans in this regard is hard to judge. The psychological factors involved are difficult to define, observe and predict. (p.60)

Condon and Yousef (1975, p. 48) refer to the "deep structure" of a culture as that which determines surface communication and behavior. Hall (1977) calls for the investigation of unconcious culture so that man can "...come to grips with the fact that there are deep cultural differences that must be recognized, made explicit, and dealt with before one can arrive at the underlying human nature we all share" (p.162).

Triandis (1972), a cross-cultural researcher, encompasses the above terms (e.g., point of view, frame of reference, unconcious culture, deep structure) with the term subjective culture. He defines subjective culture as "...a cultural group's characteristic way of perceiving its social environment" (p.3). He goes on to say that this "...refers to variables that are attributes of cognitive structures of groups of people" (p.3). He views roles as an aspect of subjective culture and states that a role exists

...when certain behaviors are considered appropriate for persons holding a particular position in a social system... The connections between such persons and behavior are both prescriptive (e.g., a father should "advise," "love," and "protect" his son), and proscriptive (e.g., a father should "not hit" his son"). (p.15) 
Roles, as noted previously, are in part composed of predictable patterned behaviors. When expected or (as Triandis describes them) appropriate behaviors are not enacted or performed, misunderstanding, negative evaluation of the performer, or conflict can result. In communicating interculturally one can behave in a manner $s /$ he thinks is appropriate and expected only to discover that the receiver of the behavior has interpreted the attempt according to a culturally different framework and found it inappropriate and possibly insulting.

To prevent this we must improve our understanding of subjective culture. We must discover how its elements--of which role is one-develop, and how they are implicated in interpersonal behavior. According to Triandis (1972):

If we learn how to analyze and measure accurately the way people look at their environments we may be able to do two kinds of study of great social significance; we may study what causes the particular perceptions of the environment and also learn about the precise consequences of these perceptions. (p.6)

This means that the cross-cultural communicator should try to discover what behaviors evoke a particular perception and subsequent evaluation in a given culture and then be able to translate his/her behavior to match the approached culture's genre or communication system so as to be understood as intended.

Interaction between international students in American universities with American professors provides a critical example of persons with different subjective cultures communicating with one another. It seems evident to those engaged in such encounters that their respective roles are defined differently and that there are differences in the 
way that the behavior associated with the roles of student and professor are communicated and evaluated. One might also hypothesize that miscommunication and misunderstanding characterize some aspects of such interactions. Applying Triandis' idea to the interaction between American professors and international students, communication in this role-set could be improved by informing professors and students which behaviors are expected and perhaps not present in the lexicon of behaviors associated with the role-set as one or the other has learned them. However, no empirical cross-cultural analysis exists which specifies such differences. To confirm the need for such an investigation the next section of this chapter discusses the status of cross-cultural research on the roles of students and professors in a cross-cultural context.

\section{Cross-Cultural Studies}

As previously stated, roles are made up of certain behaviors that are "considered appropriate for persons holding a particular position in a social system" (Triandis, 1972, p.15). These behaviors are evaluated in both prescriptive (should) and proscriptive (should not) terms. Discovering the behaviors--both prescriptive and proscriptive-associated with a role is a large task, particularly when the behaviors associated with a given role position may vary from culture to culture. To define a role cross-culturally it is necessary to determine for each culture which behaviors are associated with that role. A complete lexicon of behavior would be taxing to develop, as Triandis (1972, p.269) estimates that in a given culture there are some 250 roles and 100 social behaviors. 
When one is examining and comparing a role across cultures $s / h e$ first must determine the social behaviors associated with the role in each culture being studied. To this is the added complexity stemming from the fact that a particular social behavior (e.g. love, control, respect) is communicated differently in different cultures and thus can lead to misinterpretation, misunderstanding, and subsequent communication breakdown in an intercultural communication setting. Triandis (1972) gives as an example his finding that "...the behaviors to help, to advise, to feel sorry for, to thank, to praise, and to appreciate are seen by Greeks as related to the "giving of love" to a much greater extent than do Americans" (p.315).

Before one can discover which particular behaviors constitute the matrix of social behavior the practitioner must still translate each behavior (e.g., to respect) into descriptive terms viable for the particular culture s/he is operating in. Depending on one's culture, a behavior may be shown or acted out in different ways. As in the example: respect may be shown by looking downward when talking to a person one respects, or it may be shown by how an individual bows, or by wheres/he is seated at a table.

Research and examination of roles cross-culturally is still in a developmental stage, as is cross-cultural research in general. Concepts and methodologies have been developed, but tests are still felt to be in the "Middle Phase" because the tests and methodologies largely used have been developed in the West with a Euro-American bias (Triandis, 1980 , pp. 39-40). 
Therefore, a search of the literature for cross-cultural research on roles reveals little, except what has been accomplished by Triandis and his associates. Published material relating to the roles of professor and student cross-culturally for the most part is anecdotal, or based on unsubstantiated observation and opinion. Some comments about teacher and student expectations and behaviors are included in incidental findings of larger studies on international adjustment. Most of the literature focuses on student behavior as perceived by university personnel, or on professorial behavior as reported by students to researchers and foreign student advisors. No literature can be found about the roles of student and professor that contains comparative observations made by professors and international students.

Because hypotheses for empirical studies often originate from observations made informally about observed phenomena, it would be useful to review the basis of information on which the following research rests. As noted, roles involve both normatively prescriptive and proscriptive behaviors. Therefore, it has been possible in reading literature concerning behaviors associated with the roles of professor and student to assess each observer's comments on the behaviors $s / h e$ perceives in professors and international students.

Following is an overview of perceptions, opinions, and observations about professors and international students as expressed in the literature. Implicit in them are expectations of behaviors, skills, and traits--sometimes conflicting--associated with these two roles. Information as to how important a particular behavior is, its frequency 
of enactment, or if it is particular to international students or to all students, was not available in the materials examined.

A review of observations and comments about student behaviors is followed by a review of observations and comments about professorial behaviors. For ease of reference comments are grouped by author in alphabetical order. It should be kept in mind that in the cases reviewed below the descriptions of the behaviors are based on opinions rather than on statistically valid surveys except as noted.

\section{Perceptions of Student Behaviors}

Azar (1978, pp.16-22) comments that Middle Eastern ${ }^{2}$ students need extra work on study skills and habits and that they do not know how to approach the material covered in class. Students are of ten perceived as having low motivation, as approaching their studies casually, and as having the idea that admission constitutes graduation. They sometimes negotiate the requirements for a course. Professors have observed that they often seem less concerned than other students with attendance and examinations, sometimes feeling they should not take a test if not ready for it. Their reasons for missing classes and exams are "illogical." She also mentions that Middle Eastern students frequently have poor handwriting and have difficulty doing well on objective tests.

2 Both the terms "Middle Eastern" and "Arab" are found in the literature. For the purposes of the accompanying literature review, use will be made of the different terms employed by the various authors as their ideas are discussed in the text. Generally, "Middle East" is more precisely a geographical rather than cultural term, and encompasses an area in which Arabs and many other cultural groups live (e.g. Turks, Persians, Coptics, Kurds and Baluchis). 
Barakat (1978, p.49) notes that Middle Eastern students are observed to have heated debates and arguments.

Barna (1979, pp.7,9,10) notes that some professors have complained that students don't look them in the eye, are late with papers, and sometimes miss assignments. Professors, she says, are sometimes upset by "bargaining type" behavior from students. She also reports that professors complain that students want special attention and consideration, seem unconcerned about attendance, seem unwilling to evaluate concepts presented in class, and that they expect a personal invitation to go to a professor's office as well as a more paternalistic attitude from their professors. Professors have also noted that students don't seem to feel comfortable asking for help and that they frequently make excuses to substitute for academic excellence.

According to Baron and Goode (1975, p.15-19) students in the United States should "...show a good deal of individual initiative in seeking help" (p.16). Most international students, they report, have confidence in their academic ability just by virtue of having survived the admissions process, but then have difficulty learning to talk openly about problems encountered with their studies. They state that students need to be aware of the types of exams given in the United States, the kinds of research papers that will be expected of them and how to do them. Students of ten don't realize the importance of reading lists and using the library. Professors, they say, expect a good deal of individual initiative from students, that students need to learn to be assertive and to show initiative in seeking out the professor or teaching assistant after class to clarify points of the lecture or for 
help in making decisions about courses and project topics.

Barry (1967, pp.63,94,97) conducted research among Thai students in the United States and in Thailand. These students made the following observations about good student behavior and characteristics: a student should not leave the classroom before the teacher; to show respect a student should waj (a respectful bow); most students cited "openness to sources of knowledge", a critical and analytical disposition, and a willingness to pay attention as being important in the ideal student. Some mentioned the importance of friendliness, obedience, moral responsibility, and good behavior as being important. Compliance to regulations and authority was also stressed as a good quality in a student as an expression of respect; however, a student may work to change a regulation with which $s /$ he disagrees.

Mexican students in the United States were frequently cited by Beals and Humphrey $(1957$, pp.62,68-69,119) to be inadequate in their English and academic preparation, to lack preparation for a competitive grading system and the structure of the United States university system, to tend to take advisors'suggestions as final and not make themselves aware of their options, and to want greater contact with their professors than they get.

Borkin and Carpenter (1979, pp.i,3-5,11,28-29) observed American and international students in conferences with professors and noted the following expectations that professors and students seem to have for one another: students are expected to be responsible for decisions about the intellectual content of the projects, yet they want direction and guidance; students are expected by professors to think for themselves as 
independent researchers who can make their own decisions; and students should be able to think independently, formulate their own ideas, be able to evaluate critically and be creative in their thinking. Brislin and Pederson (1976, p.140) made some observations on American students overseas. They mentioned that they usually have inadequate preparation in the language needed for serious study and that they lack prerequisite courses and a historical perspective for living in another country. American students, they say, have difficulty keeping up with the host nationals due to the extra time they need to study. They mention that, like international students in the United States, they are not acquainted with the methods of instruction abroad or the host country's university system. American students expect course outlines, reading lists, regular exams and structured instruction whereas they are expected by host country professors to work independently in a less structured environment. They also say that American students are often unprepared for the examination system which in some countries relates less to the lectures given and which are intended to evaluate extensive independent study.

Cable (1974, p.41) mentions that international students are of ten shy and quiet, and are afraid of their English and for their pride. He also says that they choose not to confide in professors or seek out special assistance or instruction, and that they tend to deny having academic difficulties.

Chapman and Forman (1978, p.8), who spent a year in Iran say they had to learn the meaning of, and how to deal with, several different behaviors of their Iranian students. They comment that they appeared 
to be an unresponsive audience and that they could not tell if students were interested or if they understood the lessons. When students talked, which seemed to be a good deal of the time (they label it "the noisy ripple effect"), they felt as though they were losing control. Chapman and Forman also mention that students attempted to trade with the teachers and that on one occasion didn't want to take a test because they were not ready for it.

Clifford Clark (1975, pp.6-7) observes that international students resist dealing with recognized problems and do not seek a counselor when in trouble.

Referring to Middle Eastern students Cowan (1978, pp.7-12) writes that they have skills in memorization, dialectical invention, conversation, and in poetic and rhythmic prose. He says that these are skills unlike those needed in an American university, skills such as being able to analyze and subordinate linguistically. He continues that these students are not accustomed to taking tests frequently and find cheating difficult to resist.

In his doctoral dissertation Etemadi (1977, p.2555-A) compares Iranian traits to American traits. He found Iranian students to be more submissive, considerate, pessimistic, suspicious, unstable, dissatisfied, realistic, and conservative than American students.

Asian students reported surprise when they looked at their American counterparts at the University of Michigan. They perceived that American students seem to dress for recreation, in that they sometimes go barefoot and in shorts, and they are in general very informal in dress and in 
manner when compared to students in their countries (Glass, 1972-73, 22). Gorden (1979) reports, "A student addressing a professor should always use the title professor or doctor before the last name" (p.208). This comment is from part of a larger work dealing with American students studying in Colombia.

In an acculturator ${ }^{3}$ prepared by Gosnell (1979, pp.313-320) guidelines are found for the international student studying in the United States and explanations for professorial behavior. From the discussion in the assimilator the following perceptions and observations of student behavior are made: 1) Students need to think analytically, 2) They need to learn to ask questions of the professor and not see it as embarrassing for the student to ask nor for the professor to be asked, 3) Students, he says, should be willing to legitimately challenge the professor, to ask him/her to clarify a point, or to disagree with a particular point. Gosnell also indicates that professors often criticize international students' tendency to write papers that consist of a series of quotes (often labelled by professors as plagiarism) in contrast to using sources creatively to show a point.

Greis (1979) documents comments of faculty who were queried as to what they considered to be foreign students' problems. Outside of

3 An acculturator is an adaptation and refinement of the culture assimilator communication training technique. A culture assimilator is a self-administered, programmed training device consisting of a series of brief episodes or "critical incidents" which exemplify common instances of misunderstanding and conflicts that might arise in intercultural interactions. An acculturator is a training device that prepares one for interactions without the implication of giving up one's own culture in the process. (Gosnel1, 1979, pp.xi,xii,8) 
those that deal with language difficulties he summarizes two areas of concern:

Cultural orientation: cultural adjustment, culture shock, missing cultural meanings, culturally related aspects of the subject, no grasp of the assumptions in U.S. education and of basic American institutions, poor attitude toward women (one instructor complained that student behavior of ten openly displayed that women's status was inferior).

Attitude toward learning: poor study habits, lise of memorization, lack of independent analysis and use of reasoning and inference, not asking when they don't understand, reluctance to communicate with the instructor, absenteeism and not finding out what they missed, tardism, not taking notes in class, expectation of special treatment, lack of confidence, defensive behaviors, not following instructions, playing on their communication "problem" to their advantage. (p.7)

Grove (1978, Pp.14-16) has studied the adaptation of Portuguese students to the U.S. and contrasted the school systems of Portugal and the United States. In Portugal he found that a student is not expected to contribute to the lesson. S/he is to sit quietly, listen respectfully, and take copious notes. Students are expected to study individually at home with their books and be ready to take exams based on recall.

This is unlike the skills a student nceds in the United States, Grove writes. In the United States, one is supposed to contribute to class, ask questions, offer information, and discuss issues. The student may disagree with the teacher. Inductive thinking skills are important. Students often learn by doing and by verbal trading of ideas and experiences. A student must be able to adopt a point of view in a paper or on a quiz. 
Haas (1972-73, p.47) lists the following pointers for Asians coming to the United States. He says that students are expected in some graduate courses to comment and discuss on their own initiative and not wait for a direct question from the professor. He also warns them that students may be the main presenters of a class discussion topic in the United States.

Hagey and Hagey (1974, p.42) observe that international students need library and listening skills. They say that international students should not be reliant on reading as their only source of information and should become more involved in classroom activities. They also cite the students' unfamiliarity with objective tests as being a problem. Jarvahi-Zadeh and Eichman (1970, pp.89-91) tabulated responses of American and Middle Eastern students to a questionnaire relating to their adjustment at college. In their findings, they report that Middle Eastern students are more defensive than Anerican students regarding their deeper feelings and that they would not look within themselves for the source of their difficulties. They note, too, that Middle Eastern students appear quite sure of themselves and that they seem to be able to cope with some adverse circumstances better than the average American student.

Asians in Australia were the subject of a three year study by Keats (1970, p.250). They were observed to be less ready to express critical opinions than Australian students, to have more difficulty taking notes, to not particlpate in class discussion, to be reticent, 
and to need to increase their capability to think critically and to express their thoughts.

Lockyear $(1975$, pp.68,71) reiterates that Middle Eastern students do not know how to use a library or laboratory and that they are weak academically.

Marr (1978, pp.51-62) noted many perceptions that pertain to Middle Eastern students in the United States. They are gregarious, extroverted, highly personable, and informal in their dealings; also, they like personal attention and doing things on a personal basis. "Pull" is expected and appropriate for them. She also writes that they are often observed to exaggerate or brag, but are sensitive to public criticism, dislike abrasiveness, and are shy to talk about their problems; and, that they seem to have less academic curiosity and stress memorization. Frequently, Marr says, they are cited as having problems with time--meeting deadlines, planning their agenda and schedules. Another problem for them is their unfamiliarity with essay writing; apparently, she writes, they are not trained to write imaginative or logical essays. She notes that there is a high incidence of plagiarism and cheating among them and that they have difficulty with objective tests, time limits on quizzes and exams, and the absence of the opportunity to retake exams. She also mentioned Middle Eastern students' perception of the lack of politeness in American life. An example of the latter point is the seeming willingness of Americans to make another person lose face.

Martinez and Akpan (1978, p.14) questioned faculty at Portland State University about problems relating to international students. In addi- 
tion to language, professors cited poor educational background, lack of understanding of the United States educational system, and low motivation as contributors to poor academic performance.

Mize (1978, pp.35-38) cited international students' problems as low competitiveness, low motivation to strive academically, difficulty with culturally related American subjects and topics, and little experience with failure.

In a paper addressed to persons working with Middle Eastern students, Parker and colleagues (n.d., pp.7-16) delineate their perceptions by describing Middle Easterners as retaining a certain formality in manner, as being more able to imitate than to be creative, as tending to give opinions easily, and as being less able than other students to present facts. They continue that personal relationships are very important to them as are talking, "sharing words", and listening. They also mention that initial strong guidance and control work well with these students.

Schwartz (1975, p.4) observes that international students are more task and degree oriented than their American counterparts and that professors see them as industrious and devoted to their studies. Sereno and Bodaken (1975, p.223) note that students can choose among behaviors depending on the one $s /$ he wishes to perform. They say that a student with equal ease might expect him/herself to "remain very quiet" or "to try to enter discussions and be very active." Spindler (1974, pp.305-6) cites Grindal's (1972) description of a clessroom in Northern Ghana in order to illustrate behaviors quite unlike those in an American university. The "classroom environment 
was characterized by a mood of rigidity and an almost total absence of spontaneity... When the teacher enters the class falls silent" (p.305). There is an absence of discussion and explanations, he says, and interactions are characterized by an authoritarian rigidity. Other things he mentions are: students rise when the teacher enters as a sign of respect; if the teacher needs anything done the students will do it; students are expected not to ask questions, but to give correct answers to the teacher's questions; and that students will raise their hands to answer and will respond--eyes lowered--and then sit down. Spindler also noted Grindal's observation that, "If the answer is wrong or doesn't make sense, the teacher corrects him and occasionally derides him for his stupidity" (p.306).

Iranian students are described by Zonis (1978, pp.73-89). He observes first that they are an intelligent, adaptable, open, sensitive, and sophisticated people. Yet, he says they are often seen as aimless and uncertain because they will give different answers to the same question depending on when one asks the question. At times they are challenging, and at other times they will accept everything uncritically. They will go from politeness to hostility quickly, he says. Professors often comment that they seem to "act out" their moods in class. They have a tendency to avoid dealing with personal problems. by locating them externally. Zonis indicates that American educators believe Iranian students cheat.

\section{Perceptions of Professorial Behaviors}

Barna (1979, p.9) writes that Arab students expect a more paternalistic approach from their professors. They also complain that 
professors give them impossible deadlines to meet. Middle Eastern students have also commented that professors do not seem to care if they come to class or not and that they should give more factual lectures. International students are also critical of professors who permit students to take up class time with "irrelevant" questions. They feel that the professor should demand the attention of the class, that s/he should not sit on his/her desk or dress informally, nor permit students to bring coffee to class. Barna also reports that international students have commented on their observation that American professors permit students to sleep in class.

Barry (1967, pp.88,91-92) reports on his questioning of Thai students as regards their idea of an ideal professor. $62 \%$ of the students felt that the most important characteristic of a professor was that s/he have an interest in and understanding of students. An ability to communicate a feeling of warmth and empathy to students was also rated highiy. Barry also notes that traditionally the professor has been viewed as an expert who is "correct in everything he utters" (p.63). This was reinforced in students' responses to the question that asked for reasons for teachers' failures. $42 \%$ of the students cited lack of knowledge as a reason. $29 \%$ attributed teacher failure to poor presentation of material. 23\% attributed it to personality characteristics. He also writes that authoritarianism is a teacher's trait in Thailand, and reports that a teacher must be shown respect and take responsibility. Borkin and Carpenter (1979, pp.1-4) observe that professors place intellectual responsibility on students even though the student expects 
and wants direction from the professor. Students also expect professors to tell them how much they need to do to satisfy the requirements of the class or project. They note that in their observations of professors and students it did not seem that professors held the same expectations for themselves as students did.

Breuder (n.d., pp.5-6) has used the Michigan International Student's inventory to question students. International students frequently commented on the unwillingness of Americans to adapt foreign ways even when they are proven better and the self imposed feeling of American superiority students perceive in their interactions with professors.

In her doctoral dissertation Brun (1977, p.650-A) discovered which factors are important in assessing instructor competence among various groups of university students. Some of the factors she mentions are: interest and enthusiasm of the professor; ability to communicate the subject matter; ability to interest and motivate students; appropriate amounts and levels of difficulty of assigned work; and the professional qualities of the instructor such as his/her attitude and knowledge of the subject.

Cable (1974, p.140) provides comments international students have made to him about their professors. In summary, they are: a perceived lack of care by American professors about foreign students; that foreign students are treated as if they were the same as American students; that sometimes professors don't try to understand what foreign students are saying or asking; that some professors seen to lack committment; that some seem unable to establish a rapport with the class; 
that they are unaware of the foreign students' fears and timidity; and that they speak too rapidly. Cable suggests that professors should help foreign students individually and tell them how best to study for their classes. He notes that the foreign students do not understand the informal teacher-student relations in the United States and that many students feel professors are too casual. One other suggestion he makes is for professors to learn and correctly pronounce the names of their students.

Cowan (1978, p.11) says that international students do not expect professors to be so "middle class". Professors are also less sociable than studen.ts woli.d like.

Glass (1972-73, p.22) reports that Asian students had made the following remarks about their American professors: they sometimes dress like students; they sometimes introduce themselves by their first and last names; that professors call students by their first names. In his contribution to a handbook for Asian students coming to the U.S., Glass informs Asian students that American students do not expect formal invitations from professors to come to their offices because professors usually expect students to come on their own initiative to see them during posted office hours.

Gosnell (1979, pp.265-266, 386-389), in his acculturator, includes information about the professor's role. He observes that:

... in many cultures, the professor is the absolute master of the classroom. Everything he says must be taken as the truth. His decisions are his and his alone. His actions in the classroom are above criticism by the students. (pp.265-266) 
In the United States, on the other hand,

...although the professor still has great authority, he is expected to consider the needs and desires of his students in making his decisions and in teaching his class... it is recognized that both students and professors can and do make mistakes. (p.266)

Gosnell notes in another incident that in some cultures a professor would never admit to making a mistake, but that American instructors usually are willing to admit publicly that they have made an error. In speaking of professors he also tells students that "...most instructors are very concerned about the progress of their students... and are willing to help the student individually outside of class" (pp. $286,287)$.

Grove (1978, pp.15,34) comments that in Portugal teachers can give corporal punushment. Portuguese students comment that American teachers are warmer, kinder, friendlier, more human than more or all of their teachers in Portugal.

Haas (1972-73, p.47) describes the variety of graduate classroom behavior that Asian students should expect in America. He says that lecturers at the graduate level are of ten informal and that they do not give "solid" presentations, but may conduct informal discussions. Professors don't determine the grade by a final written examination alone, he informs them, and they usually consider classroom participation in grading. A professor may also base final exam questions on material assigned as outside reading and not covered in the classroom sessions.

Marr (1978, p.62) in speaking of the expectations that Middle Eastern students have for professors says that they are accustomed to 
paternalism and expect to be dealt with firmly.

Mize (1978, p.34,38) shares the impression some Middle Eastern students have expressed about their professors not having reverence for the written word. In speaking of grading, he says that in some universities (Libyan universities as an example) a professor does not judge the students even though he does teach and prepare the exams for them. Sometimes a group of faculty members will discuss and determine the grades for students in contrast to the United States where each professor determines the grade for each student in the classes s/he teaches. Nangle (1974, pp.7,15,64,66,69), in studying the adjustment of international students, elicited the following impressions of faculty. Some were mentioned by many students, others by only one or two. Students commented that the faculty was knowledgeable and helpful. However, some felt that faculty teaching skills could be better, that they were discriminatory, that they didn't relate to students informally, and that they were disorganized. Others responded that professors were non-professional, had negative attitudes towards students, had narrow fields of interest, were impersonal and incompetent, gave boring lectures, and had no time for students.

In response to research carried out on teacher effectiveness, students rated the following highly: appearance, ability to explain lessons, friendliness, firmness, discipline, homework assignments, enjoyment of teaching, voice and mannerisms, and knowledge of their subject (Norris, 1977, P.1203-A).

West (1975, pp.1-7) has the following suggestions for teachers going to Iran: arrive and leave class on time; be wel1-prepared; keep 
the class pace brisk; show a genuine concern for your students' progress; show enjoyment of your job; always look and/or give an impression of being in control; dress well--no sandals, open shirts, or shorts; do not embarass a student in front of his peers; call colleagues by Miss, Mr., or Mrs.; call students by their last names; don't lose your temper--this indicates a lack of professionalism. He also mentions that a professional decorum does not include sitting on the desk, smoking, or disclosing too many facts about one's personal life--at least not before establishing respect.

Zonis (1978, pp.84-86) says that Middle Eastern students expect the professor to provide students with the information they will need for their exams--the passing of which is synonymous with being educated. He also relates that professors are expected to impose order in the classroom.

\section{Concluding Remarks}

From the cited literature one could attempt to make generalizations about students from specific countries or cultural backgrounds. The author hesitates to do so because most of the observations made were not methodologically based. However, as a source of discovering problem areas they can be useful. The reader is referred to Appendix E where the behaviors and characteristics of professors and students as stated in the literature and in interviews have been grouped and categorized.

The observations about professors and international student provide evidence to support the notion that professors and international 
students have many unfulfilled expectations for one another. One can hypothesize that professors and international students define and evaluate the roles of professor and student differently by virtue of their different status. Or, one could hypothesize it is by virtue of their different backgrounds. No empirical research has been discovered which substantiates either hypothesis or provides information as to which factor is more $s$.gnificant in affecting evaluative tendencies. The following explo:atory research attempts to do so. 


\section{CHAPTER III}

\section{BASIS OF THE STUDY}

Introduction

Cross-cultural research on roles is still in the beginning stages. Most empirical work on the subject has been done by Triandis (1972). However, research such as that done by Chapman and Kelley (1979), who conducted a study comparing Iranian and American high school students' preferences for learning styles, has demonstrated that significant differences exist between educational environments in Iran and the United States. This leads one to the conjecture that the same must be true regarding educational preferences among other cultures.

Cross-cultural research on roles and educational environments and preferences have given impetus to this exploratory cross-cultural study of the roles of professor and student.

\section{The Research Questions}

The following questions are addressed in the research study:

1. What behaviors are often associated with the role of professor?

2. What behaviors are often associated with the role of student?

3. How do members of different culture groups evaluate the various role behaviors of professor and student as revealed by a sample population? 
4. Are some role behaviors evaluated similarly by a cross-cultural sample?

5. Are some role behaviors evaluated differently by a crosscultural sample?

6. Will an individual's status as professor or student affect how $s /$ he evaluates the roles of student and professor?

7. If role status affects the manner of evaluation and culture affects the manner of evaluation, which factor is the most significant in affecting the differences in evaluation?

8. Are there any other factors, such as sex, that can be shown to affect the manner in which one evaluates?

\section{Research Hypotheses}

There are three major hypotheses. Stated in the null form they are:

I. There will be no significant difference in how international students and American students evaluate the role behaviors of student and professor.

II. There will be no significant difference in how international students and American professors evaluate the role behaviors of student and professor.

III. There will be no significant difference in how American students and American professors evaluate the role behaviors of student and professor.

\section{Definitions}

American: Persons whose native country is the United States of America will be referred to as American unless otherwise noted. American student: The American students of the study will be university students in attendance at Portland State University who declare their cultural background to be American. 
International student: The international students of the study will be university students in attendance at Portland State University who declare their cultural background to be other than American. American professor: The American professors of the study will be university professors who are in the employ of Portland State University and who declare their cultural background to be American. Role behavior: A role behavior is a descriptive statement of a characteristic or behavior. An example of a role behavior is: Inviting students to one's office (for a professor).

\section{Criteria of Hypotheses Assessment}

Scale: Subjects will evaluate the desirability of each role behavior on a seven point Likert-type scale. With one being the low end of the scale, an evaluation of one, two, or three will indicate the role behavior's degree of undesirability in the opinion of the subject rating an item. Seven will be the high end of the scale. An evaluation of five, six, or seven will indicate the role behavior's degree of desirability in the opinion of the subject rating an item. A rating of four will indicate that in the opinion of the subject, the role behavior is neither desirable nor undesirable.

Statistical Procedures: Evaluation scores of the target populations (e.g., American students, international students, and American professors) will be tabulated to find the mean and standard deviation for each target population for each role behavior item. Using the Statistical Package for the Social Sciences (SPSS) program for the 
"T-Test for Comparisons of Independent Samples" (described by Klecka et al., 1975), the statistical significance of the difference between the means of the subject groups will be calculated for each role behavior. That is, for each role behavior item, the difference and the significance of the difference will be calculated between international students and American students, between international students and American professors, and between American students and American professors.

Significance Levels: A significance level of .05 will be used as part of the criteria necessary for rejecting the null hypothesis. A difference between the means of the subject groups' ratings of a behavior item of .5 or more will be the basis of determining if a difference in evaluation exists between groups.

If a role behavior item's significance level is less than or equal to .05 and the difference between the mean scores of the two subject groups being compared is .5 or more the null hypothesis will be rejected and the observed difference between the subject groups' evaluation of the item will be interpreted as being significant. 
CHAPTER IV

RESEARCH DESIGN AND METHODOLOGY

\section{Introduction}

The research design consists of three parts. First it was necessary to develop behavior lists for the roles of professor and student. The next stage involved the development of a questionnaire that could be reliably administered to a population of students and professors. The third stage was the actual administration of the questionnaire to American and international students and professors at Portland State University and the analysis of the results of this administration.

Development of Behavior Lists

As there were no known available behavior lists that pertain to the roles of student and professor, it was necessary to develop them. Triandis used open-ended questionnaires to obtain behaviors in their cross-cultural study of Greek and American roles (1972, p.264). This research study employed four methods to construct the needed behavior lists, reviewed in the following:

1) A review of the literature (Chapter II) resulted in a list of behaviors as perceived by international students, foreign student advisors, faculty, and others interested in international student affairs. The items provided by the literature tended to be stated as problems and were seldom presented in unambiguous descriptive language. 
2) Open-ended interviews were employed to obtain more insight into the nature of international student-professor interaction in the academic setting. In the Fall of 1979 one to two hour interviews were held with five administrative and academic faculty and two international students. Interview notes were written up and analyzed. Statements and comments pertaining to student and professor behavior were extracted and added to the behavior lists.

3) As behaviors associated with a role vary from culture to culture, it was necessary to query a broader population of Americans and internationals. This was accomplished through the administration of an open-ended questionnaire to students enrolled in an upper division course in Intercultural Communication and to students enrolled in a lower division Communications course. Five professors also responded to the same questionnaire, two orally and three in writing. The professors represented the fields of philosophy, geography, journalism and english. Statements from these questionnaires were extracted for inclusion on the behavior lists.

4) English as a Second Language students at Portland State University discussed the professor and student roles in small groups as part of a class activity. Students were assigned as homework the following questions: 1) What is a good professor?; 2) What does a good professor do?; 3) What is $s /$ he like?; 4) What is a good student?; 5) What does a good student do?; 6) What is s/he like? Students discussed their ideas in small groups and then shared them with the class. The results of their class presentations and the subsequent in-class discussions were recorded by the researcher.

To informally verify the research hypotheses, additional English as a Second Language classes were asked to respond to the lists of characteristics drawn up by previous students. Their differences of opinion were discussed in class. One group also responded to some of the items from a list of behaviors that had been administered to a small group of professors in the Fall of 1979. (See Appendix B for a copy of the questionnaire administered.) A difference of evaluation was noted on some items between the two populations, but the analysis at this point was informal and could not be considered statistically significant. 
Thus, with input from international and American students and professors accomplished, behavior lists for the role of student and for the role of professor were compiled. (The compiled behavior lists can be found in Appendix F). The next stage of the research was to develop a questionnaire that could be administered to populations of students and professors using items selected from the behavior lists.

\section{Questionnaire Development}

Questionnaire development involved several steps. Items from the behavior lists were selected and written in a standardized form for inclusion in a questionnaire. A questionnaire format and scale were selected and the limits of reliability set. The questionnaire was administered twice, two weeks apart, to determine its reliability-that is, to determine which items could be included in the final version of the questionnaire. The above are discussed in detail in the following paragraphs.

Selection and Writing of Items. The behavior lists were analyzed, sorted into categories, and frequently mentioned items noted. Items with unclear language or containing inferences rather than behavior descriptions were screened out as much as possible. (Inferences such as "nice", "friendly", "has lots of energy", "looks respectable" are derived from different behavior forms from culture to culture). Another group of items were ruled out because they were not related to the context of academic and professor-student interaction.

It was desirable that each behavior item, for inclusion on the questionnaire, be stated in non-evaluative, grammatically simple and 
descriptive language. Since the future target populations would include non-native speakers of English, idiomatic language was avoided. The lists were reviewed and critiqued by a university professor whose field is intercultural communication and who has extensive experience teaching students with various levels of language proficiency, and finalized based upon that consultation.

Resolving a Definitional Problem Concerning Students. During the formulation of the behavior lists students and professors of ten commented that there are two kinds of students present in the university. The student who wants to learn and understand the content of his/her courses is one type; the student primarily interested in getting a good grade and obtaining his/her degree is the other. The subject came up often and without prompting. Further consideration determined that it might lend clarity to the questionnaire if the role of student could be defined in one of the two ways. Subjects who participated in reliability testing of the questionnaire items responded to two student questionnaires. They were asked once to respond to the items where a student was defined as being interested in understanding and learning the material, and secondly to respond to the itens where a student was defined as being interested in getting good grades and passing his/her courses.

Scale Selection. Biddle and Thomas (1966) discuss the use of unipolar and bipolar scales in studying behaviors. They recommend the use of a unipolar scale if one desires to study the levels of permissiveness of prescription from a level of indifference to either 
obligatoriness or forbiddenness. Since, however, it was the intent of the research to distinguish between obligatory and forbidden behaviors, a bipolar scale seemed preferable. Such a scale was selected and the terms "absolutely desirable" and "absolutely undesirable" were chosen for use on the extreme ends of the scale.

Reliability Limits. The limits of reliability set by Guilford for determining the significance of correlation coefficients are commonly used in research of this nature (Williams, 1979, p.128). According to Williams, Guilford suggests the following guidelines:

$$
\begin{array}{ll}
.00 \text { to } .20 & \text { slight, almost negligible relationship } \\
.20 \text { to } .40 & \begin{array}{l}
\text { low correlation, definite but small } \\
\text { relationship }
\end{array} \\
.40 \text { to } .70 & \begin{array}{l}
\text { moderate correlation, substantial rela- } \\
\text { tionship }
\end{array} \\
.70 \text { to } .90 & \begin{array}{l}
\text { high correlation, marked relationship } \\
.90 \text { and up }
\end{array} \quad \begin{array}{l}
\text { very high correlation, very dependable } \\
\text { relationship }
\end{array}
\end{array}
$$

It was decided that behavior items calculated to have a correlation coefficient of less than .50 would be arbitrarily eliminated from the questionnaire while those with a correlation coefficient above .50 would be considered for inclusion.

Reliability Testing. Thirty-five subjects participated in the reliability testing of the questionnaire. (A copy of this questionnaire is in Appendix C). Seventeen were from a lower division communications class at a local community college, six were upper division students enrolled in an advanced Intercultural Communications course, four were ESL faculty at Portland State University, and eight were graduate 
teaching assistants from the Speech Communication and ESL departments. All questionnaires were administered by the researcher. All subjects completed the 175 item questionnaire on their own time and returned it to the researcher. Two weeks following the first administration, the subjects took the questionnaire again. Thirty-four completed sets were used to tabulate the student role forms and also item numbers forty-two to sixty-one of the professor role forms. Thirty-two sets were included in the tabulations for items one through forty-one of the professor form.

Results of Reliability Testing. Questionnaire items with a correlation coefficient of .65 and above were retained from the student role and professor role forms of the questionnaire. (See Appen$\operatorname{dix} G$, Tables VII, VIII, and IX for the statistical summary of the reliability calculations).

The questionnaire used for the final administration included all forty-five items which met the reliability criteria of .65 or above.

Conclusion and Resulting Questionnaire

The final version of the questionnaire consisted of a cover page with a note of introduction and directions for completing the questionnaire forms, the three questionnaire forms--one pertaining to the student who defines success as getting high grades and passing courses, one pertaining to the student who defines success in terms of understanding and learning the material of his/her courses, and one pertaining to the ideal professor--, and a page requesting demographic information about the subject taking the questionnaire. (See Appendix D 
for a copy of the questionnaire). Informal testing of the questionnaire revealed that the questionnaire would take fifteen minutes for administration and completion.

There are two student forms in the final questionnaire. They are identical. However, only items one through thirteen on the form for the student who defines success in terms of high grades and passing and items thirteen to twenty-five on the form for the student who defines success in terms of understanding and learning the material meet the reliability criteria and are included in the statistical analysis of the data. All nineteen items on the professor form are included in the statistical analysis. 


\section{CHAPTER V}

TEST ADMINISTRATION

\section{$\underline{\text { Introduction }}$}

Problems of administration centered around obtaining a sufficient sample of the target population so as to allow significant statistical analysis. It was also necessary that the sample be representative of faculty and students--both graduate and undergraduate--of the five major colleges of the university.

\section{Subject Representation}

A goal of three-hundred subject responses was set, equally distributed among American students, international students, and American professors. The minimum acceptable number of responses was designated as 150 , equally distributed among the target populations. Responses were desired from the five major schools of the university (i.e., Education, Social Sciences, Arts and Letters, Science, and Business Administration), and from both graduate and undergraduate students. Of the 501 questionnaires returned, 486 provided the demographic data needed to determine if the goal for subject representation had been met. Two hundred and thirty-eight responses were received from American students, 104 from international students, and 129 from American professors. The other fifteen were from the administrative faculty and international professors. Out of the total sample of students and professors, $9.3 \%$ were from the College of Education, $17.7 \%$ from 
the School of Social Sciences, $23.7 \%$ from the School of Arts and Letters, $18.1 \%$ from the School of Science, $22.8 \%$ from the School of Business Administration, and $8.4 \%$ from other colleges and divisions. For a more detailed breakdown, see the sumnary of the population breakdown in Table I.

TABLE I

DISTRIBUTION OF SUBJECT POPURATIONS

BY ACADEMIC MAJOR/FIELD

\begin{tabular}{lcccc}
$\begin{array}{l}\text { SCHOOL OF } \\
\text { MAJOR/FIELD }\end{array}$ & $\begin{array}{l}\text { ENTIRE } \\
\text { POPULATION(\%) }\end{array}$ & $\begin{array}{l}\text { AMER PROF } \\
\text { POPULATION(\%) }\end{array}$ & $\begin{array}{l}\text { AMER STUDENT } \\
\text { POPULATION(\%) }\end{array}$ & $\begin{array}{c}\text { INT'L STUDENT } \\
\text { POPULATON(\%) }\end{array}$ \\
\hline Education & 9.3 & 12.4 & 8.8 & 6.7 \\
Social Sci. & 17.7 & 27.1 & 13.4 & 15.4 \\
Arts \& Let. & 23.7 & 27.1 & 24.8 & 14.4 \\
Science & 18.1 & 17.1 & 12.6 & 31.7 \\
Business Ad. & 22.8 & 14.7 & 25.6 & 29.8 \\
Other & 8.4 & 1.6 & 14.8 & 2.0 \\
\hline Totals & 100.0 & 100.0 & 100.0 & 100.0 \\
\hline
\end{tabular}

Questionnaire Administration

The questionnaire was administered to students and faculty in several manners, each of which will be described below. In no case was the taking of the questionnaire made mandatory. Anonymity was guaranteed; however, some professors requested that their questionnaires be identified so that they could compare their responses with the tabulated results. These requests were accommodated. 
Administration to Students. Most students received the questionnaire during a class period. The selection of classes was made with the goals of subject composition in mind. Instructors of lower division introductory courses in the targetted colleges were contacted. If there was more than one section of a particular course, the instructors of section four and multiples of four were selected for contact. Al1 instructors approached agreed to the administration. Upper division and graduate courses were located through contacts made with professors during distribution of the questionnaire to faculty. A major goal was to locate courses in which international students were enrolled. If in speaking to a professor it was ascertained that international students were enrolled in a course s/he was teaching, s/he was asked if it would be possible to administer the questionnaire to that class. In all cases professors responded affirmatively.

The questionnaire was administered to thirteen lower division (courses numbered 100, 200, and 300) and seven upper division (courses numbered 400 and 500) classes.

Approximately $60 \%$ of the questionnaires were administered by the researcher in a classroom environment. (Approximate percentages only are given due to the anonymity of response and the fact that many questionnaires were returned through the campus mail.) In this case the researcher briefly introduced the nature of the research being conducted and reiterated verbally the instructions for completion of the questionnaire as written on its cover page. Depending on the wishes of the class's instructor, students either filled out the questionnaire 
during class or returned them to the professor at a subsequent class meeting after completing them at home.

Approximately $35 \%$ were administered by class instructors to students in the selected classes. In this case the researcher discussed the questionnaire and procedures for its administration with the instructor. Again, depending on the instructor, students either filled out the instrument during class or brought it to a subsequent class meeting after filling it out at home.

The remainder (about 5\%) were administered individually to students by the researcher or by the secretary in the International student Services office.

A total of 351 usable questionnaires were received from students who were administered the questionnaire in one of the above manners. Administration to Faculty. Personal interviews and personalized mailing of the questionnaire were employed where faculty were concerned. This was to ensure a substantial and representative input from faculty in view of the low return rate on mailed questionnaires ${ }^{2}$ as well as the tendency of some persons, on principle, to not fill out questionnaires received by mail.

Between May 19th and May 28th, and between June 17th and June 26th, 1980 the questionnaire was personally given to 109 faculty in

1 Nine questionnaires lacking complete demographic data were included in the analysis, thus accounting for the total: 342 plus nine $=351$ (see page 55).

2 A questionnaire sent to faculty through campus mail by the Center for English as a Second Language had a response rate of $19 \%$. One sent by the International Student Services had a response rate of $33 \%$. 
their offices. The researcher visited each department of the target colleges at various times during the day and evening on the dates cited above. The researcher approached any occupied faculty office, knocked, introduced herself, and requested two minutes of the professor's time to explain the purpose of the visit. Depending on the particular professor and situation the researcher remained to talk to the faculty member and to administer the questionnaire, made an appointment to return at a more convenient time, or thanked the individual and left. These office visits lasted from five minutes to one and one-half hours, the average lasting twenty-five minutes. The actual administration of the questionnaire took no more than three minutes. This consisted of the researcher verbally explaining the purpose of the study--which also was outlined in a letter written by the International Students' Board endorsing the research and attached to the questionnaire--and verbally reiterating the instructions on page of one of the questionnaire.

In late June, a follow-up letter was sent to each one of the 109 faculty members contacted, thanking them for agreeing to complete the questionnaire and reminding any who had not returned it to do so by July 11,1980 . The rate of return on the questionnaires distributed in this fashion was $84.5 \%$.

As the goal of one-hundred faculty members had not been met, another 109 questionnaires were sent to Summer Term faculty of the five target colleges. Individuals were selected in a predetermined random fashion from the Summer Term course schedule book. A handwritten, personal note accompanied each questionnaire requesting the 
faculty nember to contact the researcher if $s /$ he had any questions about the questionnaire. No follow-up letter was sent to faculty who received their questionnaire by mail. The return rate of questionnaires administered in this fashion was $53.2 \%$.

Of the 150 questionnaires returned--giving a overall rate of return of $68.8 \%--147$ were from teaching faculty. The other three were either research or administrative faculty.

$\underline{\text { Summary }}$

The Student-Professor Role Behavior Questionnaire was completed acceptably ky a representative sample of 501 Portland State University faculty and students. After receipt, the questionnaires were coded onto computer cards for analysis. The results of the statistical analysis are the subject of Chapters VII and VIII. Copies of the questionnaire, the cover letter, and the follow-up letter are in Appendix D. 
CHAPTER V

\section{LIMITATIONS AND ASSUMPTIONS}

By nature, much methodological research is contrived and studied out of context with accompanying limitations such as representativeness of the sample and/or the bias of the researcher and his/her methods. Cross-cultural research methodology must acknowledge these concerns as well as others that are peculiar to research involving subjects from cultures outside his/her own.

Hall (1977) says that "...it is impossible to separate the individual from the environment in which he functions (p.100). In asking subjects to respond to a questionnaire about professor and student behavior, they are, in essence, being asked to consider the actions of professors and students out of context. They are not being asked to comment on a specific professor at a specific time in a class with a specific format. The findings, therefore, cannot be utilized to predict how a particular student or professor may evaiuate a particular student or professorial behavior. Hopefully, the findings can give us guidelines through which we can begin to understand the evaluative tendencies among different cultures regarding role behaviors.

Representativeness of the sample is a potential limitation of any study, including this one. Everything possible recognized as sufficient for research of this type has been done to ensure a representative sample of Portland State University's student and professor population. 
A limitation more specific to this research study, due to its cross-cultural nature, is that many of the subjects did not take the questionnaire in their native language. Translation can lead to problems of equivalency if either the subject takes a questionnaire written in his/her non-native language or if it is translated into his/her own language. Care was taken, as noted previously, to write the role behavior items in descriptive, grammatically simple, and non-jargonistic or idiomatic language as much as possible since internationals would be taking the questionnaire in a non-native language. It was assumed for this study that subjects could read and understand the meaning of each role behavior item. To help ensure this, only international students who had completed language training and who had been admitted to the university (which requires demonstration of language proficiency for admission) were targetted. A few subjects in the last weeks of English training also participated. They were allowed the use of dictionaries, the opportunity to ask the test administrator for clarification, and additional time to complete the questionnaire if desired. Another limitation of cross-cultural research is that the use of specific research tools might be a "...momentary and strange imposition on the subjects" (Brislin, et al., 1973, p.4). The questionnaire used in this study and its design are familiar to the United States. Here, most university students, by virtue of their reaching college have had experience taking pencil and paper tests and questionnaires such as the one employed in this study. International students, too, by virtue of their being accepted and arriving for study at a U.S. university have 
had the experience of filling out forms and of taking pencil and paper proficiency examinations such as the Test of Engish as a Foreign Language (TOEFL) or the Graduate Record Examination (GRE). For the English as a Second Language students taking the questionnaire, whose classes include training in this skill, the questionnaire and how to take it were given additional time and emphasis at the time of administration.

A limitation of any study in which subjects are asked to provide information to a researcher is the truthfulness and accuracy of that information. To allay this problem, subjects were given the choice of taking or not taking the questionnaire, and were guaranteed anonymity of they chose to take it. The questionnaire does not contain material that might be considered threatening, at least insofar as mainstream American culture is concerned. However, to allow for internationals who might prefer for one reason or another to keep even their country of affiliation out of the study the option of giving either country (i.e. Saudi Arabia) or cultural background (i.e. Arab, Palestinian) was provided. Test administrators were asked to explain the purpose of the study and the need for honest opinions, and also to give further assurance that no one would be able to know who filled out what questionnaire.

By taking the above precautions the major limitations were acknowledged and dealt with through the means available. The researcher still acknowledges that these, and other limitations exist, but are not unusual in this type of research study.

In summary, the research rests on the following assumptions which were made about the subjects who took the role behavior questionnaire: 
1. The subjects are representative of the populations from which they were drawn;

2. the subjects can read and understand the meaning of each role behavior item;

3. the subjects are able to use the tools of the research method (e.g. a pencil and paper questionnaire);

4. The subjects will answer honestly and their responses reflect their personal opinion and evaluation of each item on the questionnaire. 
CHAPTER VII

HYPOTHESES TESTING: RESULTS AND DISCUSSION

Introduction

Chapters VII and VIII present the results of the research and a discussion of the analyzed data from the completed questionnaires.

Chapter VII presents the results and discussion of the t-test analysis of the data performed to determine the acceptance or rejection of the three hypotheses stated in Chapter III. In the discussion the "etic-emic" quality of role behavior interpretation will be emphasized. In addition, normative structures of the role behaviors are defined and the role behaviors of the research categorized by these definitions. Selected role behaviors are examined to demonstrate the usefulness of learning the "etic-emic" and normative qualities of role behaviors. Chapter VIII discusses the variables culture area/country, status and sex and how they may affect the evaluation of a role behavior. Further areas for research on variables affecting evaluation of role behaviors are suggested as well as the need to show the usefulness for undertakings of this kind.

Hypothesis I: Results

Hypothesis I: There will be no significant difference in how international students and American students evaluate the role behaviors of student and professor. 
The evaluations by international students and American students of the forty-five student and professor role behaviors selected for analysis through reliability testing were tabulated and statistically analyzed and judged according to the criteria set out in Chapter III. The null hypothesis was rejected for seventeen of the forty-five role behavior items: ten pertaining to the student ${ }^{1}$ role and seven pertaining to the ideal professor role. For a statistical summary of the hypothesis testing results see Tables $\mathrm{X}$ and $\mathrm{XI}$ in Appendix G.

The role behavior items that international and American students evaluated in a significantly different way for the student role are:

1. Listens critically (HGPLIS). ${ }^{2}$

2. Can type (HGPTYPE).

3. Writes imaginative essays.

4. Asks to be excused from a test if not ready to take it (HGPEXC).

5. Allows the professor to precede him/her when entering and leaving the classroom (HGPOUR).

6. Allows the professor to precede him/her when entering and leaving the classroom (UALCOUR2).

7. Slants his/her papers to fit the expectations of the professor (UALSLANT).

1 The two types of "successful" student subjects were asked to respond to have been combined for this breakdown of hypothesis testing. The first three letters of the code-word following each item indicates whether the role behavior pertains to the student who defines success in terms of "getting high grades and passing courses" (HGP) or to the student who defines success in terms of "understanding and learning the material" (UAL).

2 The six to eight letter code-word following a role behavior description corresponds to the item code-name as used on the tables in the study. A complete key to code-names and the role behavior item it represents is found in Appendix A. 
8. Talks to the professor about how to get a good grade (UALGRADE).

9. Does whatever the professor directs (UALDIRCT).

10. Raises his/her hand for permission to speak (UALRAISE).

The role behavior items that international and American students evaluated in a significantly different way for the ideal professor role are:

1. Relies primarily on classroom performance for judging a student's ability (PROFPERF).

2. Prefers that students remain quiet in class (PROFQUT).

3. Will talk about his/her personal life and feelings in class (PROFPERS).

4. Changes the format of the class (i.e., lecture, movies, discussion) from time to time (PROFFORM).

5. Posts and keeps office hours (PROFHRS).

6. Is dedicated and devoted to his/her work (PROFDED).

7. Gives the necessary information of the course during class and doesn't expect student to go to the library to learn it (PROFINFR).

Hypothesis II: Results

Hypothesis II: There will be no significant difference in how international students and American professors evaluate the role behaviors of student and professor.

The evaluations by international students and American professors of the forty-five student and professor role behaviors selected for analysis through reliability testing were tabulated and statistically analyzed and judged according to the criteria set out in Chapter III. The null hypothesis was rejected for twenty-three of the forty-five role behavior items: twelve pertaining to the student role 
and eleven pertaining to the ideal professor role. For a statistical summary of the hypothesis testing results see Tables $X$ and XII in Appendix G.

The role behavior items that international students and American professors evaluated in a significantly different way for the students role are:

1. Listen critically (HGPLIS).

2. Can type (HGTYPE).

3. Writes imaginative essays (HGPIMAG).

4. Asks to be excused from a test if not ready to take it (HGPEXC).

5. Allows the professor to precede him/her when entering and leaving the classroom (HGPCOUR).

6. Allows the professor to precede him/her when entering and leaving the classroom (UALCOUR2).

7. Accepts the authority of the professor (UALAUTH).

8. Reads a lot (UALREAD).

9. Slants his/her paper to fit the expectations of the professor (UALSLANT).

10. Talks to the professor about how to get a good grade (UALGRADE).

11. Does whatever the professor directs (UALDIRCT).

12. Raises his/her hand for permission to speak (UALRAISE).

The role behavior items that international students and American professors evaluated in a significantly different way for the ideal professor role are:

1. Relies primarily on classroom performance for judging a students ability (PROFPERF). 
2. Can answer any question that is asked in class about the subject matter (PROFQUEST).

3. Prefers that students remain quiet in class (PROFQUT).

4. Changes the format of the class (i.e. lecture, movies, discussion) from time to time (PROFFORM).

5. Encourages students to speak in class (PROFSPK).

6. Assigns the reading of materials that are not included in the tests $s /$ he gives (PROFMTRL).

7. Posts and keeps office hours (PROFHRS).

8. Is available to students whenever they need him/her, including calls at home (PROFAVBL).

9. Determines grades for students by how well they meet set standards without regard for their individual abilities and skills (i.e. language ability) (PROFLANG).

10. Is dedicated and devoted to his/her work (PROFDED).

11. Gives the necessary information of the course during class and doesn't expect students to go to the library to learn it (PROFINFR).

Hypothesis III: Results

Hypothesis III: There will be no significant difference in how American students and professors evaluate the role behaviors of student and professor.

The evaluations by American students and professors of the forty-five student and professor role behaviors selected for analysis through reliability testing were tabulated and analyzed and judged according to the criteria set out in Chapter III. The null hypothesis was rejected for five of the forty-five role behavior items: one pertaining to the role of student and four pertaining to the role of ideal professor. For a statistical summary of the hypothesis testing see Tables $X$ and XIII in Appendix G. 
The role behavior itam that American students and professors evaluated in a significantly different way for the role of student is:

1. Asks for comments and criticism (HGPCRIT).

The role behavior items American students and professors evaluated in a significantly different way for the ideal professor role are:

1. Asks for comments and criticism (HGPCRIT).

2. Assigns the reading of materials that are not included in the tests $s /$ he gives (PROFMTRL).

3. Determines grades for students by how well they meet set standards without regard for their individual abilities and skills (PROFLANG).

4. Gives the necessary information of the course during class and doesn't expect students to go to the library to learn it (PROFINFR).

Discussion: "Etic"/"Emic" Distinction and Determination of Normative Structures of Role Behaviors

It would be useful to look at the forty-five role behaviors the subject populations evaluated and suggest which behaviors, on the basis of the data, might be expected to contribute to miscommunication among and/or between American students, international students, and American professors by reason of their cultural background or status, and, which behaviors, due to similar evaluation tendencies probably would not lead to communication breakdowns.

The data indicate that when a role behavior is evaluated differently it can be due to either the status (student or professor) or the culture of the subject. Culture is the significant variable for sixteen of the role behaviors and status for five others. Both culture and status are significant for one role behavior. For four of the remaining role behaviors evaulated differently according to the 
hypothesis criteria it is not possible to determine from the data the variable responsible. The other nineteen role behaviors were evaluated similarly across culture and status.

Cross-cultural researchers are interested in learning of cultural components such as role and role behaviors that are evaluated differently across cultures; however, they are also interested in discovering components of culture that might be similarly viewed across cultures. Brislin (1980, pp.54-62) notes that the cross-cultural researcher aims to learn which components of a culture are "etic," or universal, and which components are "emic," or particular in form or meaning to a particular group or culture. From the results of this role behavior research, it appears that several "etic" and "emic" role behaviors have been located for the roles of student and professor. The role behaviors included in this study are by no means exhaustive, but they do provide a starting point for further cross-cultural research into the roles of student and professor.

Through data analysis, in addition to emic and etic qualities of role behaviors, one can also learn some of a culture's or population's normative structures by observing whether or not the evaluations are polarized (Jackson, 1966, pp.113-116). Both the discovery of the etic/emic quality of a role behavior and the discovery of the normative structure of a role behavior are useful to persons concerned with improving intercultural communication. Discovering the etic/emic quality of a role behavior will aid the intercultural communicator in his/her interpretation of observed phenomena (e.g. role behavior). 
Knowing something of the normative structure of an evaluation allows one to judge the importance of enacting a particular behavior and the probability of its being sanctioned if violated. (For example, is the norm held by most of a population and therefore a carrier of societal sanctions for violating it, or is it evaluated in a variety or ways depending on the individual and carry fewer societal sanctions?)

From the data, the normative structure of the evaluations can be determined by observing if the evaluations polarize positively (i.e. a rating of five, six, or seven on the basis of a behavior's desirability), negatively (i.e. a rating of one, two, or three on the basis of the behavior's undesirability), or neutrally (i.e. a rating of four, the midpoint on the desirable-undesirable scale employed).

For the purposes of this discussion the normative structure of a role behavior will be defined as follows:

high: if $80 \%$ or more of a population evaluates a role behavior as positive, negative, or neutral.

strong: if $65 \%$ or more of a population evaluates a role behavior as positive, negative, or neutral.

significant: if $50 \%$ or more of a population evaluates a role behavior as positive, negative, or neutral.

The next section will briefly delineate these etic and emic groups of role behaviors as revealed by a t-test and show how the normative structures of the individual role behaviors can be examined by use of a few illustrative examples. 
Discussion: Etic Role Behaviors

According to the t-test analysis, nineteen role behaviors were evaluated similarly by all groups and might be considered etic in quality. This means that we can hypothesize that international and American students and American professors in the United States agree as regards whether or not these behaviors are desirable or undesirable and are thus unlikely to be at the root of communication breakdowns among them. Table II lists the etic role behaviors and normative structure of each one.

The etic role behaviors for the student who wants to get high grades and pass his/her courses (henceforth referred to as StudentHGP) can be examined. Approximately $78 \%^{3}$ of all groups think that Student-HGP should have a strong sense of purpose for why $s /$ he is in school (HGPPUR). At least $64 \%$ of all groups think that Student-HGP should consult his/her professor to find a project or paper topic (HGPCON), more than $89 \%$ think s/he should ask to know the course requirements and expectations (HGPREQ), and at least $53 \%$ feel it is desirable for Student-HGP to memorize his lecture notes (HGPMEM). More than $71 \%$ of the subject populations feel that Student-HGP should go to his/her professor to find out what happened in class if absent from a meeting (HGPABS), but only just more than $45 \%$ feel s/he should

3 Appendix G, Table XIV, Normative Structures of Role Behavior Items: Subject Groups Collapsed Evaluation Rating of Each Item, contains the statistical data upon which the discussion of normative structures is based. 
TABLE II

"ETIC" ROLE BEHAVIORS AND THEIR NORMATIVE STRUCTURES

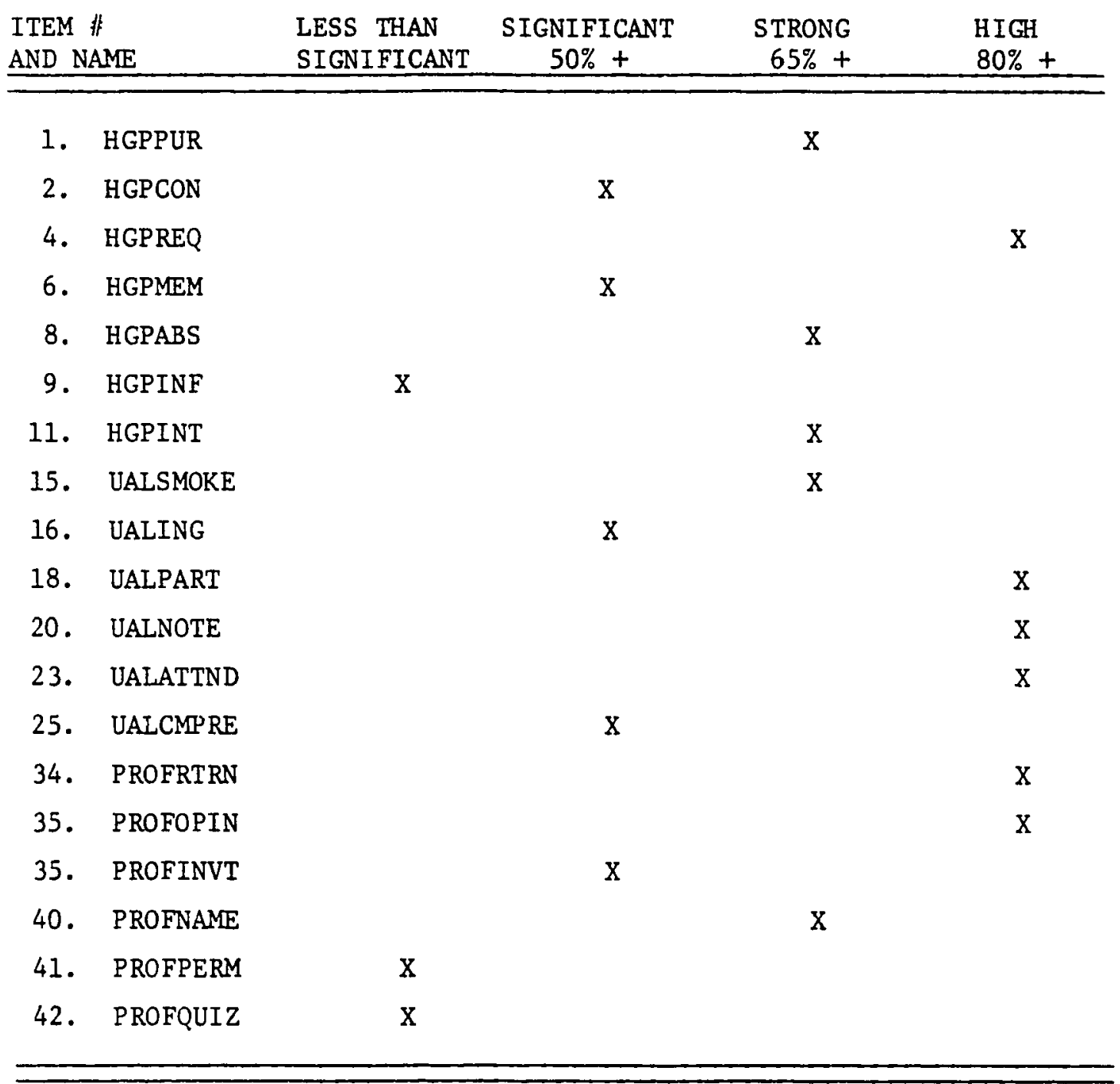

KEY : $\mathrm{X}=\mathrm{All}$ subject populations compared were at the indicated level or higher in their calculated normative structure data. (See Table XIV in Appendix $G$ for the statistical data on which this table is based.) 
inform the professor when s/he anticipates an absence (HGPINF). Over 73\% of all subjects think that Student-HGP should know specifically what $s /$ he wants when $s /$ he goes to the professor's office (HGPINT). Observing the polarization percentages for the etic role behaviors of Student-HGP one can note that asking about course requirements has a high normative structure. Having a strong sense of purpose, seeing the professor after a missed class, and having a specific purpose when going to a professor's office have strong normative structures. Informing the professor about an anticipated absence has a less than significant structure. This would probably indicate that going to see a professor before missing a class is more of a personal than societal norm. What is important to remember is that all three subject populations evaluated these items similarly and that it is probable that there are few misunderstanding among them that would stem from a culturally different way of viewing and evaluating the behaviors. Similarly, the role behaviors for the student who measures success in terms of understanding and learning the material of his/her courses (henceforth referred to as Student-UAL) can be examined. The etic role behaviors for Student-UAL having a high normative structure are: participates in class discussions and shares ideas (UALPART); takes notes (UALNOTE); and attends class regularly (UALATTND). Smoking in class (UALSMOKE) has a strong normative structure. Being concerned with knowing the grades and scores of other students (UALCOMPRE) and drinking and/or eating in class (UALING) have significant ones. The first three were evaluated as desirable, and the latter three as being undesirable behaviors in Student-UAL. 
For the professor role the behaviors with an etic quality are: returning quizzes and papers to students at the class meeting subsequent to their submission (PROFRTRN) and asks for students' opinions (PROFOPIN), which have high normative structures; knowing the names of students (PROFNAME) which has a strong normative structure; and inviting individual students to his/her office (PROFINVT), which has a significant normative structure. All of these role behaviors were evaluated as desirable in the ideal professor by a majority of the respondents. Two other etic professorial role behaviors have less than significant structures suggesting their individualistic as opposed to societally determined character. They are giving many quizzes (PROFQUIZ) and permitting students to take over and direct the class (PROFPERM).

\section{Discussion: Emic Role Behaviors}

Whereas nineteen role behaviors were evaluated similarly by all groups and are unlikely to be at the root of misunderstanding due to culture or status differences, the other twenty-six were evaluated differently. Even though both status and culture seem to affect the evaluation of the role behavior items, culture seems to be the variable most often associated with the differences in evaluation. Table III shows the classification of the emic role behaviors by the variable determined responsible for evaluation differences among the subject groups of the study. 4

4 Table III summarizes relevant data extracted from Tables $\underline{X}, \underline{X I}$, $X I I, X I I I$ in Appendix $G$. The reader interested in the statistical basis of Table III is encouraged to consult these tables. 
TABLE III

CLASSIFICATION OF "EMIC" ROLE BEHAVIORS

BY VARIABLE RESPONSIBLE FOR

DIFFERENCE IN EVALUATION

\begin{tabular}{|c|c|c|c|c|c|}
\hline $\begin{array}{l}\text { ITEM } \\
\text { AND N }\end{array}$ & AME & $\begin{array}{c}\text { CULTURE } \\
\text { AND STATUS } \\
\end{array}$ & $\begin{array}{l}\text { CULTURE } \\
\text { ONLY }\end{array}$ & $\begin{array}{l}\text { STATUS } \\
\text { ONLY }\end{array}$ & UNDETERMINED \\
\hline 3. & HGPCRIT & & & & $\mathrm{x}$ \\
\hline 5. & HGPLIS & & $\mathrm{X}$ & & \\
\hline 7. & HGPTYPE & & $\mathrm{x}$ & & \\
\hline 10. & HGPIMAG & & $\mathrm{x}$ & & \\
\hline 12 . & HGPEXC & & $\mathrm{x}$ & & \\
\hline 13. & HGPCOUR & & $\mathrm{X}$ & & \\
\hline 14. & UALCOUR2 & & $\mathrm{x}$ & & \\
\hline 17. & UALAUTH & & $X$ & & \\
\hline 19. & UALREAD & & & $\mathrm{X}$ & \\
\hline 21. & UALSLANT & & $\mathrm{x}$ & & \\
\hline 22. & UALGRADE & & $\mathrm{x}$ & & \\
\hline 24. & UALDIRCT & & $\mathrm{x}$ & & \\
\hline 26. & UALRAISE & & $\mathrm{x}$ & & \\
\hline 27 & PROFTEST & & & & $\mathrm{x}$ \\
\hline 28. & PROFPRFM & & $\mathrm{x}$ & & \\
\hline 29. & PROFQUES & & & & $\mathrm{X}$ \\
\hline 30. & PROFQUT & & $\mathrm{X}$ & & \\
\hline 31. & PROFPERS & & & & $\mathrm{X}$ \\
\hline 32 . & PROFORM & & $\mathrm{x}$ & & \\
\hline 33. & PROFSPK & & & $\mathrm{X}$ & \\
\hline 36. & PROFMATR & & & $X$ & \\
\hline 38. & PROFHRS & & $\mathrm{X}$ & & \\
\hline 39. & PROFAVLB & & & $\mathrm{x}$ & \\
\hline 43. & PROFLANG & & & $\mathrm{x}$ & \\
\hline 44. & PROFDED & & $\mathrm{X}$ & & \\
\hline 45. & PROFINFR & $\mathrm{X}$ & & & \\
\hline
\end{tabular}


Differences due to culture and status: Using the hypothesis criteria only one role behavior was judged differently by all three paired subject groupings. This is the professor role behavior that is stated: "Gives the necessary information of the course during class and doesn't expect students to go to the library to learn it" (PROFINFR). Almost twice as many students--both American and international--as professors feel it is desirable for a professor to give the necessary information of a course in the classroom. It is evaluated as undesirable twice as often by American professors as by American students, with the percentage of international students evaluating this behavior as undesirable being greater than American students by about $10 \%$, but this percentage of international students is still less than American professors by about 14\%. Via these findings one finds support for the impression that professors do not like it if students complain about too much outside work and can understand that it is not surprising that professors do not feel it is part of their job to "spoon-feed" a degree to students. When it appears that over $54 \%$ of all students would prefer that professors give them the necessary information of the course during class it is not surprising that there might be conflict between them stemming from their differing perceptions of what they would like a professor to do as part of his job.

Differences due to culture: There are sixteen role behaviors evaluated significantly different through t-test comparisons of the role behavior ratings between international students and American students and between international students and American professors, but not between American students and American professors. Five pertained to Student-HGP, six to Student-UAL, and five to the professor role. The 
sixteen role behaviors will be listed and one discussed in detail for purposes of illustrating the significance of discovering these emic behaviors for improving intercultural communication.

For Student-HGP the emic behaviors are: listens critically (HGPLIS); can type (HGTYPE); writes imaginative essays (HGPIMAG); asks to be excused from a test if not ready to take it (HGPEXC); and allows the professor to precede him/her when entering and leaving the classroom (HGPCOUR).

For Student-UAL the emic behaviors are: allows the professor to precede him/her when intering and leaving the classroom (UALCOUR2); accepts the authority of the professor (UALAUTH); slants his/her papers to fit the expectations of the professor (UALSLANT); talks to the professor about how to get a good grade (UALGRADE); does whatever the professor directs (UALDIRCT); and raises his/her hand for permission to speak (UALRAISE).

The emic role behaviors for the professor role are: relies primarily on classroom performance for judging a students ability (PROFPRFM); prefers that students remain quiet in the classroom (PROFQUT); changes the format of the class from time to time (PROFFORM); posts and keeps office hours (PROFHRS); and, is dedicated and devoted to his/her work (PROFDED).

Applying these findings to the real world one would expect that a negative evaluation of a behavior positively evaluated by another would lead to misunderstanding and communication breakdown between these two individuals. If the evaluations are normatively held by a majority of the populations represented by the two individuals, frequent 
miscommunication between the two populations due to differing evaluation tendencies might be predicted.

To illustrate the significance of this, one role behavior item will be examined. On item number twelve subjects were asked to indicate the level of desirability or undesirability for the Student-HGP to ask to be excused from a test if not ready to take it (HGPEXC).

The t-test results showed that at a significance level of .0000 international students, when compared with both American students and American professors, differed in their evaluation of this role behavior. The difference between the means when international students are compared with American students is 1.326 and the difference when compared to American professors is 1.768. American students and American professors evaluated the item similarly with the difference between their means being only .357.

With a significance level of .0000 , over $65 \%$ of the American professors rate this behavior as undesirable whereas only $23 \%$ of the international students of the sample rate it as undesirable. Most of the international students (about 59\%) think that it is desirable to ask not to take a test if not ready for it and another $17 \%$ indicate that it doesn't matter one way or the other. This means that it is likely that international students frequently violate a strong norm of the American university culture and are negatively sanctioned for a behavior that seems relatively normal and "okay" to them.

A student asking to take an exam at a later date may see no reason for a professor's disagreeableness due to his request and may be surprised to find the professor thinks s/he is lazy, disorganized, 
irresponsible, and not serious about his/her studies. The international student, on the other hand, may view the professor's response to the request as being unreasonable and not very human or understanding. Interpretations such as these can lead to dislike, loss of respect, and to uncomfortable interactions between international students and professors. In a communicative environment such as this, further miscommunication can easily ensue. Therefore, it would be useful for international students and American professors to know particular behaviors such as the one which has been discussed and the others that were identified in the research which, due to culturally different evaluative tendencies, can lead to misunderstanding and eventual communication breakdown between them.

Differences due to status. There are five role behaviors viewed differently by virtue of a person's status. For purposes of improving intercultural communication they are less significant than those items delineated in the previous section, but they can still have significance for the international student who, as a student, wants to improve his/her relations with his/her professors.

For the Student-UAL there was one behavior evaluated differently on the basis of status: reads a lot (UALREAD). Even though the normative structure of this role behavior is high for all groups, it is apparent that professors believe reading a lot is absolutely essential for the student who wants to understand his/her courses. (Only one professor of 129 rating this item evaluated it as undesirable). 
Four professorial behaviors were rated differently by students and professors. They are: encourages students to speak in class (PROFSPK); assigns the reading of materials that are not included in the tests $s /$ he gives (PROFMATR); is available to students whenever they need him/her, including calls at home (PROFAVLB); and, determines grades for students by how well they meet set standards without regard for their individual abilities and skills (PROFLANG). The evaluation results of these items seem to reinforce the item discussed previously regarding the professor's giving the necessary course information during class and could lead one to hypothesize that there is considerable conflict about the active role of the professor in the teaching process and the student as a passive as opposed to active learner. Differences that cannot be accurately accounted for by culture or status alone. There are four role behaviors whose evaluation ratings can not be attributed definitively to either status or culture. Two are peculiar to American students and American professors, one is peculiar to international students and American professors, and one to American and international students. American students and professors differ about the desirability of Student-HGP asking for comments and criticism. Both groups see it as desirable, but professors more so than American students. The other item concerns the desirability of a professor's relying primarily on tests for judging a student's ability. More than half the students see this as undesirable, and only $37 \%$ of the professors rated this item as undesirable. 
International students and American professors differ on one item relating to professorial behavior. About $20 \%$ more international students than professors think it is desirable if a professor can answer any question that is asked in class about the subject matter.

International students differed somewhat with American students on the desirability for a professor to talk about his personal life and feelings in class. Americans see it as more desirable and internationals as more undesirable, but the normative structure of this role behavior was not significant in any direction by any of the subject groups. It is likely, therefore, that preferences regarding this behavior are determined more from an individual's personal preference than his/her culture or status.

Sumnary

With the above breakdown and brief analysis of the etic and emic qualities of the role behaviors examined in this research, some of the research questions posed in Chapter III can be addressed.

The data analysis reveals that there are role behaviors that are evaluated similarly across cultures. This research has delineated nineteen etic role behaviors.

The data analysis also revealed that there are role behaviors that are evaluated differently across cultures. Sixteen role behaviors evaluated in this study can be considered emic due to the variable of culture.

It was also observed that status may affect the manner in which 
a role behavior is evaluated. Five role behaviors were evaluated differently due to the status (professor or student) of the evaluator.

Thus, the results of the study show that both culture and status may affect the manner in which a role behavior is evaluated; however, culture seems to be the stronger variable as more than three times as many differences in evaluation can be attributed to culture than can be attributed to status. It may now be stated that in communication among the subject populations that miscommunication between international students and professors is more a result of their cultural differences than their difference in status. Further study will be necessary to discover more role behaviors that pertain to these roles and to show that increased awareness of the fact that that role behaviors are evaluated differentially could lead to improved understanding and communication. This study should provide the starting point for such an investigation. 
OTHER RESULTS, AND SUGGESTIONS

FOR FURTHER RESEARCH

The primary purposes of this research were to: 1) develop a questionnaire that could be used to measure differences between American and international populations in their evaluations of role behaviors pertaining to the roles of professor and student and 2) administer the developed questionnaire to find out if and what similarities and differences in evaluation tendencies between international and American populations exist. The previous chapter outlines the results of this endeavor.

As a follow-up to this exploratory study, a replication of the study at another university is suggested. Universities, by virtue of their size, location, philosophy, being of the public or private sector, etc. can embody a culture of their own. As the entire sample of this study was drawn from one university, it would be useful to learn if the findings of this study have external validity. Validation is necessary to the development of research and theory in intercultural communication (Smith, Alfred G., 1977, pp.6-7).

The researcher was also interested in obtaining information about other factors that affect role behavior evaluation. To this end, subjects were asked to supply information pertaining to their 
culture or country, their status as undergraduates or graduates, and their sex. Not all subjects supplied this additional information, but using the data from those that did additional statistical tests were performed on the data. For the following discussion the reader is cautioned to remember that the sample populations for some of the statistics are small and that the results are, therefore, less significant. However, for the heuristic value of suggesting directions for further research the results that follow are not only interesting, but useful.

\section{Variable: Culture Area/Country}

To determine possible variations in evaluation among the various culture groups represented in the sample population, American professors' evaluaticns were compared with those of eight different culture areas or countries. Due to sufficient numbers in the sample it was possible to separate Iran from the rest of the Middle Eastern sample and Japan from the Asian sample. ${ }^{1}$ Table IV has the summary of the results of the t-test calculations for independent samples as performed by the SPSS program. Items for which there is a difference in evaluation, the level of significance being set at .05 , are noted.

The results indicate that American professors and Western European students view the roles of professor and student most similarly and that Middle Eastern students and American professors view them the most differently. The results lead one to hypothesize that Asian, Middle

1 Table XV in Appendix includes a breakdown of the countries represented by the designated culture areas. 
TABLE IV

RESULTS OF T-TEST COMPARISON OF AMERICAN PROFESSOR WITH ALL CULTURE AREA/COUNTRY GROUPS

ITEM ASIA JAPAN M.E. IRAN AFRICA L.AMER. W.EUR. U.S.

\begin{tabular}{|c|c|c|c|c|c|c|c|c|}
\hline \multicolumn{9}{|l|}{ HGPPUR } \\
\hline HGPCON & & & & & & & & $\mathrm{X}$ \\
\hline HGPCRIT & & & $\mathrm{X}$ & & & & & $\mathrm{X}$ \\
\hline \multicolumn{8}{|l|}{ HGPREQ } & $\mathrm{X}$ \\
\hline HGPLIS & & $\mathrm{X}$ & $\mathrm{X}$ & & & & & $\mathrm{X}$ \\
\hline HGPMEM & & $X$ & & & & $\mathrm{X}$ & & \\
\hline HGPTYPE & & & $\mathrm{X}$ & & & $\mathrm{X}$ & & \\
\hline HGPABS & $\mathrm{X}$ & & & & & & & \\
\hline HGPINF & & & & $\mathrm{x}$ & & & & \\
\hline HGPIMAG & & $\mathrm{X}$ & $\mathrm{x}$ & $X$ & & $\mathrm{X}$ & & \\
\hline \multicolumn{9}{|l|}{ HGPINT } \\
\hline HGPEXC & $\mathrm{X}$ & & $\mathrm{X}$ & & $\mathrm{X}$ & $\mathrm{X}$ & $\mathrm{x}$ & \\
\hline HGPCOUR & $X$ & & $\mathrm{X}$ & $\mathrm{X}$ & & & & \\
\hline UALCOUR2 & & & $\mathrm{X}$ & $X$ & & $\mathrm{X}$ & & \\
\hline UALSMOKE & & & & $\mathrm{X}$ & $\mathrm{X}$ & & & \\
\hline \multicolumn{9}{|l|}{ UALING } \\
\hline UALAUTH & $\mathrm{X}$ & & & $\mathrm{X}$ & & & & \\
\hline \multicolumn{9}{|l|}{ UALPART } \\
\hline UALREAD & $x$ & & $\mathrm{X}$ & $\mathrm{X}$ & & & & $\mathrm{X}$ \\
\hline UALNOTE & & & & $\mathrm{X}$ & $\mathrm{X}$ & & & \\
\hline UALSLANT & $\mathrm{X}$ & & $\mathrm{X}$ & $\mathrm{x}$ & & & & \\
\hline UALGRADE & $\mathrm{X}$ & & $\mathrm{X}$ & $\mathrm{X}$ & & & & \\
\hline UALATTND & & & & & $\mathrm{X}$ & & & \\
\hline UALDIRCT & $\mathrm{X}$ & & $\mathrm{X}$ & $\mathrm{X}$ & $\mathrm{X}$ & $\mathrm{X}$ & & \\
\hline UALCMPRE & & & $X$ & & & & & \\
\hline UALRAISE & $\mathrm{X}$ & $\mathrm{X}$ & $X$ & $\mathrm{X}$ & $\mathrm{X}$ & & & \\
\hline
\end{tabular}


TABLE IV (continued)

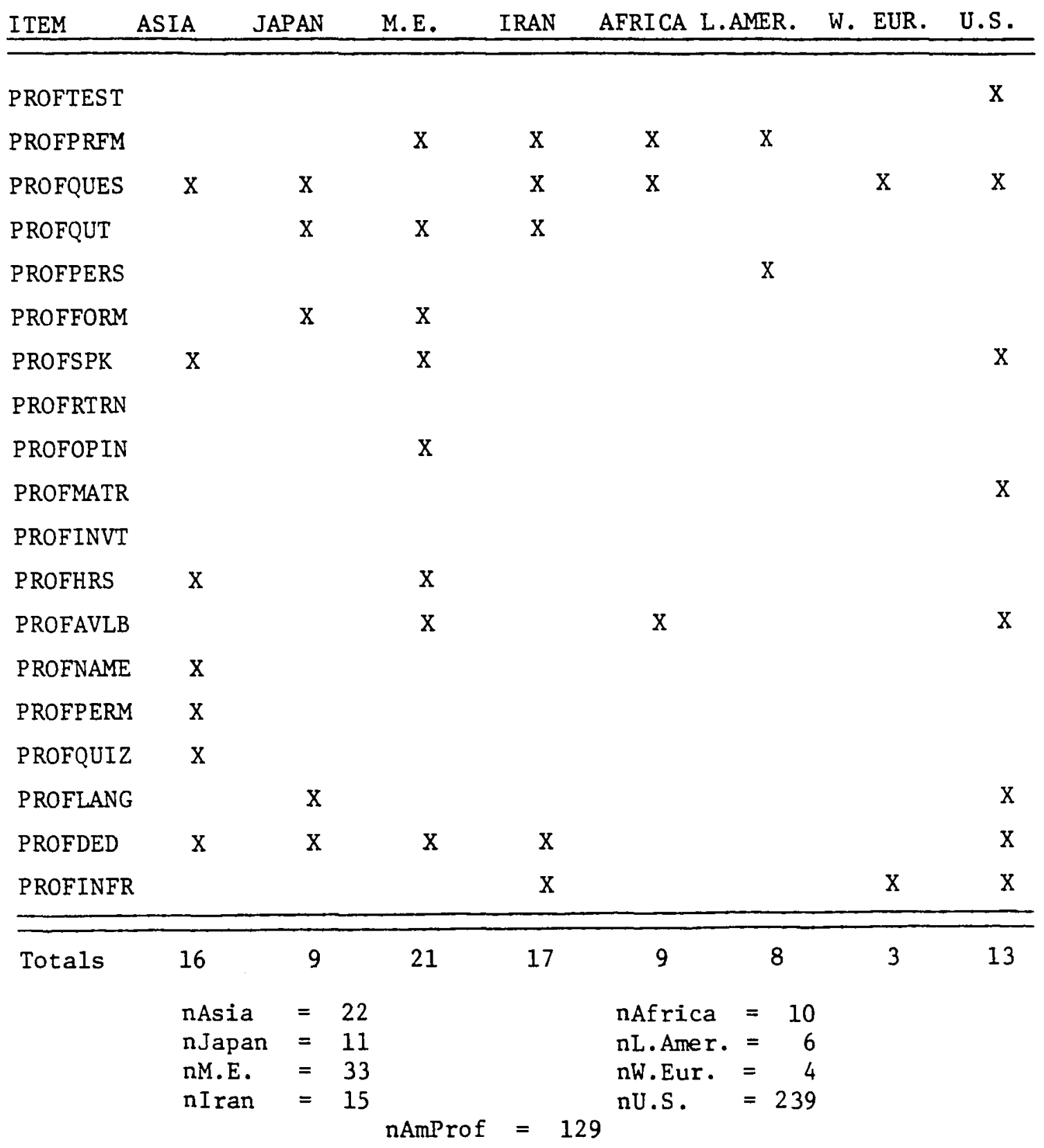

KEY : $X=$ level of significance of the difference between the means of the group being compared with American professors is .05 or less. 
Eastern, and Iranian students experience more difficulties with their professors than do Japanese, African, Latin American or Western European students. Further research on particular countries would be warranted by institutions with large groups from individual countries. An item-by-item analysis of the results might yield insights into a particular culture, but this is not within the scope of this study.

Variable: University Status

Population samples of international and American graduate and undergraduate students were compared with American professors via t-test calculations for independent samples as performed by the SPSS Program.

Table $\mathrm{V}$ contains the summary of the results. Items for which there is a significant difference in evaluation are noted. The results further support the main study's finding that culture is a more significant factor than status in affecting evaluation. However, the results do indicate that graduate students evaluate the student and professor role behaviors more similarly with professors than do undergraduate students. Perhaps time in the university culture creates conformity--or non-conformists are gradually selected out. This researcher will not say, but perhaps others may wish to examine this subject more fully.

Variable: Sex

International male and female students were compared with American male and female professors in an effort to discover if the sex of an 
TABLE V

RESULTS OF T-TEST COMPARISON OF GROUPS DEFINED

BY UNIVERSITY STATUS AND CULTURE

HGPPUR

HGPCON

HGPCRIT

$\mathrm{X} \quad \mathrm{X}$

HGPREQ

$\mathrm{X}$

$\mathrm{X}$

$\mathrm{X}$

HGPLIS

$\mathrm{X}$

$\mathrm{X}$

$\mathrm{X}$

$X \quad \mathrm{X}$

HGPMEM

HGPTYPE $\mathrm{X}$

$\mathrm{X}$

X

HGPABS

HGPINF

HGPIMAG $\mathrm{X}$

$\mathrm{X}$

$\mathrm{X}$

HGPINT $X$

HGPEXC $\mathrm{X}$

$x$

HGPCOUR $X \quad X$

UALCOUR2 $\mathrm{X}$

$\mathrm{X}$

$\begin{array}{ccccc} & x & x & & x \\ X & & x & x \\ X & & & \end{array}$

UALSMOKE

UALING

$\mathrm{X}$

UALAUTH

UALPART

UALREAD

UAINOTES

$\mathrm{X}$

$\mathrm{X}$

$\mathrm{X}$

$\mathrm{X}$

UALSLANT $\mathrm{X}$

$\mathrm{x}$

UALGRADE $\mathrm{X} \quad \mathrm{X}$

$\mathrm{X} \quad \mathrm{X}$

$\mathrm{X}$

$\mathrm{X} \quad \mathrm{X}$

$\mathrm{X}$

UALATTND

UALDIRCT $\mathrm{X}$

$\mathrm{X} \quad \mathrm{X}$

$\mathrm{X}$

UALCMPRE

$\mathrm{X}$

UALRAISE $\mathrm{X}$

$\mathrm{X}$

$\mathrm{X}$

$\mathrm{X}$

\footnotetext{
KEY: $A=$ American $\quad U=$ Undergraduate (Continued on next page.)

$I=$ International $\mathrm{G}=$ Graduate

$P=$ Professor
} 
TABLE V (continued)

\begin{tabular}{|c|c|c|c|c|c|c|c|c|}
\hline ITEM & $\mathrm{AU} / \mathrm{IU}$ & $\mathrm{AU} / \mathrm{AG}$ & $\mathrm{AU} / \mathrm{AP}$ & $I U / I G$ & $\mathrm{IU} / \mathrm{AP}$ & $A G / I G$ & $\mathrm{AG} / \mathrm{AP}$ & $I G / A P$ \\
\hline PROFTEST & & & $\mathrm{x}$ & & & & $\mathrm{X}$ & \\
\hline PROFPERF & $\mathrm{X}$ & & & & $\mathrm{X}$ & $\mathrm{x}$ & & $\mathrm{X}$ \\
\hline PROFQUEST & $\mathrm{X}$ & & $\mathrm{X}$ & & $\mathrm{x}$ & & & $\mathrm{X}$ \\
\hline PROFQUT & $\mathrm{x}$ & $\mathrm{x}$ & & & $\mathrm{X}$ & $\mathrm{X}$ & & $\mathrm{X}$ \\
\hline PROFPERS & & & & & & $\mathrm{x}$ & & $\mathrm{X}$ \\
\hline PROFFORM & $\mathrm{X}$ & & & & $\mathrm{X}$ & & & $\mathrm{X}$ \\
\hline PROFSPK & $\mathrm{X}$ & & $\mathrm{X}$ & & $\mathrm{X}$ & & $\mathrm{X}$ & $\mathrm{X}$ \\
\hline PROFRTRN & & & & & & $\mathrm{X}$ & & \\
\hline PROFOPIN & & & & & $\mathrm{X}$ & & & \\
\hline PROFMTRL & & $\mathrm{X}$ & $\mathrm{X}$ & $X$ & $\mathrm{X}$ & & & \\
\hline \multicolumn{9}{|l|}{ PROFINVT } \\
\hline PROFHRS & $\mathrm{x}$ & & & & $\mathrm{X}$ & $\mathrm{X}$ & & \\
\hline PROFAVLB & & $\mathrm{x}$ & $\mathrm{X}$ & & $X$ & $\mathrm{X}$ & & $\mathrm{X}$ \\
\hline \multicolumn{9}{|l|}{ PROFNAME } \\
\hline PROFPERM & & & & $\mathrm{X}$ & & $\mathrm{X}$ & & $\mathrm{x}$ \\
\hline FROFQUIZ & & & & & $\mathrm{X}$ & & & \\
\hline PROFLANG & $\mathrm{X}$ & $\mathrm{X}$ & $\mathrm{X}$ & & & & & $\mathrm{X}$ \\
\hline PROFDED & $x$ & & $\mathrm{X}$ & & $\mathrm{X}$ & $\mathrm{x}$ & & $\mathrm{X}$ \\
\hline PROFINFR & & $\mathrm{x}$ & $\mathrm{X}$ & & $\mathrm{X}$ & & $\mathrm{X}$ & \\
\hline \multirow[t]{2}{*}{ Totals } & 17 & 10 & 14 & 3 & 24 & 16 & 8 & 22 \\
\hline & & \multicolumn{4}{|c|}{$\begin{array}{l}\text { nAmerican Undergraduate (AU) } \\
\text { nInternational Undergraduate (IU) } \\
\text { nAme:ican Graduates (AG) } \\
\text { nInternational Graduates (IG) } \\
\text { nAmerican Professors (AP) }\end{array}$} & $\begin{array}{rr}= & 19 \\
= & 6 \\
= & 4 \\
= & 3 \\
= & 12\end{array}$ & & \\
\hline
\end{tabular}

KEY : $X$ = Ievel of significance of the difference between the means of the groups being compared is .05 or less. 
international student is a significant variable affecting evaluation of role behaviors. The results of the t-test analysis are found in Table VI. Comparison of groups on items yielding a significant difference (significance level of .05) are noted.

The most dramatic finding is seen in the comparison of the evaluations of international female students with American female professors. Their evaluation of the role behaviors differ in only half as many cases as they do when other groups' evaluations are compared. Note, also, that most of the items (i.e. seven out of ten) evaluated differently were in regards to the role of professor. It would be interesting to interview female professors to discover their perception of how they get along with male international students as opposed to female international students. From the data, one would hypothesize that they would have a more favorable impression of the female half of the international student population.

With an increasing interest on the part of third world women in participating in their own and the world's culture, there may be an influx of international female students into American universities. This could create an accompanying need for those who deal with international students to identify specific problems that women might encounter in the university millieu by virtue of their femaleness. Further research in the area of adjustment specific to men and women international students would be welcome in the intercultural communications field. 
TABLE VI

RESULTS OF T-TEST COMPARISON OF GROUPS: MALE AND FEMALE INTERNATIONAL STUDENTS WITH MALE AND FEMALE AMERICAN PROFESSORS

\begin{tabular}{lcccc} 
& MALE INT'L & FEMALE INT'L & MALE INT'L & FEMALE INT'L \\
ITEM & MALE PROF & MALE PROF & FEMALE PROF & FEMALE PROF \\
\hline
\end{tabular}

HGPPUR

HGPCON

HGPCRIT

HGPREQ

HGPLIS

$\mathrm{X}$

$\mathrm{X}$

$\mathrm{X}$

$\mathrm{X}$

HGPMEM

HGPTYPE

$\mathrm{X}$

$\mathrm{X}$

HGPABS

$\mathrm{X}$

$\mathrm{X}$

HGPINF

HGPIMAG

$\mathrm{X}$

$\mathrm{X}$

HGPINT

$\mathrm{X}$

HGPEXC $\mathrm{X}$

$\mathrm{X}$

$\mathrm{X}$

$\mathrm{X}$

HGPCOUR

$\mathrm{X}$

$\mathrm{X}$

$\mathrm{X}$

JALCOUR2

$\mathrm{X}$

$\mathrm{X}$

UALSMOKE

$\mathrm{X}$

UALING

UALAUTH

$\mathrm{X}$

$\mathrm{X}$

UALPART

UALREAD

$\mathrm{X}$

$\mathrm{X}$

UALNOTE

UALSLANT

$\mathrm{X}$

$\mathrm{X}$

UALGRADE

$\mathrm{X}$

UALATTND

UALDIRCT

X

UALCMPRE

$\mathrm{X}$

UALRAISE

$\mathrm{X}$

$\mathrm{X}$

$\begin{array}{cc} & \mathrm{X} \\ \mathrm{x} & \mathrm{x} \\ \mathrm{x} & \mathrm{x}\end{array}$


TABLE VI (continued)

MALE INT'L FEMALE INT'L MALE INT'L FEMALE INT'L MALE PROF MALE PROF FEMALE PROF FEMALE PROF

\begin{tabular}{|c|c|c|c|c|}
\hline ITEM & MALE PROF & MALE PROF & FEMALE PROF & FEMALE PROF \\
\hline PROFTEST & & $\mathrm{x}$ & & \\
\hline PROFPERF & $\mathrm{X}$ & & $\mathrm{X}$ & \\
\hline PROFQUEST & $\mathrm{x}$ & $\mathrm{x}$ & & \\
\hline PROFQUT & $\mathrm{x}$ & $\mathrm{X}$ & $\mathrm{x}$ & \\
\hline PROFPERS & & & $\mathrm{X}$ & \\
\hline PROFFORM & & $\mathrm{X}$ & $\mathrm{X}$ & $\mathrm{x}$ \\
\hline PROFSPK & $\mathrm{x}$ & $\mathrm{X}$ & $\mathrm{X}$ & $\mathrm{X}$ \\
\hline PROFRTRN & & & & \\
\hline PROFOPIN & & & & \\
\hline PROFMTRL & & $\mathrm{X}$ & & $\mathrm{x}$ \\
\hline PROFINVT & & & & \\
\hline PROFHRS & $\mathrm{X}$ & & $\mathrm{x}$ & \\
\hline PROFAVLB & $\mathrm{X}$ & $\mathrm{X}$ & & $\mathrm{X}$ \\
\hline PROFNAME & & $\mathrm{x}$ & & \\
\hline PROFPERM & & $\mathrm{x}$ & & \\
\hline PROFQUIZ & & $\mathrm{x}$ & & $\mathrm{X}$ \\
\hline PROFLANG & $\mathrm{X}$ & & & \\
\hline PROFDED & $\mathrm{x}$ & $\mathrm{X}$ & $\mathrm{X}$ & $\mathrm{X}$ \\
\hline PROFINFR & $\mathrm{X}$ & $\mathrm{x}$ & & \\
\hline Totals & 22 & 19 & 20 & 10 \\
\hline
\end{tabular}

KEY: $X=$ level of significance of the difference between the means of the groups being compared is .05 or less. 
CONCLUSION AND FURTHER SUGGESTIONS FOR RESEARCH

Culture/country, status, and sex as they affect role behavior evaluation are but three variables that could be further explored. Others, such as age, marital status, time in the U.S., sponsorship, and school system of the home country would perhaps be useful in helping the university provide specific orientation information for professors and students. But before proceeding with role research of this kind, it would be important at this point to discover if increasing the awareness and understanding of the professor and student roles cross-culturally can actually result in improved communication and relations between international students and their host country professors and students. To this end a controlled longitudinal study involving orientation about students and professor roles cross-culturally is recommended. 
CHAPTER IX

SOME PRACTICAL IMPLICATIONS AND CONCLUDING REMARKS

\section{Practical Implications}

To put the research into a practical perspective it is possible to look at the data in terms of behaviors that might be at the root of communication breakdowns and others that may not cause problems. The reader must bear in mind the limitations of the study and that subject matter, format, and size of class as well as the particular professor and student involved in an interaction all have an impact on the communicative environment. First there will be a review of the similar expectations held by the subject groups for the student and professor roles. It will be followed by a review of expectations for the student and professor roles that were not held similarly by the subject groups and which, therefore, might contribute to misunderstandings between professors and international students.

All three subject groups--American students, international students, and American professors--think it is important for a successful student to know a course's expectations and then to come to class, take notes, and participate. Likewise there is a strong feeling that students should know why they are in school. As regards absences, even though there is no strong feeling on the part of students or professors about a student's informing the professor ahead of time about an anticipated absence, it is believed desirable to check with the professor 
about what happened in a missed class. Most students and professors also agree that a student should have a specific purpose in mind if s/he visits a professor in his/her office. (One professor said that even if the student just wants to stop by to get to know him, that that is fine as long as the student will make it known that this is the purpose of the visit.) There is also agreement among the subject groups about the undesirability for a student to eat, drink, or smoke in class. Another expectation held in common is the desirability for a student to consult his/her professor about suitable topics for papers and projects. Professors and students should be aware, though, that there may be a desire on the part of the student to be told what topic to choose whereas the professor would prefer to be consulted about topics the student has already considered--a fact which could lead to dissatisfaction on the part of both.

As regards professorial behavior there is a high expectation that professors know their students names and actively elicit opinions from students. There is also a mutual feeling that it is desirable for professors to invite students to come see them in their offices. There seems to be a mutual expectation that an ideal professor should actively approach his/her teaching and encourage students in their pursuit of a university education. Students seem to be looking for direction from their professors, and professors--whether they are able to provide it or not--seem to feel that it is a reasonable expectation.

of course, each individual, within or out of the confines of his or her culture may differ in his or her own expectations from the above 
generalizations, but the data indicated a commonality of expectations for these specified behaviors irrespective of the culture or university status of those who participated in the study.

There now follows a review of expectations for student and professorial behavior that might contribute to misunderstanding between professors and international students. These differences stem primarily from their differences in cultural background, but may also be due to their different statuses in the university setting.

International students seem to expect a more authoritarian professor than the average American student and may need help in making the transition to a classroom where s/he is expected to question and think critically about the information presented in class or assigned as reading. He or she may need to learn that it is not impolite to ask an honest question of the professor. The professor, on the other hand, needs to realize that silence from international students in the class doesn't necessarily mean that they don't understand and/or aren't Iistening critically, but that they may not feel comfortable challenging their professor.

It cannot be ascertained from the data why, but the subject of typing ability was viewed quite differently by international student; and professors. A professor might try to be explicit in explaining why or why not s/he prefers typed papers and perhaps give suggestions on how to locate a typist if it is of particular importance to him/her that papers be typed.

A behavior of international students that a professor might find particularly irritating is a seeming willingness of international 
students to be asked to be excused from a test. To allay this from happening one might stress the importance of a test date and of the need to take all tests and quizzes on the date specified. If the professor allows some leeway in this matter, it would be best that $s /$ he be clear as to what a special circumstance is and the desirability of being notified well in advance so that adjustments can be made. Students should be instructed that in the United States this kind of request is unusual and should be made only for extraordinary reasons.

Though not a majority of international students may appear to be overly concerned with how to earn a particular grade, still twice as many international as American students may appear to be so and may request explicit information and committments regarding the number of papers that must be written and the number needed on a particular test to get a particular grade. For some this may be due to the custom of adhering to precise numbers in the administration of exams in their own countries. For others, it could be due to the pressure of maintaining a particular grade point average to ensure that their student visas are renewed. Professors need to be aware of the pressure on international students to get good grades and its potential effect on their being overly-concerned with how to receive them. International students should be made aware that this behavior is not viewed positively by many professors and that it may communicate that the student is not sufficiently interested in learning.

Professorial behaviors which might be at the root of communication breakdowns between international students and professors seem to 
fall into two main areas: the active-passive attitude towards learning being one, and the personal or parental authoritarian image being the other. Many international students (and American, too) may expect their professors to be more directive and all-knowing than professors expect themselves to be. A professor may also perceive students as wanting too much from him/her in that students seem to want all the "important" information of the course given to them in class by the professor. Perhaps if a professor would state his/her own particular philosophy and expectations to the class it would help.

An indicator of an expectation for an authoritarian tendency in professors by international students is their desire to have a professor who controls the class and maintains order. Order might be evidenced in how discussion is controlled, if "too much" or "irrelevant" input from classmates is allowed, or if the professor tolerates disrespectful behavior from students in the classroom. These behaviors may be hard for a professor to pinpoint. For example, a professor's tolerance of a coffee-drinking, obviously tired-looking student who has managed to come to class may be interpreted by a particular international student observing the situation as the professor's allowing disrespectful behavior. Both the professor and the international student should be aware that control and order may be shown in different ways.

International students seem to differ from professors on how open they feel a professor should be as regards his/her personal life. International students see a professor's willingness to talk about his/her personal life in class as more undesirable than do professors and American students, who tend to approve this more as an indicator of equality. 
Students and professors may also differ on the nature and meaning of the personal relationship between them. Students seem to want to be seen as individuals and to be accomodated to because of a professor's understanding of each one's particular situation. An international student might be less concerned about a professor's absence from his/her office during posted office hours than American students, but s/he would like to feel free to make contact when he or she feels a need to do so. Along these lines, students may be helped if they are made aware of the fact that though professors are interested in knowing and helping each student as an individual, that students should not expect this interest to mean that they can expect accompanying accommodations to be made for them. For example, they should still expect to meet course expectations and to be judged and graded by the criteria of the course equally with their classmates.

Earlier it was noted that there are many role behaviors that make up some one-hundred social behaviors that may be associated with a particular role in a particular culture. In this study only a few role behaviors for the roles of student and professor have been examined. Thus the suggestions contained in this brief discussion can only be considered a starting point towards a full awareness of the similarities and of the existence of differences between international students and American professors and how to deal with them in a positive manner. However, it is hoped that this discussion with its accompanying suggestions can provide direction in thinking about and interacting interculturally in the university environment. 
Concluding Remarks

This research thesis has explored the field of research on roles cross-culturally. It has explained the development, administration and results of a questionnaire designed to provide insight on how specific role behaviors pertaining to the roles of professor and student are evaluated cross-culturally. It is hoped that some of the results and the discussion and suggestions emanating from them will prove immediately useful for those wanting to improve communication and relations between international students and American professors. For others, who are interested in exploring further either the roles of professor and student or other roles of particular interest in their work or life, it is hoped that a basis for studying them has been provided. 
REFERENCES CITED

Adler, Ron, and Neil Towne. Interpersonal Communication. Corte Madeira, California: Rinehart Press, 1975.

Azar, Donald. "Programming and Teaching English as a Second Language for Arab and Iranian Students." In Students From the Arab World and Iran. Ed. Gary L. Althen. Washington, D.C.: NAFSA, 1978, 15-23.

Barakat, Halim. "Political Factors Affecting Arab Students." In Students From the Arab World and Iran. Ed. Gary L. Althen. Washington, D.C.: NAFSA, 1978, 41-50.

Barna, LaRay M. "Ethics and Intercultural Communication." Paper presented at the Annual Conference of the Society for Intercultural Education, Training and Research (SIETAR) in Mexico City, Mexico. March 1979.

Baron, Marvin, and Ted Goode. "Advising the Foreign Student in the Academic Sphere." In Advising, Counselling, and Helping the Foreign Student. Ed. Marvin Baron. Washington, D.C.: NAFSA, Fall 1975, 15-20.

Barry, Jean. Thai Students in the United States: A Study in Attitude Change. Data Paper $\$ 66$. Ithaca, New York: S.E. Asia Program, Department of Asian Studies, Cornell University, May 1967.

Beals, Ralph L., and Norman D. Humphrey. No Frontier to Learning: The Mexican Student in the United States. Minneapolis: University of Minnesota Press, 1957.

Berlo, David K. "Interaction: The Goal of Interpersonal Communication." In Nothing Never Happens. Teacher's Edition. Ed. Kenneth G. Johnson, John J. Senatore, Mark C. Liebeg, Gene Minor. Beverly Hills: Glencoe Press, 1974, 285-291.

Biddle, Bruce J., and Edwin J. Thomas. Role Theory: Concepts and Research. New York: John Wiley and Sons, Inc., 1966.

Borkin, Ann, and Cristin Carpenter. "Academic Guidance in ProfessorStudent Consultations." Pre-publication draft. Ann Arbor, Michigan: University of Michigan Department of Linguistics, April, 1979.

Breuder, Robert L. "A Statewide Study Identified Problems of International Students..." ERIC ED 062977. 
Brislin, Richard W. "Cross-Cultural Research Methods." In Human Behavior and Environment. Vol. 4 (1980). Ed. Irwin Altman, Amos Rapaport, and Joachim F. Wohlwill. New York: Plenum Publishing Corporation, 47-82.

--------, and Paul Pederson. Cross Cultural Orientation Programs. New York: Gamer Press, Inc., 1976.

-------, Walter J. Lonner, and Robert M. Thomdike. Cross-Cultural Research Methods. New York: John Wiley and Sons, Inc., 1973.

Broom, Leonard, and Philip Selznik. Sociology: A Text with Adapted Readings. 4th ed. 1955; rpt. New York: Harper and Row, Publishers, 1968.

Brun, Faye Hendrick. "A Study of Perception of Teacher Competence Among Grade-Level Groups of University Students." DAI, 38 (1977), 650-A (Northwestern State University of Louisiana).

Cable, John N. "Foreign Students in the United States." Improving College and University Teaching. XXII (Winter 1974), 40-41.

Chapman, David W., and David C. Forman. "Perspectives on Teaching in Another Culture." Pre-publication copy. Ann Arbor, Michigan: The University of Michigan School of Education, Project CHOICE, Nov. 1978.

------ and Edward F. Kelley. "A Comparison of the Dimensions Used by Iranian and American Students in Rating Instruction." Pre-publication copy. Ann Arbor, Michigan: The University of Michigan School of Education, Project CHOICE, June 1979.

Clark, Clifford. "The Influence of Culture on the Foreign Student and the Counselor." In Advising, Counselling, and Helping the Foreign Student. Ed. Marvin Baron. Washington, D.C.: NAFSA, Fal1 1975, 6-8.

Condon, John C., and Fathi Yousef. An Introduction to Intercultural Communication. Indianapolis: The Bobbs-Merril Company, Inc., 1975.

Cowan, James. "Factors Influencing Arab and Iranian Students--In Country and in the United States." In Students From the Arab World and Iran.i Ed. Gary L. Althen. Washington, D.C.: NAFSA, 1978, $1-14$.

Dance, Frank E. X., and Carl E. Larson. Speech Communication: Concepts and Behavior. New York: Holt, Rinenart and Winston, Inc., 1972.

Davis, F. James. "Evaluation of Their American University Education by Turkish Students Returned Home." Pre-publication copy. Normal, Illinois: Illinois State University, Dept. of Sociology-Anthropology, [1975?]. 
Etemadi, Ahmad. "Personality Traits and Personality Change as Influenced by Culture and College Experiences of Iranian and American Students." DAI, 38 (1977), 2555-A (The Louisiana State University and Agricultural and Mechanical College).

Gergen, Kenneth J. The Psychology of Behavior Exchange. Reading, Massachusetts: Addison-Wesley Publishing Company, 1969.

Glass, Johanne M. "Campus Etiquette." In Asian Student Orientation Handbook. 11th ed. Ed. C. Y. Hsu. San Francisco: The Asian Student, 1972-73, 22-24.

Gorden, Raymond L. "The Guest's General Role in the Family." In Towards Internationalism. Ed. Elise C. Smith and Louise Fiber Luce. Rowley, Massachusetts: Newberry House Publishers, Inc., 1979, 196-225.

Gosnell, Paul Wayne. The University Acculturator For International Students: An Empirically Based, Multi-cultural Communication Training Technique. Diss. The University of Texas at Austin 1979. Ann Arbor, Michigan: University Hicrofilms International, 1979.

Greis, Naguib. "Instructors and the Foreign Student with Inadequate English Proficiency: A Preliminary Report on the Findings of a Questionnaire." Portland, Oregon: Center for English as a Second Language, Portland State University, January 1979.

Grindal, Bruce T. Growing up in Two Worlds: Education and Transition Among the Sisala of Northern Ghana. New York: Holt, Rinehart, and Winston, Inc., 1972.

Grove, Cornelius Lee. "The Culture of the Classroom in Portugal and the United States." The Bridge: A Review of Cross-Cultural Affairs. 3 (Summer 1978), 14-15,34.

Haas, G. James. "United States Graduate Study." In Asian Student Orientation Handbook. 11th ed. Ed. C. Y. Hsu. San Francisco: The Asian Student, 1972-73, 46-48.

Hagey, A. R., and Joan Hagey. "Meeting the Needs of Students From Other Cultures." Improving College and University Teaching. XXII (Winter 1974), 42-44.

Hall, Edward T. Beyond Culture. Garden City, New York: Anchor Books, 1977.

Hoyle, Eric. The Role of the Teacher. London: Routledge and Kegan Paul, 1969.

Jackson, Jay M. "Structural Characteristics of Norms." In Role Theory: Concepts and Research. Ed. Bruce J. Biddle and Edwin J. Thomas. New York: John Wiley and Sons, Inc., 1966, 113-126. 
Jarvahi-Zadeh, Ali, and William J. Eichman. "The Impact of Socio-cultural Factors on Middle East Students in the United States." International Educational and Cultural Exchange. (Winter 1970), $82-94$.

Keats, Daphne. "Some Effects of Austrailia University Education on Asian Students." In Scholars in Context, The Effects of Environment on Learning. Ed. W. J. Campbell. Sydney, Austrailia: John Wiley and Sons Austrailasia PTYLTD, 1970, 241-257.

Klecka, William R., Norman H. Nie, and C. Hadlai Hull. Statistical Packages for the Social Sciences Primer. New York: McGraw-Hill Book Company, 1975.

Kupferer, Harriet J., and Thomas K. Fitzgerald. Culture, Society, and Guidance. Boston: Houghton Mifflin Company, 1971.

Linnton, Ralph. "Status and Role." In Sociological Analysis: An Introductory Text and Case Book. Ed. Logan Wilson and William L. Kolb. New York: Harcourt, Brace, and World, Inc., 1949, 211-223.

Lockyear, Frederick E. "Factors Affecting Non-Sponsored Students From Iran." In Students From the Arab World and Iran. Ed. Gary L. Althen. Washington, D.C.: NAFSA, 1978, 67-72.

Marr, Phebe. "Social, Cultural and Religious Problems of Adjustment for Arab Students from the Fertile Crescent and Gulf." In Students From the Arab World and Iran. Ed. Gary L. Althen. Washington, D.C.: NAFSA, 1978, 51-63.

Martinez, Raul, and Edet Akpan. "Results of a Questionnaire on FacultyStudent Interaction." In-house paper. Portland, Oregon: International Student Services of Portland State University, Spring 1978.

Mize, David. "Social Cultural and Religious Factors Affecting North African Students." In Students From the Arab World and Iran. Ed. Gary L. Althen. Washington, D.C.: NAFSA, 1978, 27-39.

McDermott, R. P. "Achieving School Failure: An Anthropological Approach to Literacy and Social Stratification." In Education and Cultural Process: Toward an Anthropology of Education. Ed. George Dearborn Spindler. New York: Holt, Rinehart, and Winston, Inc., 1974, 82-118.

Nangle, John E. "A Study of the Graduate Students Attitudes Regarding Graduate Education at Westem Michigan University." May 1974. ERIC ED 131747.

National Association For Foreign Student Affairs (NAFSA). The College, The University, and the Foreign Student. Washington, D.C.: NAFSA, 1974 . 
Norris, Roger Alan. "The Relationships Among Leaming Style, Teaching Style, and Student Perception of Teacher Effectiveness." DAI, 38, (1977), 1303-A (University of Idaho).

Oesar, Oscar A., and Frank Harary. "Role Structures: A Description in Terms of Graph Theory." In Role Theory: Concepts and Research. Ed. Bruce J. Biddle and Edwin T. Thomas. New York: John Wiley and Sons, Inc., 1966, 92-102.

Parker, Orin D., et al. "Cultural Clues to the Middle Eastern Student." Occasional Paper No. 2. ERIC ED 136604.

Porter, Richard E. "An Overview of Intercultural Communication." In Intercultural Communication: A Reader. Ed. Larry A Samovar and Richard E. Porter. Belmont, California: Wadsworth Publishing Company, Inc., 1972, 3-18.

Rich, Andrea L. Interracial Communication. New York: Harper and Row, 1974.

Ruesch, Jurgen. "Communication and Human Relations: An Interdisciplinary Approach." In Interpersonal Communication: Basic Text and Readings. Ed. Bobby R. Patton and Kim Griffin. New York: Harper and Row, $1974,56-67$.

Ruhly, Sharon. "Orientations to Intercultural Communication." In Modules in Speech Communication (MODCOM). Ed. Ronald L. Applbaum and Roderick P. Hart. U.S.A.: Science Research Associates, Inc., 1976.

Schwartz, Frieda. "The Foreign Student and Interpersonal Relations." In Advising, Counselling, and Helping the Foreign Student. Washington, D.C.: NAFSA, Fall 1975, 1-5.

Sereno, Kenneth K., and Edward M. Bodaken. Trans-Per: Understanding Human Communication. Boston: Houghton Mifflin Company, 1975.

Singer, Marshall R. "Perception in International Affairs and a Note on Identity." In Overview of Intercultural Education, Training and Research, Vol. I: Theory. Ed. David S. Hoopes, Paul B. Pederson, and George W. Renwick. LaGrange Park, I11.: Intercultural Network, Inc., 1977, 31-48.

Sitaram, K. S. "What is Intercultural Communication?" In Intercultural Communication: A Reader. Ed. Larry A. Samovar and Richard E. Porter. Belmont, California: Wadsworth Publishing Company, Inc., $1972,18-23$. 
Smith, Alfred G. "Research and Theory in Intercultural Communication." In Overview of Intercultural Education, Training and Research, Vol. I: Theory. Ed. David S. Hoopes, Paul B. Pederson, and George W. Renwick. LaGrange Park, I11.: Intercultural Communication Network, Inc., 1977, 3-9.

Smith, Arthur L. Transracial Communication. Englewood Cliffs, New Jersey: Prentice-Hall, Inc., 1973.

Society Today. Contributing consultants: Robert R. Alford and thirtyeight others. Del Mar, California: Communications Research Machines, Inc., 1971.

Spaulding, Seth et al. The World's Students in the United States: A Review and Evaluation of Research on Foreign Students. New York: Praeger Publishers, 1976.

Spindler, George Dearborn, Ed. Education and Cultural Process: Towards An Anthropology of Education. New York: Holt, Rinehart and Winston, Inc., 1974.

Stewart, Edward C. American Cultural Patterns: A Cross-Cultural Perspective. LaGrange Park, I11.: Intercultural Network Inc., 1972.

Swenson, Clifford H., Jr. Introduction to Interpersonal Relations. Glenview, Illinois: Scott, Foresman and Company, 1973.

Szalay, Lorand, B., and Glen H. Fisher. "Communication Overseas." In Towards Internationalism. Ed. Elise C. Smith and Louise Fiber Luce. Rowley, Massachusetts: Newberry House Publishers, Inc., 1979, 57-82.

Triandis, Harry C. The Analysis of Subjective Culture. New York: Wiley-Interscience, A Division of John Wiley and Sons, Inc., 1972.

-----. "Trends in Cross-Cultural Research." Journal of CrossCultural Psychology. 11 (March 1980), 35-58.

West, Donald C. "Cross-Cultural and Interpersonal Relations in the EFL Class room." In-house paper. Chicago, I11.: Language House International (now Telemedia, Inc.), April 9, 1975.

Williams, Frederick. Reasoning With Statistics. 2nd ed. 1968; rpt. New York: Holt, Rinehart and Winston, 1979.

Wilson, Logan, and William L. Kolb. Sociological Analysis: An Introductory Text and Case Book. New York: Harcourt, Brace and World, Inc., 1949 .

Young, Kimball. Sociology: A Study of Society and Culture. New York: American Book Company, 1942. 
Zonis, Marvin. "Social, Cultural and Religious Factors Affecting Iranian Students." In Students From the Arab World and Iran. Ed. Gary L. Althen. Washington, D.C.: NAFSA, 1978, 73-89. 
APPENDIX A

KEY TO ITEM NUMBERS, ITEM CODE NAMES, AND ITEM DESCRIPTIONS 
KEY TO ITEM NUMBERS, ITEM CODE NAMES, ITEM DESCRIPTIONS

\begin{tabular}{|c|c|c|}
\hline ITEM \# & CODE NAME & DESCRIPTION \\
\hline 1. & HGPPUR & $\begin{array}{l}\text { Has a strong sense of purpose for why s/he } \\
\text { is in school. }\end{array}$ \\
\hline 2 . & HGPCON & $\begin{array}{l}\text { Consults his/her professor to find a project } \\
\text { or paper topic. }\end{array}$ \\
\hline 3. & HGPCRIT & Asks for conments and criticism. \\
\hline 4 . & HGPREQ & $\begin{array}{l}\text { Asks to know the course requirements and expec- } \\
\text { tations. }\end{array}$ \\
\hline 5 . & HGPLIS & Listens critically. \\
\hline 6. & HGPMEM & Memorizes his/her lecture notes. \\
\hline 7. & HGTYPE & Can type. \\
\hline 8. & HGPABS & $\begin{array}{l}\text { When absent from a class meeting s/he goes } \\
\text { to his/her professor to find out what happened } \\
\text { in class. }\end{array}$ \\
\hline 9. & HGPINF & $\begin{array}{l}\text { Informs the professor when s/he is going to } \\
\text { be absent from class. }\end{array}$ \\
\hline 10 & HGP IMAG & Writes imaginative essays. \\
\hline 11. & HGPINT & $\begin{array}{l}\text { Knows specifically what s/he wants when s/he } \\
\text { goes to the professor's office. }\end{array}$ \\
\hline 12. & HGPEXC & $\begin{array}{l}\text { Asks to be excused from a test if not ready } \\
\text { to take it. }\end{array}$ \\
\hline 13. & HGPCOUR & $\begin{array}{l}\text { Allows the professor to precede him/her when } \\
\text { entering and leaving the classroom. }\end{array}$ \\
\hline 14. & UALCOUR2 & $\begin{array}{l}\text { Allows the professor to precede him/her when } \\
\text { entering and leaving the classroom. }\end{array}$ \\
\hline 15. & UALSMOKE & Smokes in class. \\
\hline 16. & UALING & Drinks and/or eats in class. \\
\hline
\end{tabular}




\begin{tabular}{|c|c|c|}
\hline ITEM \# & CODE NAME & DESCRIPTION \\
\hline 17. & UALAUTH & Accepts the authority of the professor. \\
\hline 18. & UALPART & $\begin{array}{l}\text { Participates in class discussion and shares } \\
\text { ideas. }\end{array}$ \\
\hline 19. & UALREAD & Reads a lot. \\
\hline 20. & UALNOTES & Takes notes. \\
\hline 21. & UALSLANT & $\begin{array}{l}\text { Slants his/her papers to fit the expectations } \\
\text { of the professor. }\end{array}$ \\
\hline 22. & UALGRADE & $\begin{array}{l}\text { Talks to the professor about how to get a } \\
\text { good grade. }\end{array}$ \\
\hline 23. & UALATTND & Attends class regularly. \\
\hline 24. & UALDIRCT & Does whatever the professor directs. \\
\hline 25. & UALCMPRE & $\begin{array}{l}\text { Is concerned with knowing the scores and } \\
\text { grades of other students in class. }\end{array}$ \\
\hline 26. & UALRAISE & Raises his/her hand for permission to speak. \\
\hline 27. & PROFTEST & $\begin{array}{l}\text { Relies primarily on tests for judging a } \\
\text { student's ability. }\end{array}$ \\
\hline 28. & PROFPERF & $\begin{array}{l}\text { Relies primarily on classroom performance for } \\
\text { judging a student's ability. }\end{array}$ \\
\hline 29. & PROFQUEST & $\begin{array}{l}\text { Can answer any question that is asked in class } \\
\text { about the subject matter. }\end{array}$ \\
\hline 30 . & PROFQUT & Prefers that students remain quiet in class. \\
\hline 31. & PROFPERS & $\begin{array}{l}\text { Will talk about his personal life and feelings } \\
\text { in class. }\end{array}$ \\
\hline 32. & PROFFORM & $\begin{array}{l}\text { Changes the format of the class (i.e. lecture, } \\
\text { movies, discussion) from time to time. }\end{array}$ \\
\hline 33. & PROFSPK & Encourages students to speak in class. \\
\hline 34. & PROFRTRN & $\begin{array}{l}\text { Returns auizzes and papers to students at } \\
\text { the class meeting subsequent to their submis- } \\
\text { sion. }\end{array}$ \\
\hline
\end{tabular}


35.

$$
\text { PROFOPIN }
$$

36.

37.

38.

39.

40.

41.

42.

43.

44.

45.
PROFINVT

PROFHRS

PROFDED

PROFMTRL

PROFAVBL

PROFNAME

PROFPERM

PROFQUIZ

PROFLANG

PROFINER
Asks for the students' opinions.

Assigns the reading of materials that are not included in the tests s/he gives.

Invites individual students to his/her office.

Posts and keeps office hours.

Is available to students whenever they need him/her, including calls at home.

Knows the names of his/her students.

Will permit students to take over and direct the class.

Gives many quizzes.

Determines grades for students by how well they meet set standards without regard for their individual abilities and skills (i.e. language).

Is dedicated and devoted to his/her work.

Gives the necessary information of the course during class and doesn't expect students to go to the library to learn it. 
APPENDIX B

FIELD TEST EDITION OF QUESTIONNAIRE REGARDING INTERNATIONAL STUDENT BEHAVIORS GIVEN TO

PROFESSORS DURING THE FALL OF 1979 
Dear Professor:

Enclosed please find a questionnaire. It should not take more than 20 minutes to complete.

The information you provide will contribute to research

being done in the burgeoning field of Intercultural Commin-

cations---in this case as it applies to the university setting. Your contribution, via completing the questionnaire, will

be much appreciated.

Thank-you very much.

\section{DIRECTIONS:}

Read the statement. Consider it in light of your experience in dealing with international students. Then, mark in the appropriate box how prevalent the behavior or characteristic is among the international students you have dealt with.

Following that you are asked to give your opinion as to whether having this behavior or characteristic would help an international student succeed at the university. Please circle the $\underline{Y}, \underline{N}$, or $\underline{D M}$ (Yes, it would help; No, it wouldn't help; or that it Doesn't Matter.). 
1. They ask when they don't understand.

2. They share their point of view and offer opinions.

3. They defend their positions willingly.

4. They know how to approach the material covered in clasg.

5. They write imaginative and logical essays.

6. They are motivated by academic curiosity and the challenge of learning.

7. They come to conclusions and form opinions without consulting a variety of resources.

8. They don't admit to having a problem until it is under control.

9. They get attached to one teacher.

10. They are tagk and degree oriented.

11. They understand what plagiarism and cheating are.

12. They come to see me near the end of the course about Withdrawal, taking an Incomplete, Pass/Fail options, and the effect of the final on the grade.

13. They talk openly about things they haven't mastered.

14. They expect opecial treatment, attention, and/or allowances.

15. They know specifically what they want when they come to see me.

16. They come late to class.

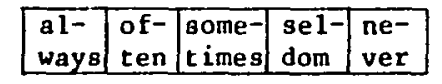

Would this behavior \&/or characteristic help them to succeed?

Doesn't

Yes No. Matter

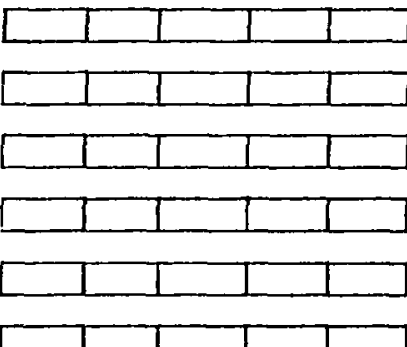

$\begin{array}{lll}\mathbf{N} & \mathrm{DM}\end{array}$

Y N DM

Y N DM

Y N DM

$\mathbf{N} \quad \mathbf{N} \quad$ DM

Y N DM

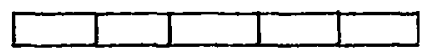

$\mathbf{Y}$

N DM

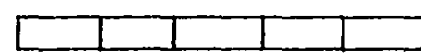

$\mathbf{x}$

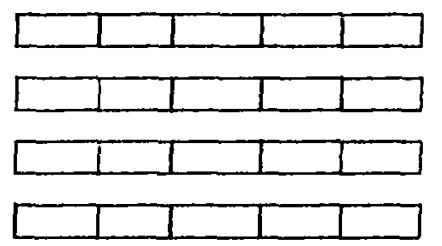

$\begin{array}{lll}\mathbf{N} \quad \text { DH } & \text { N }\end{array}$

Y N DM

Y N DM

Y N DM

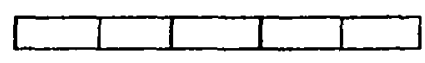

Y N DM

Y N DM

Y N DM

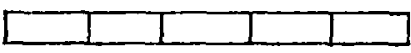

Y N DM 
17. They don't leave my office and continue pressuring me to their way of thinking----particularly if it is in regards to a grade change.

18. They meet desdlines and schedules for assignments and projects.

19. They are hostile towards me.

20. They have trouble handling the freedoms here.

21. They appreciate the value of and utilize the scientific method.

22. They leave me mentally and physically exhausted.

23. They are confident of their academic ability.

24. They know how to participate in class discussions.

25. They exaggerate and brag.

26. They are industrious and conscientious in regards to their studies.

27. They express disagreement with what is said in class.

28. They study with friends and curn in identical homework.

29. They prefer a structured class and strong teacher.

30. They are friendly.

31. They know when it is time to leave my office and who should initiate leaving.

32. They perform and contribute well in group activities and assignments.

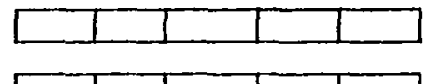

a1- of- some- bel- ne-

ways ten times dom ver

Would this behavior $8 /$ or characteristic help then to succeed?

Doesn't

Yes. No. Matter.

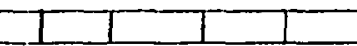

DM
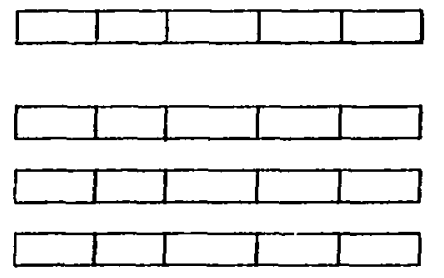$$
\text { DM }
$$$$
\text { Y N DM }
$$$$
\text { Y N DM }
$$$$
\text { Y N DM }
$$
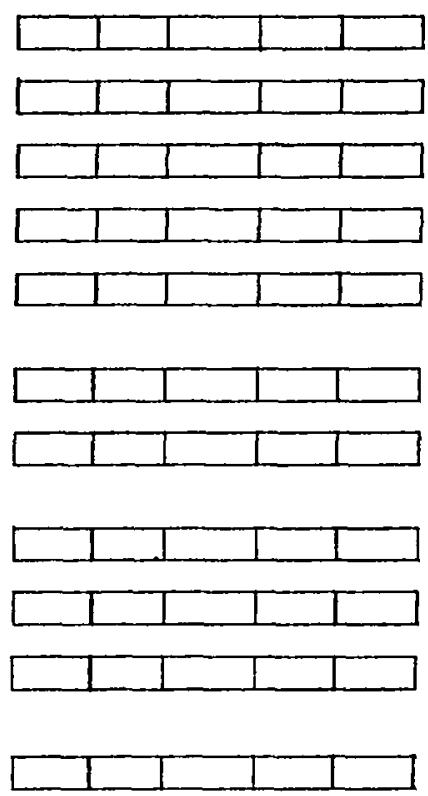
33. They expect their stated reasons for absence, poor performance on a test due to a missed class or lecture, or their late completion of projects to be accepted without penalty.

34. They resist dealing with problems that have been pointed out to them.

35. They become dependent on the help offered them.

36. They jump ahead and are eager to finish at any cost.

37. They accept counseling willingly.

38. They approach their atudies casually.

39. They are a pleasure to help.

40. They accept it when I say, "No."

41. They say they shouldn't take a test if not prepared for it.

42. They seem aimless.

43. They are polite, courteous.

44. They are adaptable.

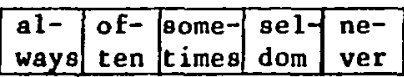

Would this behavior \&/or characteristic help them to succeed?
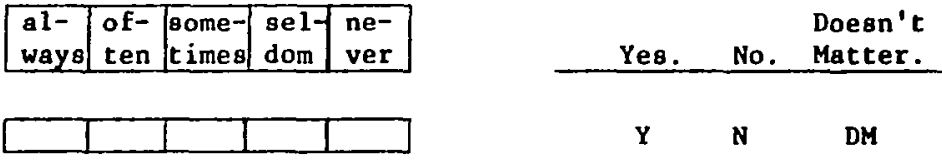

DM

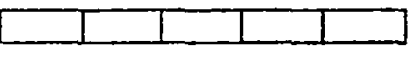

DM

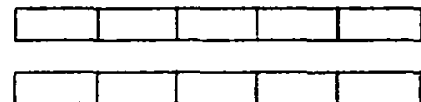

Y N DM

Y N $\quad$ DM

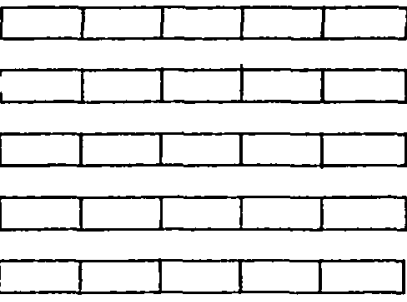

Y N DM

Y N D

Y N DM

$\mathbf{Y} \quad \mathbf{N} \quad$ DM

Y N DM

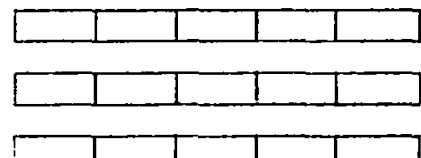

Y N DM

$\mathbf{Y} \quad \mathbf{N} \quad$ DM

Y N $\quad$ DM 
Thank-you very much!

Would you answer the following?

*have you ever studied overseas? For how long? or

*Were you ever an internstional student in a U.S. university?

*How many international students are enrolled in the courses you are presently teaching?

*Is this about the average number you have contact with each semester?

*Which department do you teach in?

The researcher acknowledges the demands on a professor's time. However, if you wish to comment on any of the items, on the questionnaire in general, or anything related to your experiences dealing with international students in the "world of academia", please do so. 
APPENDIX C

COVER LETTER AND INSTRUCTIONS, RELIABILITY

OF ROLE BEHAVIORS QUESTIONNAIRE FOR'S, AND DEMOGRAPHIC INFORMATION SHEET 
Dear Professor or Student:

Enclosed are from one to three questionnaires being used for research in the field of Intercultural Communications. Your belp in completins them will be most appreciated.

My hope is that through your help I will be able to assist jou in jour work as propessors or as students in $\theta$ University. tions.

Please feel free to contact we if jou have any ques-

Katy J. Nadal

$229-4088$

$282-8645$

\section{DIRECTIONS}

On the attached pages is a list of statements that describe some of the characteristics of students. You will be asked to complete the questionnaire two (2) times.

One time you will be osked to consider the statements in light of your idee of what a student must do to succeed at the university. 'Success' in tiris cese will be defined as PASSING COURSES AlID GETTING HIGH GEADEE.

So, as jou respona to the statements Eive rour opinicn as to which characteristics are cesirable in the siudent who wants to get high grades and pass his/her courses.

The other time jou are asked to consider the statements in light of pour idea of whot a student must do in order to succeed, but this time 'success' will be defined as UNDERSTANDING ANI IEARIING THE NATERIAI in bis/her courses. So, as you rescond to the staterents give your opinion as to which characteristics are desirable in the student who wats to learn and understand the meterial of the courses s/he takes.

There is also a list of stetements that describe soce of the characteristics of professors. Think about what your ideal professor is or would be like. The researcher would like to know zour idea of what a good professor is-not soreone else's idea or what 'the system' might think a good professor is, but your own idea.

So, as you read and respond to each item, consider what characteristics are desirable or undesirable in jour ideal professor. 
Characteristic list for the student who measures his/her success at the university in terms of:

GETPIHG HIGE GRADES MII PHSSIITG COURSE:

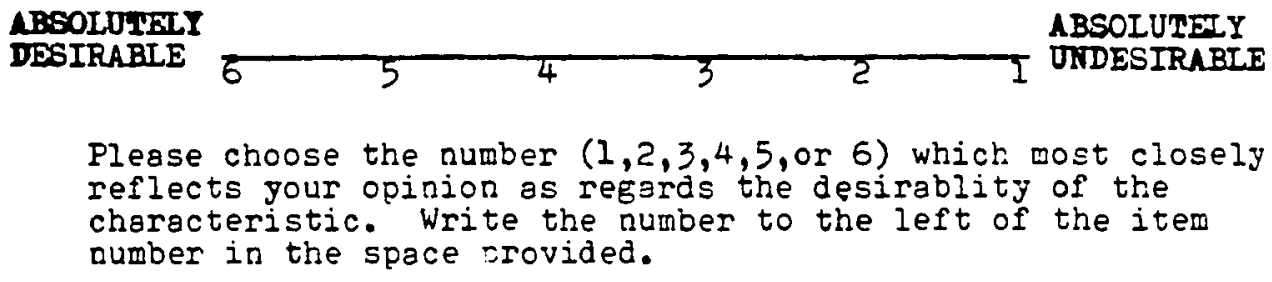

ABSOIUTEIY DTDESIRABTE

Please choose the number $(1,2,3,4,5$, or 6$)$ which most closely reflects your opinion as regards the desirablity of the characteristic. Write the number to the left of the item number in the space orovided.

1. Has a strong sense of purpose for why $s /$ he is in school.

2. Brings examples, stories, articles, experiences to class that relate to the course.

3. Consults his/her professor to find a project or paper topic.

4. Asks for comments and criticisw.

5. Has opinions that are based on consultation with a variety of sources.

6. Fresents bis/her own ideas in class.

7. Smokes in class.

8. Drinks and/or eats in class.

9. Hccepts the authority of the professor.

10. Asks to know the course renuirements and expectations.

11. Participates in class discussion and shares ideas.

12. Iistens critically.

13. Reads a lot.

14. His/her writing style is organized.

15. His/her written work is grammatically correct.

16. His/her written work is neat and easy to read.

17. Reads material related to class, but not assigned.

18. Will question or debate the professor's ideas.

19. Memorizes his/her lecture notes.

20. Takes notes. 


\section{GETIIIG HIEE GRIDES AND PASEIHIG CCLRSES}

ABSCIU'LIIY

DISIFABIE

6

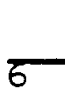

21. Asks cuestions ouring cless.

22. Thinks and speaks quickly when called on by the professor.

23. Slants his/her papers to fit the expectations of the professor.

24. Talks to the professor about how to get a good grade.

25. Can type.

26. Attends class reeularly.

27. Is present in the classrocr before the class bejins.

28. Asks guestions when $s /$ he doesn't understand.

29. Will talk openly in class about material $s /$ he hasn't mastered.

30. Has a sense of humor..

31. Knows how cheating and plagiarism are defined by the university.

32. Concentrates on learnine detail.

33. Feads and completes homework without the pressure of a deadline.

34. Has a neat appearance and is well-Eroomed.

35. Ioes whatever the professor directs.

36. Allows the professor to precede him/her when entering and leavine the classroom.

37. Is concerned with knowing the scores and grades of other students on tests and po pers.

38. Frankly tell the professor what $s /$ he really thinks.

39. Niakes friends with his/her classmates.

40. Completes homework, ossigned reading and popers, handouts by the date indicated by the professor.

41. Talks a lot in class.

42. Talks personally with the professor when his/her Erade is not setisfying. 
GETTIIT HIGE GRADES AND PASSING CCURSE:

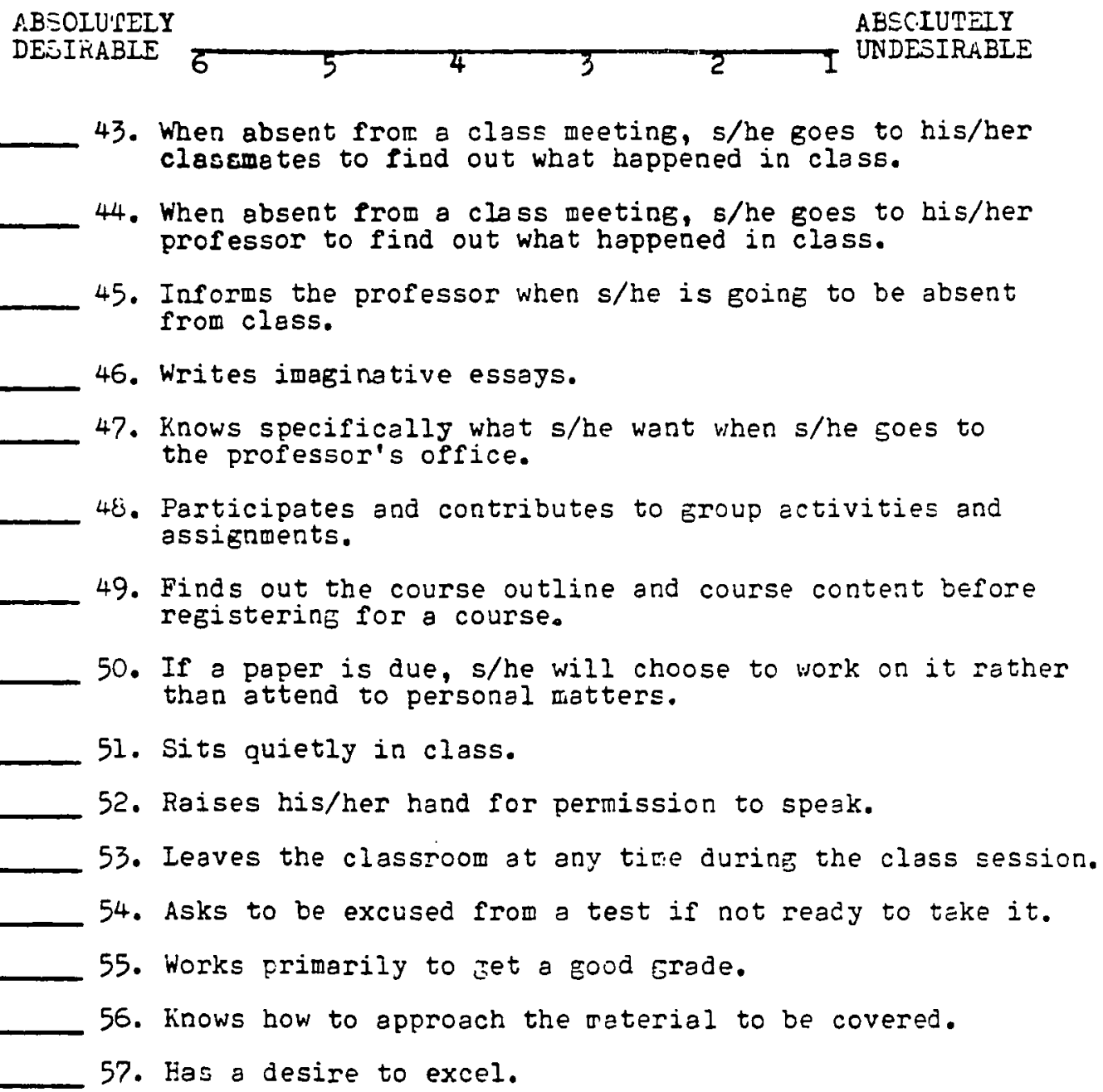

51. Sits quietly in class.

52. Raises his/her hand for permission to speak.

53. Leaves the classroom at any tire during the class session.

54. Asks to be excused from a test if not ready to take it.

55. Works primarily to set a good Erade.

56. Knows how to approach the oaterial to be covered.

57. Has a desire to excel.

\begin{tabular}{|c|}
\hline $\begin{array}{l}58 . \\
59 .\end{array}$ \\
\hline 60. \\
\hline 61. \\
\hline 62. \\
\hline
\end{tabular}


Characteristic list for the student who measures his/her success at the university in terms of:

UNDERSTAND ING AND LEARNING THE MATERIAL

ABSOLUTEZY DESIRAEIE

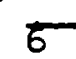

Please choose the number $(1,2,3,4,5$, or 6$)$ which most closely reflects your opinion as regards the desirablity of the characteristic. Write the number to the left of the item number in the space provided.

1. Has a strong sense of purpose for why $s /$ he is in school.

2. Brings examples, stories, articles, experiences to class that relate to the course.

3. Consults his/her professor to find a project or paper topic.

4. Asks for comments and criticism.

5. Has opinions that are based on consultation with a variety of sources.

6. Presents his/her own ideas in class.

7. Smokes in class.

8. Drinks and/or eats in class.

9. Accepts the authority of the professor.

10. Asks to know the course requirements and expectations.

11. Participates in class discussion and shares ideas.

12. Iistens critically.

13. Reads a lot.

14. His/her writing style is orgenized.

15. His/her written work is gremmatically correct.

16. His/her written work is neat and easy to read.

17. Reads material related to class, but not assigned.

18. Will question or debate the professor's ideas.

19. Memorizes his/her lecture nutes.

20. Takes notes. 
UNDERSTAND ING AND IEAPYING TEE MATERIAL

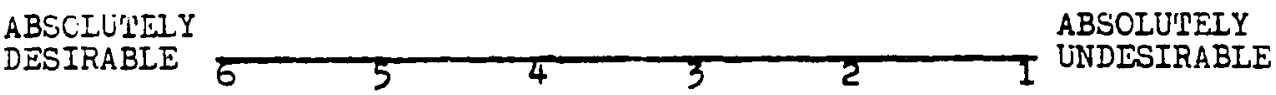

21. Asks questions during class.

22. Thinks and speaks quickly when called on by the professor.

23. Slants his/her papers to fit the expectations of the professor.

24. Talks to the professor about how to get a good grade.

25. Can type.

26. Attends class regularly.

27. Is present in the classroom before the class begins.

28. Asks questions when $s /$ he doesn't understand.

29. Will talk openly in class about material $s /$ he hasn't mastered.

30. Has a sense of humor.

31. Knows how cheating and plagiarism are defined by the university.

32. Concentrates on learning detail.

33. Keads and completes homework without the pressure of a deadine.

34. Has a neat appearance and is well-groomed.

35. Does whatever the professor directs.

36. Allows the professor to precede him/her when entering and leaving the classroom.

37. Is concerned with knowing the scores and grades of other students on tests and pors.

38. Frenkly tell the professor what $s /$ he really thinks.

39. Makes friends with his/her classmates.

40. Completes homework, assigned reading and popers, hondouts by the date indicated by the professor.

41. Talks a lot in class.

42. Talks personally with the professor when his/her grade is not satisfying. 
DNDERSTANDING AND IEARNING THE MATERIAL

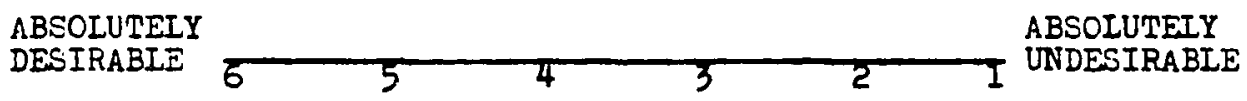

43. When absent from a class meeting, s/he goes to his/her clasemates to find out what happened in class.

44. When absent from a class meeting, $6 /$ he goes to his/her professor to find out what happened in class.

45. Informs the professor when s/he is going to be absent from class.

46. Writes imaginative essays.

47. Knows specifically what $6 /$ he want when $s /$ he goes to the professor's office.

48. Participates and contributes to group sctivities and assignments.

49. Finds out the course outline and course content before registering for a course.

50. If a paper is due, $s /$ he will choose to work on it rather than attend to personal matters.

51. Sits quietly in class.

52. Raises his/her hand for permission to speak.

53. Leaves the classroom at any time during the class session.

54. Asks to be excused from a test if not ready to take it.

55. Works primarily to set a good grade.

56. Knows how to approach the material to be covered.

57. Has a desire to excel.

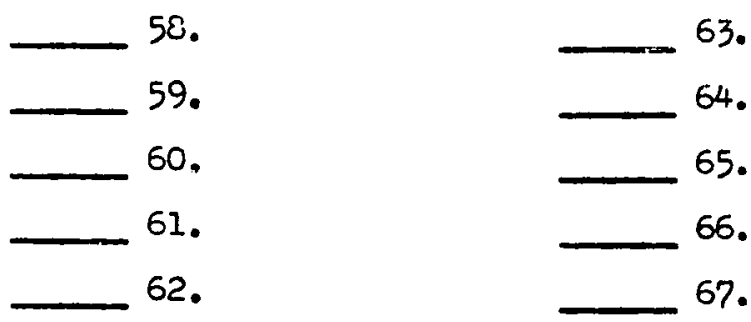


CHARACTERIETICS OF YOUR IDEAI PRCFESSOK

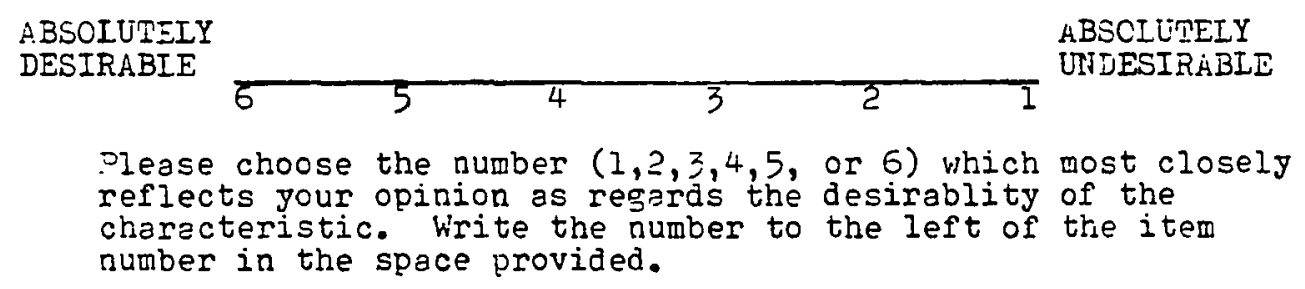

1. Relies prinarily on assigned papers for judging a student's ability.

2. Relies primarily on tests for judging a student's ability.

3. Relies primarilz on classroom performance for judeing a student's ability.

4. Can answer any question that is asked in class about the subject matter.

5. If $\mathrm{s} /$ he is shown to be mistaken, $\mathrm{s} /$ he is willing to admit it.

- . Treats students as equals to professors.

7. Comes to class on time.

8. Sticks to the lesson plan or the day's topic.

9. Prefers that students remain quiet in class.

10. Will talk about his personal life and feelings in class.

11. Leaves the classroom as soon as the class is over.

12. Remains after class to talk to students.

13. Keeps the class beyond the scheduled time.

14. Changes the format of the class (i.e. lecture, movies, discuscion) from time to time.

15. Allows the students to speak in class.

16. Encourages students to speak in class.

17. Gives the necessary information of the course during class and doesn't expect students to go to the library to learn it.

18. Speaks without needing to refer to notes.

19. Is energetic. 


\section{CHARACTYFIOTICS OF YCUR IDEAI PRCFESSOR}

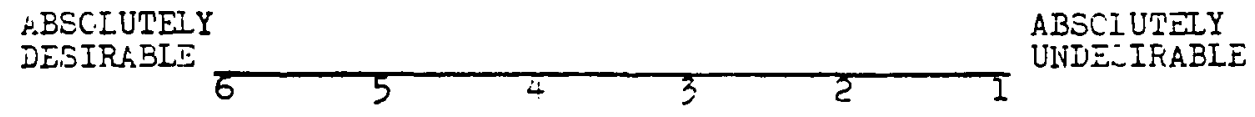

20. Tells jokes in class, orines humorous stories to illustrate his/her points.

21. Is formal.

22. Is informal.

23. Returns quizzes anci papers to students at the class meeting subsequent to their subrission.

24. Hites in a clear and simple ranner.

25. Is a frierd $a \because$ wi: as a teacher to his/her students.

26. Is concerred bitr. cetails.

27. Gives students witt special problems a lot of extra attention.

28. Permits students to leave the classroom after the class has begun.

29. Calls on individicl students to recite in class.

30. Encoureges Eroup work ano assignments.

31. Keeps an attendance record.

32. Asks for the students' opiaions.

33. Assigns the readine of materials that are not included in the tests $\mathrm{s} / \mathrm{he}$ eives.

34. Is willine to tell students exactly what they nust do in order to pass the course.

35. Criticizes students freely in class.

36. Brings in outside stories and examples in order to relate the class to the outside world.

37. Expresses his/her personal opinion about the subject matter.

38. Smokes during class.

39. Eats and/or drinks during class.

40. Is demanding and insists that students meet set standards. 
CEARACTERISTICS QR YOUR IDEAI PROPESSOR

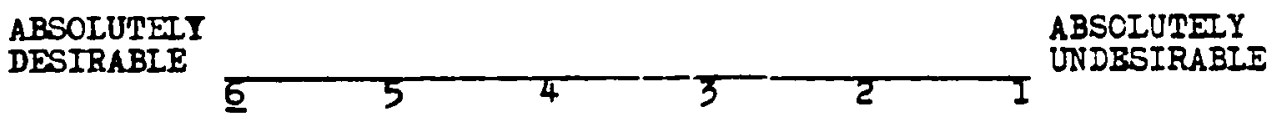

41. Explains hts/her gools and objectives for the course.

42. Considers students' individual problems when deteraining grades.

43. Has a neat appearance and is well-groomed.

44. Is frank and gives his/her opinions directly.

45. Acts according to his/her professorial status.

46. Tells students when their work is good.

47. Inites iadividual students to his/her office.

48. Posts and keeps office bours.

49. Is available to students whenever they need rim, including calls at hoce.

50. linous the names of his/her students.

51. Prefers to follow rules and not deal with students on an individual basis.

52. Will permit students to take over and direct the class.

53. Gives many quizzes.

54. Frefers a discussion format to a lecture format.

55. Looks at his/her students when lecturing.

56. Talks ebnut his her academic interests during class.

57. Has the aoility to understand the students' feelings.

58. Likes and is interested in his/her students.

59. Letermines grades for students by how well they meet set standards without regard for their individual abilities and skills. (i.e. language ability)

60. Believes that students must learn on their own.

61. Is dedicated and devoted to his/her work.

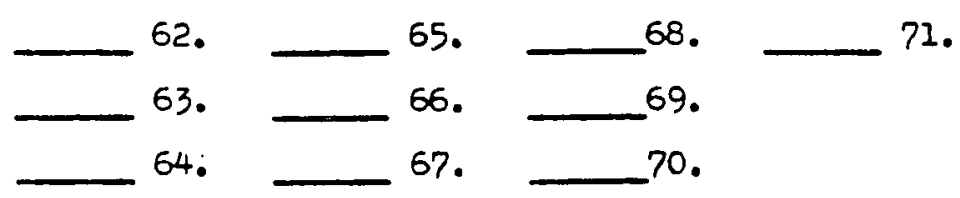


Thank you very much !

Now, would ycu please answer the following questions:

1. Are you a graduate student, an undergraduate student, or a professor.? That departwent?

2. 'here are you from--or--what is your cultural background?

3. If you arc from another country, how long have you been in the United States? (Check just one, please.)

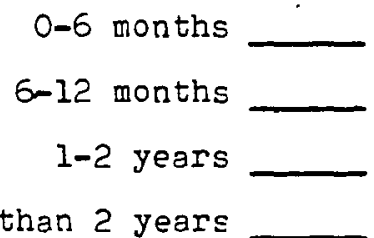

4. Are you a male or a female?

5. Consider your academic experience/life/courses. How would you rate your overall satisfaction?

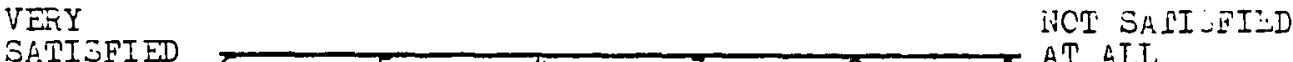

Select one number and write it here:

6. (Optional)

What is your grade point average (GPA)? 
APPENDIX D

FACULTY COVER LETTER, GENERAL COVER LETTER AND INSTRUCTIONS, FINAL QUESTIONNAIRE ON ROLE BEHAVIORS OF STUDENTS AND PROFESSORS, DEMOGRAPHIC INFORMATION SHEET, AND FOLLOW-UP LETTER TO PROFESSORS PERSONALLY CONTACTED 
FACULTY COVER LETTER

June 20,1980

Dear Faculty Member:

The accompanying questionnaire is part of a study being done by Ms. Katy Nadal, a Master's candidate in Speech Communication, to determine expectations that professors and students have regarding their mutual role behaviors. The data will be used to chart perceptual differences of the U.S. students, international students and professors. The findings will ultimately be used to develop training programs to aid the adjustment of international students to the U.S. classroom and to inform faculty of potential student/faculty difficulties beyond language.

The International Student Board has reviewed this research project and given it our strong endorsement. We encourage you to cooperate with Ms. Nadal in any way that you can.

Sincerely yours,

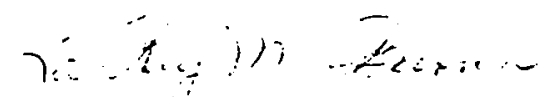

LaRay M. Barna, Chairperson

International Student Board

Meubers:

Carmela Bloise, Student Representative Kenneth Burns, Community Representative Jerome DeGraaff, Library West

Prudence Douglas, English as a Second Language

Grant Farr, Sociology

Grace Kuto, Student Representative Victor Leo, Student Representative David Martinez, Special Education Earl Rosenwinkle, Biology 
Dear Professor or Student:

Enclosed are three (3) short questionnaire forms being used for research in the field of Intercultural Communications. Your help via completing them will be most appreciated.

My hope is that through your help I will be able to assist you in your work as professors or as students in a university setting.

Please feel free to contact me if you have any questions or comments.

Katy J. Nadal

$229-4088$

282-8645

\section{DIRECTIONS}

\section{STUDENT QUESTIONNAIRES:}

On the attached pages are two identical lists of statements that describe some of the characteristics of students. You will be asked to complete each one.

One time you will be asked to consider the statements in light of your idea of what a student must do to succeed at the university. 'Success' in this case will be defined as GETTING HIGH GRADES AND PASSING COURSES.

So, as you respond to the statements give your opinion as to which characteristics are desirable in the student who wants to get high grades and pass his/her courses.

The other time you are asked to consider the statements in light of your idea of what a student must do in order to succeed, but this time 'success' will be defined as UNDERSTANDING AND LEARNING THE MATERIAL in his/her courses.

Therefore, as you respond to the statements, give your opinton as to which characteristics are destrable in the student who wants to learn and understand the material of the courses $\mathrm{s} / \mathrm{he}$ takes.

\section{PROFESSOR QUESTIONNAIRE:}

There is also a list of statements that describe some of the characterlstics of professors. Think about what your ideal professor is or would be like. The researcher would like to know your idea of what a good professor 1s--not someone else's idea or what 'the system' might think a good professor is, but your own idea.

So, as you read and respond to each item, consider what characteristics are destrable or undesirable in your ideal professor. 
Characteristic 11st for the student who seasures his/her success at the university in terms of.

\section{GEIIING HIIG: GRADES AIVD PASSING COURSES}

$\begin{array}{llllllll}\text { ABSOLUTELY } & 7 & 6 & 5 & 4 & 3 & 2 & 1 \\ \text { DESIRAELE } & & & & & & & \end{array}$

Please choose the whole number $(1,2,3,4,5,6$, or 7$)$ which wost closely reflects your opinion as regards the desirability of the characteristic. Write the number to the left of the item number in the space provided.

1. Has a strong sense of purpose for why s/he is in school.

2. Consults his/her professor to find a project or paper copic.

3. Asks for cuments and criticism.

4. Asks to know the course requirements and expectations.

5. Listeas critically.

6. 'Hemorizes his/her lecture notes

7. Can type.

8. When absent fron a class meet ing s/he goes to his/her professor to find out what happened in class.

9. Inforws the professor when $s /$ he is going to be absent frow class.

10. Writes imagioative essays.

11. Knows speciflcally what $s /$ he wants when $s /$ he goes to the professor's of fice.

12. Asks to be excused from a test if not ready to take $1 t$.

13. Allows the professor to precede hid/her when entering and leaving the classroom.
14. Smokes in class.

15. Drinks and/or eats in class.

16. Accepts the authority of the professor.

17. Participates in class discussion and silares Ideas.

18. Reads a lot.

19. Takeo notes.

20. Slants his/her papers to $f \pm t$ the expectations of the professor.

21. Talks to the professor about how to get a good grade.

22. Attends class regularly.

23. Does whatever the professor directs.

24. Is concerned with knowing the scores and grades of other students in class.

25. Raises his/her hand for permission to speak. 
Characteristic list for the student who measures his/her success at the university in terms of:

UNDERSTANDING AND LEARNING THE MATERIAL

ABSOLUTELY
DESIRAELE

Please choose the whole number $(1,2,3,4,5,6$, or 7$)$ which most closely reflects your optnion as regards the desirabllity of the characteristic. Write tine number to the left of the item number in the space provided.

1. Has a strong sense of purpose for why $s /$ he is in school.

2. Consults his/her professor to find a project or paper toptc.

3. Aske for combents and criticiom.

4. Asks to know the course requirements and expectations.

5. Listens crftically.

6. Memorlzes $\mathrm{h} 1 \mathrm{~s} / \mathrm{her}$ lecture notes.

7. Can type.

5. When absent from a class meeting s/he goes to his/her professor to find out what happened in class.

9. Informs the professor when 8 /he is going to be absent from class.

10. Writes imaginative essays.

11. Koows spectfially what $s /$ he wants when 8 /he goes to the professor's office.

12. Asks to be excused from a test if not ready to take it.

13. Allows the professor to precede $h 1 m / h e r$ when enterlag and leaving the claseroom.
14. Srokes in class.

15. Urinks and/or eats in clas:

16. Accepts the autiority of the professor.

17. Participates in class discussion and shares ideas.

18. Reads a lot.

19. Takes notes.

20. Slants his/her papers to fit the expectations of the professor.

21. Talks to the professor about how to get a good grade.

22. Attends class regularly.

23. Does whatever the professor directs.

24. Is concerned with knowing the scores and grades of other students in class.

25. Ralses his/her hand for permission to speak. 
CHARACTERISTICS OF YOUR IDEAL PROFESSOR

$\begin{array}{llllllll}\text { ABSOLUTELY } & 7 & 6 & 5 & 4 & 3 & 2 & 1 \\ \text { DESIRABLE } & & & & & & & \end{array}$

Please choose the whole number $(1,2,3,4,5,6$, or 7$)$ which most closely reflects your opinion as regards the desirability of chatacteristic. Write the number to the left of the item number in the space provided.

1. Relles primarily on tests for fudóling a student's ablilty.

2. Relies primartly on classroom performance for judging a student's ab1l1ty.

3. Can answer any question that is asked in class about the subject matter.

4. Prefers that students remain quiet in class.

5. Vill talk about his personal life and feelings in class.

6. Changes the format of the class (1.e. lecture, movies, discussion) from time to time.

7. Encourages students to speak in class.

8. Returns quizzes and papers to students at the class meeting subsequent to their submission.

9. Asks for students' oplatons.

10. Assigns the reading of materials that are not included in the tests $s /$ he gives.
11. Invites 1ndividual students to his/her office.

12. Posts and keeps office hours.

13. Is avallable to students wheneve: they need him/her, focluding calls at home.

14. knows the names of his/her students.

15. WIIl permit students to take over and direct the class.

16. Gives many quizzes.

17. Determines grades for students by how well they weet set standards without regard for their Individual abllities and skilis. (1.e. language ab1lity)

13. Is dedicated and devoted to his/her work.

19. Gives the necessary informatior of the course during class an. doesn't expect students to go to the library to learn it.

$t_{+*+*}$ Please turn to the last page $++_{+*+*}$

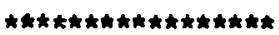

for testing purposes only:

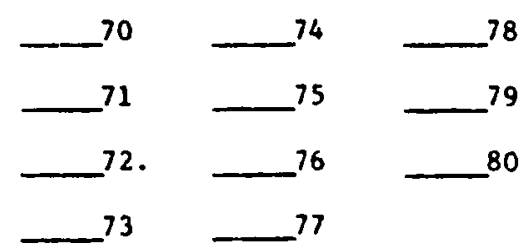


Thank-you very much:

Now, would you please answer the following questions?

1. What is your status? (check one) Undergraduate student

Graduate or Post-Baccalaureate student Teaching Assistant (Graduate)

Professor (How long have you been teaching? years.) Other.

2. What is your field of study or major?

3. Where are you from...or... What is your cultural background?

4. How long have you lived in the United States? (check one)

${ }^{0-6 m o n t h s}$
${ }^{7-12}$ months
$1-2$ years
3-5 years
6-10 years
more than 10 years

5. Are you:

$L_{\text {female }}^{\text {male }}$

6. What is your overall satisfaction with your academic life/work/experlence? (Write $1,2,3,4,5,6$, or 7 in the space provided.)

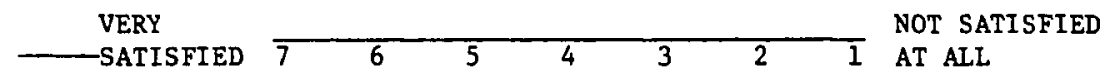

7. (optional) What is your G.P.A.? 
FOLLOW-UP LETTER TO PROFESSORS PERSONALLY CONTACTED

Dear Professor

I spoke to you in your office about

On

field of Intercultural Communicasome research I am undertaking in the tions as part of my Master's thesis.

I would like to thank you for taking the time to talk with me and also for agreeing to fill out the questionnaire I left with you. The response rate has been gratifying; however, a few are still outstanding. Since your response was anonymous I am not sure whether yours is among the ones I have received. If so, thank you. If not, I would like to ask that you fill it out and return it to me in care of the Speech Communication Department by July 11, 1980. If you have misplaced your copy please call me at 282-8645 or leave a message for me by calling the Speech Department (299-3531).

Again, thank you very much for your time and your opinion! I plan to process the data in the latter part of July and expect to have the results of the questionnaires and interviews I have done in a readable form by the end of the summer. I will contact you again at that time to see if you would be interested in knowing some of the findings.

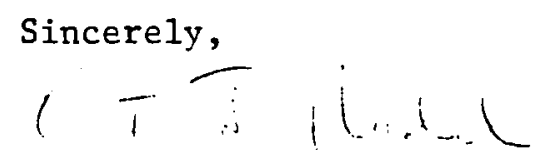

Katy J. Nadal 


\section{APPENDIX E}

PROBLEM ORIENTED PROFESSOR AND STUDENT BEHAVIOR LISTS COMPILED FROM PERSONAL INTERVIEWS AND THE LITERATURE 
PROBLEM ORIENTED PROFESSOR AND STUDENT BEHAVIOR LISTS COMPILED

FROM PERSONAL INTERVIEWS AND THE LITERATURE

\section{PROFESSORIAL BEHAVIOR}

A. Exam and Grade Related

1. Exams here don't test what I know.

2. They give unfair kinds of tests.

3. There are so many tests.

4. There are so many exams compared to my country.

5. They don't make good exams.

6. The professor doesn't provide me with the kind of information I need to pass my exams and/or to be educated.

7. The professor doesn't tell me what I must do to pass.

8. They don't try to help me pass. They are too concerned with the numbers of passing, not whether I learned or not.

9. They don't let me know clearly what I must do to succeed.

10. The professor doesn't help me get my degree.

11. They equate success with a grade. I'm a person first. They judge me as a person by how well I succeed.

12. They seem to think that the high grade is the key to success.

13. They judge us unfairly.

B. The Professorial Responsibility in Learning/Teaching

1. I don't know what kind of papers my professor expects from me.

2. They expect me to be like them.

3. Professors seem to expect me to change.

4. They expect me to do everything. They won't help me.

5. They expect me to contribute. I'm here to learn.

6. They are always telling me to go find out in the library. Why won't they just tell me what it is that I need to know. I'll learn it.

7. My professors want me to talk about things that I don't know enough about.

8. They give us reading lists, but that isn't what is on the exam.

9. Why does the professor assign group assignments? What good are they? 
C. Unfairness

1. They don't like me to work with my friends. They say that it is cheating.

2. They seem to want me to work alone and do better than my friends.

3. They don't want me to help my friends understand. They tell me to work alone.

D. Humiliation and Discrimination

1. It is humiliating to be monitored about my attendance.

2. They are prejudiced against foreign students.

3. They don't treat me as an adult.

4. They treat graduates like undergraduates and undergraduates like children.

5. They treat me as though I am lacking in academic ability.

6. They think I am inferior.

7. They seem to treat me as though I am ignorant.

8. They always treat me like a foreigner.

9. They discriminate against me.

10. There are some professors in this school who never give above a "C" to a foreign student.

E. Unrealistic Expectations .

1. They expect too much of me. I have never seen a science $1 \mathrm{ab}$.

2. They expect one to take a test no matter what may be happening in his/her personal life to make it impossible to do so.

3. They don't accept good reasons for being unable to take an exam.

4. They expect me to get all my work done and come to class even when there is something more important to do--like taking my mother to the doctor.

\section{F. Selfishness}

1. They are too busy with their own projects and concerns to help me.

2. The professor only cares about himself.

3. They only care about the best students.

4. They are more concerned with research than with teaching.

5. They don't seem devoted to their students. 


\section{G. Interpersonal Expectations}

1. They don't like to use their means to help us.

2. They are friendly and helpful one day, but not the next.

3. They are friendly, but then they don't want to help us.

4. He will listen to my problems, but he doesn't always care about them.

5. I don't think my professor really cares whether I learn or not.

6. My professor is inconsistent. Sometimes he is helpful and sometimes he is so administrative-like and unfriendly. I never know what to expect.

7. He will help me with some things and then not with others.

8. I can't depend on my professors to help me.

9. I appreciate it that the professor seems to really listen to me.

10. I wish that he would listen more.

11. You don't understand me.

12. Professors here don't seem to want to know me.

13. I don't feel like my professors really know me.

14. They don't like to do things on a personal basis.

15. I'm ashamed to admit to my professor that I don't know something.

16. In the U.S. the professor is just in his office.

17. I wish that he would call me to his office.

18. My professor won't tell me to come see him.

19. It is important to be invited to see a professor.

20. My professor won't talk to me without an appointment.

21. It seems to be hard to make personal contact with my professor. He is too busy to take time to talk with me.

22. Why does he tell me to go to a counselor? What can a counselor do to help me?

23. Why should I see a counsellor? I just want to talk to my professor. Why doesn't he help me?

24. They seem to expect me to get help from strangers.

25. My professor tells me I have problems. Isn't that my business?

\section{H. Class Format}

1. They are displeased when I disagree.

2. The professors seem to really want to know my opinion. I like it.

3. Lectures seem so practical, not theoretical.

4. Why does he want me to talk in class? I have nothing to add.

5. The teacher doesn't ask me to participate.

6. I'm never asked to recite, to tell what I know. 
I. Inappropriate Behaviors

1. They sometimes ask me questions that are inappropriate. (e.g. asking a Saudi woman her age.)

2. They sacrifice peace and tranquility for self-reliance and competition.

3. They don't seem to mind friction in their dealings.

4. Sometimes thay are quite abrasive.

5. They are so direct. They don't always use tact and sensitivity with me.

6. I don't like it when the teacher criticizes me in front of others.

7. They don't have much regard for "face."

J. Structure and Authority

1. Sometimes a professor will surprise me and be very strict.

2. They are willing to admit their weaknesses in public.

3. They don't seem to expect respect.

4. They are sometimes not demanding of the behavior of students. They are not strict in class.

5. I don't think it is good for the professor to let other students control or dominate the class.

6. He doesn't seem to care if I am disrespectful--eating or drinking in class is okay.

7. Some are too wishy washy. They need to be more definite.

8. Sometimes they don't know everything about their subject.

9. Sometimes they say they don't know the answer to a students' question.

10. They are trusting. It makes it possible for students to cheat.

11. I have to cheat because the professor has not taught me well.

12. They don't all have a good methodology in teaching.

13. The professor doesn't do his job correctly.

K. Efficiency

1. They always want to "stick to the subject" and finish what has been brought to say.

2. They feel everything must be organized, standardized. There is little consideration for the individual and his needs.

3. When it comes to school they are organized.

4. Professors are quite efficient. 
L. Overal1 Opinions, Comments, Observations

1. They have a lack of reverence for learning.

2. They are not very sociable.

3. They do not know the difference between a Persian and an Arab.

4. Teachers here are warmer, kinder, more friendly and accepting than teachers in my country.

5. They are not polite.

6. They are not considerate.

7. They never seem to take the time to learn to pronounce a students name.

8. I don't know how to make my professor like me.

9. They are not interested in applying academic disciplines internationally.

10. Professors don't have much of a global perspective.

11. They have a lack of interest in international, crosscultural affairs.

12. Some of the professors aren't very sophisticated.

13. Professors here act very different from professors in my country.

14. They don't act according to their position.

15. They are too casual. They will let students take over the class and not finish his lesson.

16. I wish that he would act like a respectable man, like a professor.

17. Their manner is informal.

18. Their appearance is very informal.

19. They are too friendly, too chumny.

20. They are so informal and want the to use first names.

II. Student Behavior

A. In the Classroom

1. It is hard to get input from them.

2. I wish they would speak up. I can't tell if they are listening.

3. They will sometimes respond to direct questions.

4. They don't ask when they don't understand.

5. Sometimes I sense that they disagree with me. At these times I sometimes sense a withdrawal, but they never speak to me.

6. If they disagree, they usually do so in private.

7. They always agree. They never question anything $I$ say.

8. Not many of them will give an opinion.

9. Some of them give opinions.

10. They will not discuss in class. 
11. They are shy to participate in class.

12. I'm often looking for comparisons. And they don't share in class.

13. They seem to listen intently to what is being said.

14. They of ten don't enter into a class discussion.

15. They might listen to a discussion, not enter in, but then come to see me about it later.

16. They will often say, when addressed, "Oh, I just can't express it well enough."

17. They don't know how to discuss properly.

18. They like to talk in class, but don't stay on the subject matter.

19. They don't seem to take criticism in public well.

20. They seem to have less truuble in classes that do not stress oral participation.

21. Based on evaluations it seems that some want the professor to lecture more.

B. The "Buddy System" and Peers

1. They study together and get the same results.

2. They do their homework with friends and it all comes out the same. They need to be able to think and work independently.

3. They like to be in classes with their peers.

4. They seem to use a buddy system. One person seems to be the spokesman. All in the group don't have the same potential.

5. They seem to use a buddy system. They might use a friend to get into a class.

6. They seem to operate under a buddy system. If one gets permission to get into a class, his (often unqualified) friend will expeci to get in, too.

C. Authority and Expectations

1. They expect the system to adapt to them. (Middle East).

2. They expect to be dealt with firmly.

3. They seem to like authority and discipline.

4. They used to have more respect for authority. Now they challenge it.

5. I think a rigid standard will help the students to succeed.

6. They seem to bridle at the rules.

7. It is their choice to come here. They must raise themselves to our level. We must not sink to theirs. 
D. Preparation

1. Academic preparation is a problem.

2. They are resistant to suggestions as to what they might need.

3. Sometimes they don't want to take a required course.

4. They begin regular (university) courses before they are really prepared.

5. They have insufficient preparation in their major field.

6. They take a course without having the proper background.

7. They depend on peers to evaluate courses and advise them.

E. Skills Related to the U.S. Academic System.

1. They are unwilling to defend themselves, even when they might be right.

2. They are reluctant to try/experience new teaching strategies.

3. They are good at remembering facts.

4. They rely on memorization.

5. They are unable to write imaginative or logical essays.

6. They don't know how to approach the material covered in class.

7. In group assignments it is often the foreign student who doesn't carry his weight.

8. They don't like to do practical research.

9. They have trouble applying their knowledge to the practical world.

10. They have trouble being specific. They seem to feel they must theorize to encompass the whole subject world.

11. They have little motivation to strive academically.

12. They don't seem to sense the challenge in learning.

13. They have difficulty handling the competitiveness of acedemia.

14. They don't seem to have academic curiosity. Seems to be in short supply.

15. Independent study is very difficult for them.

16. They do not have proficience in sharp thinking (as needed for objective tests.)

17. They have trouble grasping and appreciating the scientific method.

18. They lack the skill of reasoning and inference.

19. They lack the skill of independent analysis.

20. It is difficult for graduates to come up with opinions based on a variety of variables. 
F. Recognition of Need for Help.

1. They seem to have a resistance to dealing with recognized problems.

2. They don't ask for help.

3. They don't realize they need help.

4. They don't show individual initiative in seeking help.

5. They have a reluctance to communicate with the professor both in and out of class.

6. They don't tell me when they are having difficulties-when they can't interpret the lecture, don't understand the class or the assignments.

7. They are sometimes a little embarrassed when I approach them about a problem.

8. They are of ten hesitant when $I$ have called them in to see me.

9. They seem reluctant to ask for clarification and assistance when faced with an academic problem. (Middle East students.)

10. I never learn of a problem until it is solved or until it is too late.

11. They don't admit to having a problem until it is under control.

G. English Related, Study Skills

1. Language is their most difficult problem.

2. They are not interested in learning English as a medium.

3. They don't take notes.

4. Their written work is poor.

5. They have poor study habits.

6. They have trouble understanding instructions, notetaking, using the library, study skills.

7. They have insufficient preparation in communication skills.

8. They don't follow instructions.

9. They are often redundant in their speaking and writing.

10. Their ability to communicate is weak.

11. They must force themselves to speak English with their own group as well.

12. They ask for leniency due to English.

H. Dependency Relationship

1. They like others to help them.

2. The more willing $I$ am, the more expectant of me they become. 
3. They can become dependent on the help offered.

4. S/he sometimes expects the tutor to "feed" him/her every thing.

5. They sometimes seem to get attached to one teacher.

I. Motivation and Success/Standards and Needs.

1. They lack an understanding of the U.S. educational system.

2. They seem unable to show assertiveness and initiative in asking questions, seeking out the TA or instructor after class to clarify points, in making decisions about classes and project topics.

3. They seem to feel that success is measured by a piece of paper.

4. They think that a diploma is the most important thing.

5. They have a tendency to jump ahead and are eager to finish at any cost.

6. Just as with Americans there are two kinds of students: some who want to learn and some who want a degree. There seems to be more of the latter among international students.

7. They seem more task and degree oriented than U.S. students.

8. Some don't want to be in school, but have to be in order to stay here.

9. Some are just not academically inclined.

10. They seem to approach their studies quite casually.

11. They don't seem to realize that through effort and self discipline higher pinnacles can be reached.

12. If a student is going to come here he or she should meet the qualifications and standards for graduation.

13. They don't understand what plagiarism and cheating are.

14. Some are extremely test poor; and in those cases scores are not a good measure of ability.

15. They sometimes seem to feel that if they are not ready for a test that they shouldn't take it.

16. I wish they would envision their professional needs in relations to their studies. (Said about all students.)

17. They don't measure their success in the university by how well they are learning.

18. They don't seem to value education in and of itself, but as the route to a career or job.

\section{J. Helping and Counselling}

1. They don't have the personal resources to solve their own problems.

2. Why don't they go to see a counsellor? 
3. They need personal counselling.

4. They are reluctant to accept counselling.

5. They won't go to see a counselor and think of excuses that don't enable them to go.

6. They often come to see me at the end of the term. They are very curious about withdrawal, incomplete, and pass-fail options, and the effect of the final on the grade.

7. They usually come with good reasons to back themselves up if they want a score or grade reconsidered.

8. They are really a pleasure to help.

9. They are usually eager for help, if offered.

10. They are good about coming at posted office hours.

11. They sometimes expect me to be like a father to them.

12. They don't seem to know what it is that they want when they come to see me.

13. They don't know what it is that they want.

14. I wish they knew what it is that they need to know.

15. They are not specific about what they want when they come to see me.

16. Sometimes they come right up after class and want extended help right then. I can't always help them because there are other students there then who also have questions.

17. They are not appreciative when I have helped them.

18. They come to see me for technical questions.

19. They are persistent and want to hear what they want to hear.

20. They don't believe it when I say "no."

21. I'm left mentally and physically exhausted after talking to international students.

22. They tend to come a week or so after (e.g. when there has been something they couldn't understand). It is hard to go back and catch up at that point.

23. They won't talk openly with me about things they haven' $t$ mastered.

24. They think I should consult with them, that the student knows what is good for them.

25. If I ask a student to come see me, the careless student will say, "I came by, but you weren't available." Or, if he talks to me the attitude is, "Why do you want to see me?"

\section{K. Administratively Related Comments}

1. They want to get into a class without a card. Then they will try to add the class when it looks like they will pass.

2. They seem to think that I can do it if I want to (e.g. change a grade, etc.) They don't understand that though I of ten can, that I might not. 
3. They sometimes bargain for grades.

4. They don't seem to worry about how they are doing until the last week.

5. They have too much faith in test scores.

6. They don't want C's: "You must do it."

7. They don't want $C^{\prime} s$ : "Immigration says that I must have a "B" to stay."

8. Most international students earn C's so it is a problem.

9. They are a bit more worried about points and the cutoff points than other students.

10. They seem to be able to find the loopholes for getting into a class. (Arabs.)

11. Saudis appear to be putting in time. Then they feel they should get an A for effort.

12. They seem to feel that admission constitutes graduation.

13. They don't seem to realize that they can do well by working hard.

\section{Ending Visits}

1. It is hard getting them to leave my office, especially if they haven't gotten what they came for. I expect the visitor to call it off.

2. They don't leave my office and continue pressuring me to their way of thinking, especially if it is a grade change.

3. I of ten have to break off the visit. They don't seem to know when it is time to go, who initiates the end of a visit.

4. I can't always tell if they are satisfied when they leave after coming to see me.

M. The "Special" Issue

1. They expect special treatment.

2. They sometimes ask for special favors.

3. They demand special attention.

4. They expect allowances to be made, usually based on language.

5. Some cheat and expect special treatment because they are a foreign student.

6. They try to play on their communication abilities to their advantage.

7. They sometimes try to get out of doing an assignment.

8. They come with excuses that almost make me dread having them in class.

9. They sometimes ask for special consideration (e.g. to be admitted to a class) and then don't hold up their end in terms of attendance and assignments. 
10. Some think that anything goes. They might say, "I missed class. Can you go over what happened?" I don't like this if it is habitual.

11. The try to get away with things.

12. They give "mother's arrival" as reason to ask for special consideration.

N. Excuses, Deadlines, Time

1. They are late to class.

2. Tardyism seems to be a problem.

3. They don't give reasons for missing class.

4. If absent, they neglect to find out what was missed.

5. They give poor excuses for missing class.

6. In general, they won't give an excuse for not coming to class.

7. They feel a personal holiday is a good enough reason to miss class or not get their work done.

8. Lateness depends on the student's perception of the importance of the class. (professor value statement)

9. They seem to have trouble meeting deadlines and schedules, and planning their time.

10. They need to learn to get material in on time.

11. In general, they will give an excuse for not turning an assignment in on time.

12. They are frank and are willing to say, "I slept late!'

13. Saudis seem to have more problems with cheating and attendance.

0. Admission of Unknowns by Faculty

1. I don't know how I act or what $I$ am doing when $I$ am accused of being prejudiced.

2. I can not tell if they have liked a course or not.

3. I don't know if they really add an extra dimension to the curriculum or not.

4. They sometimes shower me with gifts. Why?

5. I can't tell a con-job from sincerity.

P. Overall Opinions, Comments, Observations

1. They don't realize the values of their own background.

2. They are picking up only American surface culture.

3. Some don't want to associate with any other international student in the class.

4. They seem to take a lot of evening courses which is curious as most of them are not working. 
5. American students don't like their being allowed dictionaries for a test, especially if the course includes learning new terminology.

6. They are very industrious in regards to their studies.

7. Socially, they seem to adjust quite well.

8. They are aware of the investment of time and money an education involves.

9. Most do well here and adapt after awhile.

10. Some work intently on their academic goals.

11. I admire them. They have left a familiar place. They have stepped out and gone to an unfamiliar place.

12. They seem to get angry for no reason at all.

13. Some are quite hostile to me.

14. They are critical of the whole system.

15. They seem so defensive at times.

16. They have a poor attitude.

17. They have low motivation.

18. Moslems seem to feel they are superior and don't need what is here.

19. They seem so confident of their academic ability.

20. They are very quiet. I have to ask them to participate. (Asizns)

21. They have a lack of confidence.

22. I wish they would act independently.

23. They must learn to step out in the world on their own. That is the way life is.

24. They tend not to share. (Asians)

25. They seem aimless.

26. They have trouble handling the freedoms here.

27. They are discourteous.

28. They are polite.

29. They are polite, very "graceful."

30. They suffer from culture shock.

31. They seem to act out a lot.

32. They are inconsistent; they give different answers to the same question.

33. They are hypocritical: they behave one way in their society and another way in ours.

34. They act one way with their peers and another way with me. They don't seem to respect me.

35. They are shy.

36. They are friendly.

37. They are gregarious, extroverted, highly personable.

38. They are adaptable.

39. They are highly informed in their dealings.

40. They can drive you up a wall.

41. They seem to exaggerate and brag.

42. They are conscientious. (Asians) 
APPENDIX $F$

OPEN-ENDED QUESTIONNAIRE FORM ON CHARACTERISTICS OF STUDENTS

AND PROFESSORS, PROFESSOR AND STUDENT BEHAVIOR LISTS

COMPILED FROM OPEN-ENDED QUESTIONNAIRES 


\section{OPEN-ENDED QUESTIONNAIRE FORM ON CHARACTERISTICS}

OF STUDENTS AND PKOFESSORS

WHAT IS A GOOD STUDENT?

Think about your idea of what a good student is. What is s/he like? What behaviors, skills, and characteristics should a student have in order to do well at the university?

WHAT IS A GOOD PROFESSOR?

Think about your idea of what a good professor is. What is s/he like? What behaviors, skills, and characteristics should a professor have in order to do his job at the university well?

What is your country or cultural background?

Are you a student or a professor? 
PROFESSOR AND STUDENT: BEHAVIOR LISTS COMPILED

FROM OPEN-ENDED OUESTIONNAIRES

\section{PROFESSOR ROLE BEHAVIORS}

A. Professors' Responses

1. Makes material clear and interesting.

2. Provides an extensive syllabus so class goals are clear.

3. Lectures on the subject. Doesn't digress.

4. Is well prepared and has a high standard of preparation.

5. Doesn't permit aggressive/dominant class members to dominate.

6. Doesn't permit the class to become the opportunity for promoting his/her personal goals or orientation.

7. Likes students.

8. Likes to help others learn.

9. Knows the subject matter.

10. Isn't an expert in everything $s /$ he teaches.

11. Likes what he or she is doing.

12. Has enthusiasm.

13. Is competent.

14. Is organized, well prepared each day.

15. Capitalizes on strengths.

16. Is an individual.

17. Can compensate for weaknesses.

18. Can think fast.

19. Knows a lot.

20. Eclectic. Has sensitivity to the styles and abilities of others.

21. Challenges one's imagination.

22. Pushes me beyond my limits.

23. Opens doors previously unknown.

24. Is ready to admit his/her ignorance.

25. Always actively learning.

26. Likes his/her subject matter.

27. Sensitive to the stress students and professors fall under.

28. Is tough and has the courage to be tough.

29. Demands a high standard of work.

30. Demands attention to detail.

31. Doesn't abandon the sincere learner with problems. 
32. Professes his opinions and biases on the subject matter.

33. Has a point of view as regards the subject matter.

34. Is challenging to others.

35. Has energy.

36. Has discipline.

37. Has imagination.

38. Has the willingness to give up what he has learned in order to more forward.

39. Has a sense of humor.

40. Has a sense of the ridiculous.

41. Is interested in his/her topic.

42. Is interested in students.

43. Is involved.

44. Has an enthusiasm that generates and boils over.

B. American Students' Responses.

1. Kind.

2. Organized.

3. Disciplined.

4. Dedicated.

5. Reasonable.

6. Quick.

7. is not overly involved in minutia.

8. Is good at clarifying.

9. Is capable of inspiring interest in others.

10. Has done research and has had experience in the area of his/her subject.

11. Knows where to find the answers.

12. Encourages students in good scholarship and objective thinking.

13. Is friendly.

14. Is understanding.

15. Is compassionate.

16. Is tough as necessary.

17. Is sensitive to students' confusions and tries to pinpoint it.

18. Can present the subject at an introductory level and challenge his/her students.

19. Is a good motivator.

20. Throws out many ideas to work on.

21. Is demanding.

22. Is worthy of respect.

23. Doesn't assume the student is al1-knowing.

24. Has enthusiasm for his/her subject.

25. Is available and ready to help.

26. Will admit when he/she doesn't know something.

27. Treats others with respect.

28. Enjoys his/her work. 
29. Uses a variety of teaching methods.

30. Is encouraging.

31. Makes the subject interesting.

32. Is flexible and can deal with the individual goals

of the students in his/her class.

33. Is available for meeting with students.

34. Can guide the students in interests within his/her subject.

35. Is down to earth.

36. Straight

37. Knows the bureaucracy of the school.

38. Is unaffected.

39. Can inspire.

40. Can guide.

41. Cares about his/her students.

42. Is accessible.

43. Is willing to give of his/her time.

44. Can impart information in an understandable way.

45. Is open to discussion.

46. Accepts criticism.

47. Is organized in his/her presentation.

48. Is knowledgeable in his/her field.

49. Is objective in grading.

50. Encourages insight in a specific area.

51. Doesn't treat students like idiot children.

52. Has clear expectations and makes them known.

53. Encourages independent thought.

54. Doesn't dump all responsibilities on the student.

55. Can pick out the individual in the group in order to evaluate performance.

56. Is flexible.

57. Is personable.

58. Is an independent thinker.

59. Is a good listener.

60. Doesn't force his/her ideas on others.

61. Is prompt in returning papers and quizzes.

62. Encourages and motivates.

63. Speaks and writes in a clear and simple manner.

64. Is aware of students as persons who are becoming.

65. Responds well and clearly to questions.

66. Is interested in students and shows it.

67. Is reasonable with homework.

68. Doesn't waste time explaining assignments.

69. Stimulates students intellectually.

70. Is able to differentiate between opinions, beliefs, and absolute truths.

71. Is open to different ways of thinking.

72. Is prepared.

73. Is willing to talk to and explain things to students.

74. Provokes the student to want to learn.

75. Is patient, but demanding. 
76. Is available to guide and direct.

77. Is willing to discard bad ideas and try new ones.

78. Spends time with students on an individual basis.

79. Has the ability to communicate.

80. Is a friend as well as a teacher.

\section{International Students Responses}

1. Helps the student without criticizing.

2. Encourages weak students.

3. Finds out what the student needs more of and concentrates on teaching that.

4. Knows the goals of his job.

5. Knows how to get his/her ideas across to students.

6. Follows new things in his/her field.

7. Can control the class.

8. Considers different learning abilities among students.

9. Is fair among students.

10. Shares the discussion of the lesson with students.

11. Is patient because $s /$ he is dealing with different people.

12. Has enough knowledge in his/her major to give students the best $s /$ he can.

13. Has a good personality.

14. Tries to be close to each student.

15. Tries to treat each student as a friend.

16. Trusts students (without this students won't feel comfortable.)

17. Looks at student's problems as his/her problem.

18. Tries to understand the students' positions.

19. Guides and orients the students to the purpose of the class.

20. Supervises and advises--not just of studies, but of personal things.

21. Makes students feel the class is valuable and helpful.

22. Loves his/her students.

23. Has the ability to understand students' feelings.

24. Is a friend with students and if possible keeps up the friendship outside of school and class hours.

25. Is nice.

26. Is kind.

27. Is smart.

28. Really wants to teach.

29. Really wants to give knowledge to students.

30. Prepares lessons carefully before coming to class.

31. Knows how to control the class.

32. Knows how to help students anticipate.

33. Knows how to help students pay attention in class.

34. Should stimulate and help students who misunderstand.

35. Is vivacious. 
36. Is cheerful.

37. Makes students feel easily (comfortable) to ask questions.

38. Loves and understands students.

39. Is friendly with students.

40. Is a good listener.

41. Explains ideas and concepts clearly.

42. Has sensitivity for the level of knowledge of the students.

43. Teaches with his/her heart.

44. Works hard.

45. Enervates the class hour.

46. Is not chummy with students.

47. Has strict standards.

48. Acts like a father.

49. Always right. Must not do anything wrong.

50. Is formal.

51. Does not socialize with students.

52. Devoted to teaching.

53. Uses humor.

54. Socializes outside of class.

55. Lets the students talk about the subject discussed in class.

56. Acts on a different level from the students.

57. Has and/or shows feeling and facial expressions.

58. Prepares well before class.

59. Knows the subject.

60. Has schedule for the term.

61. Has power to control the class.

62. Has a good method to teach.

63. Presents material in an organized way.

64. His/her teaching method allows students to follow thinking.

65. Is organized and logical.

66. Has a good sense of humor.

67. Must be relaxed.

68. Has enough knowledge.

69. Must know foreign students and their problems.

70. Knows every student.

71. Speaks clearly.

72. Must focus on foreign students.

73. Gives foreign students special attention, recognizes their situation.

74. Maintains the attention of the class.

75. Is patient.

76. Is not nervous.

77. Is honest in giving knowledge.

78. Must discuss the material with the students.

79. Has a nice manner. (Walks nicely, does not disturb or distract.) 
80. Is not prejudiced.

81. Gives good tests and allows enough time.

82. Gives fair tests.

83. Is on time.

84. Prepares the lesson every day before class.

\section{STUDENT ROLE BEHAVIORS}

\section{A. Professors' Responses}

1. Is willing to read, think, listen, and express ideas (the latter, when appropriate.)

2. Is capable of writing, speaking clearly about the subject matter.

3. Is prepared for every class.

4. Is willing to contribute when s/he has something important to say.

5. Has intellectual curiosity.

6. Has a desire to excell.

7. Is passive.

8. Can absorb comments about his/her ideas.

9. Is willing to share at an intellectual level.

10. Can type.

11. Cares about learning and education more than enything else at this moment.

12. Can evaluate what needs to be done in order to learn the material.

13. Goes to every class.

14. Reads all the assignments.

15. Is responsible and independent towards his/her work.

16. Can distinguish useful and interesting material from irrelevant and uninteresting material.

17. Knows his/her academic strengths and weaknesses.

18. Has a good memory.

19. Can theorize.

20. Doesn't rock the academic boat.

21. Has discipline, is willing to spend long hours tackling his/her work.

22. Is imaginative, creative.

23. Pays attention to details.

24. Can master techniques needed in his/her discipline.

25. Is questioning.

26. Looks for radical departures from the system.

27. Is willing to learn what the system has to offer.

28. Is conscientious.

29. Tries hard.

30. Asks questions.

31. Does the (assigned) work. 
32. Becomes involved in the course.

33. Contributes to the class.

34. Adds and comments.

35. Is outgoing.

36. Looks and is interested.

37. Has a sense of problem.

38. Goes beyond what is required.

39. Is able to think fast.

40. Responds quickly to questions.

41. Is sincerely interested.

\section{B. American Students' Responses}

1. Has self discipline.

2. Is able to pick out main ideas from complex material and relate them.

3. Participates aggressively in class. Asks questions.

4. Speaks in a small group.

5. Is able to generate questions of his/her own and to research them.

6. Is dedicated and has perseverance.

7. Is tenacious.

8. Is able to budget time.

9. Is dependable.

10. Is a good listener.

11. Can organize and analyze the material of the course.

12. Has a sense of humor.

13. Follows instructions.

14. Attends class.

15. Takes good notes.

16. Reviews notes regularly.

17. Writes fairly well.

18. Reads with comprehension.

19. Seeks counsel when needed.

20. Is industrious.

21. Has a flexible mind.

22. Has a good memory.

23. Organization and writing skills.

24. Has a questioning mind.

25. Has a goal--a future orientation.

26. Doesn't question the teacher's authority.

27. Does the required reading.

28. Doesn't try to memorize.

29. Is intellectually aggressive, seeks beyond the surface.

30. Spends outside class hours studying, and enjoys it.

31. Seeks help and asks questions when s/he doesn't understand.

32. Gets assignments in on time.

33. Doesn't complain when an assignment is given. 
34. Can put thoughts into words.

35. Can socialize; can converse well and develop friendships.

36. Is open to experiences and people.

37. Is able to apply learned knowledge.

38. Is able to deal with stress and anxiety.

39. Has a pleasing personality.

40. Is an independent thinker.

41. Is creative.

42. Respects and appreciates his/her teachers.

43. Understands the teacher's expectations.

44. Takes his/her studies seriously.

45. Gives studies daily attention.

46. Talks personally to the professor if his/her grades are not satisfying to him/her.

47. Asks around if something is confusing.

48. Will ask others if $\mathrm{s} /$ he has missed an assignment.

49. Is versatile.

50. Is self motivated.

51. Is interested in his/her field.

52. Has stick-to-it-iveness.

53. Empathizes with the professor's goals and can slant his/her research to fit it.

54. Doesn't study just for the grade.

55. Helps others.

56. Does not get easily discouraged.

C. International Students' Responses

1. Divides his/her time between work and fun with care.

2. Has a good reputation among his/her classmates and teachers.

3. Is careful about attendance.

4. Is careful about doing his/her assignments.

5. Needs to "cut any far distance" between him/her and his/her classmates and teachers.

6. Has a strong purpose of why he/she is studying.

7. Has the ability to manage time.

8. Should be frank.

9. Should not cheat.

10. Attends all classes -- rarely misses.

11. Does all homework and on time.

12. Knows how to take good notes.

13. Knows how to study hard.

14. Is a critical listener.

15. Has good health.

16. Has a plan for the future.

17. Uses study time effectively.

18. Wants to improve his/her skill/knowledge. 
19. Finishes all assignments.

20. Enlarges on the ideas of the lessons.

21. Researches and studies on his/her own.

22. Anticipates in class.

23. Makes friends with others.

24. Is helpful.

25. Is honest.

26. Is cheerful.

27. Has self confidence.

28. Has self respect.

29. Is rare in character.

30. Is gentle in everything.

31. Finds a good way to study.

32. Finds good and clever friends.

33. Learns from friends.

34. Pays attention in class.

35. Feedbacks in class.

36. Review notes day by day .

37. Respects instructors.

38. Respects classmates.

39. Depends on him/herself.

40. Is patient.

41. Should know why $\mathrm{s} /$ he is in college.

42. Should know how to get a good grade.

43. Should know how to get a job.

44. Should know how to realize personal fulfillment.

45. Cares about his/her work.

46. Likes to read.

47. Is organized. Has a calendar, a schedule.

48. Likes to go to class.

49. Tries to develop own knowledge.

50. Is ambitious.

51. Goes to an advisor if $s /$ he has problems.

52. Studies hard.

53. Is responsible.

54. Is serious.

55. Concentrates in class.

56. Sleeps at least 8 hours.

57. Has a good appearance.

58. Is well-groomed.

59. Asks questions when s/he doesn't understand.

60. Is enthusiastic.

61. Is eager to learn.

62. Is motivated.

63. Likes his/her major field of study.

64. Tries to uncierstand the subject.

65. Doesn't learn for the grade.

66. Participates in sport activities.

67. Recognizes how to use free time.

68. Reads outside school books. 
69. Selects a major of interest.

70. Tries to understand the class.

71. Tries to be interested in class.

72. Asks the teacher about problems.

73. Studies hard at home.

74. Doesn't cram.

75. Asks for clarification of unclear points.

76. Takes the number of credits according to his/her ability.

77. Reads carefully. 
APPENDIX G

STATISTICAL TABLES: VII, VIII,

$I X, X, X I, X I I, X I I I, X I V, X V$ 
TABLE VII

RESULTS OF RELIABILITY TESTING OF BEHAVIOR ITEMS:

STUDENT--HIGH GRADES AND PASSING

ITEM \# ON QUESTIONNAIRE**

1.

2 .

3.

4.

5.

6.

7.

8.

9.

10.

11.

12.

13.

14.

15.

16.

17.

18.

19.

20.

21.

22.

23.

24.
MEAN X

4.50

4.23

4.58

4.76

4.70

4.58

1.76

1.64

4.70

5.26

4.94

4.67

4.76

5.05

5.08

5.11

4.17

3.61

4.05

5.41

4.62

4.61

4.67

4.26
SD $\mathrm{X}$

1.26

1.20

1.28

1.18

1.08

1.28

1.82

.84

1. 36

1. 10

1.12

1.09

1.15

1.05

1.01

.87

1.19

1. 37

1.43

$$
.92
$$

.97

.92

1.49

1.52
MEAN Y

4.79

4.41

4.52

4.76

4.38

4.11

1.44

1.73

4.91

5.38

4.94

4.76

4.55

4.94

4.94

5.05

4.14

3.47

4.08

5.17

4.79

4.67

4.76

4.50
CORRELATION

SD Y COEFFICIENT

$.97 \quad .65$

$1.07 \quad .38$

$1.07 \quad .75$

$.95 \quad .67$

$1.12 \quad .51$

$1.06 \quad .41$

$.70 \quad .17$

$.82 \quad .55$

$1.08 \quad .55$

$.88 \quad .75$

$.81 \quad .32$

$.98 \quad .65$

$1.04 \quad .51$

$.96 \quad .52$

$.90 \quad .61$

$.77 \quad .52$

$1.18 \quad .62$

$1.28 \quad .62$

$1.23 \quad .74$

$.86 \quad .43$

$.84 \quad .61$

$.97 \quad .56$

$1.18 \quad .60$

$1.61 \quad .62$

** See Appendix B for copy of questionnaire.

KEY : $X=$ First generation of testing

$\mathrm{Y}=$ Second generation of testing

$\mathrm{SD}=$ Standard deviation

(Table VII continued on next page.) 
TABLE VII (continued)

ITEM \# ON QUESTIONNAIRE
MEAN X

25.

26.

27.

28.

29.

30 .

31.

32 .

33.

34.

35.

36.

37.

38.

39.

40.

41.

42.

43.

44.

45.

46.

47.

48.

49.

50.

51.

52.

3.97

5.52

4.50

4.97

3.55

3.85

4.61

4.32

4.55

3.91

4.70

3.52

3. 35

3.17

3.94

5.61

2.67

4.55

5.11

4.72

4.53

4.55

5.28

5.23

4.84

5.11

3.58

4.32
SD $\mathrm{X}$

1.26

.78

1.02

.99

1.56

1. 32

1.45

1.17

1.18

1. 33

.93

1. 35

1. 70

1.38

1. 20

.65

1.12

1.10

.96

1.55

1.20

1.10

.88

.84

.98

.97

1.25

1.14
4.26

5.38

4.55

4.97

3.61

3.70

4.76

4.35

4.58

3.94

4.88

3.67

3. 76

3.05

4.05

5.44

2.88

5.05

4.94

4.75

4.29

4.36

5.17

5.15

4.92

5.08

3.73

4.35
CORRELATION
SD Y COEFFICIENT

$1.16 \quad .68$

$.73 \quad .37$

$.99 \quad .22$

$.79 \quad .34$

$1.43 \quad .55$

$1.00 \quad .33$

$1.07 \quad .36$

.98

1.10

.23

.52

$.91 \quad .34$

$.94 \quad .57$

$\begin{array}{ll}.94 & .57 \\ 1.29 \quad .65\end{array}$

$1.45 \quad .59$

$1.32 . \in 2$

$.98 \quad .61$

$.70 \quad .64$

$1.09 \quad .56$

$.88 \quad .58$

$.96 \quad .63$

$1.47 \quad .81$

$1.07 \quad .68$

$1.05 \quad .67$

$.91 \quad .77$

$.90 \quad .50$

$1.01 \quad .48$

$1.02 \quad .47$

$\begin{array}{rr}.99 & .63 \\ 1.15 & .46\end{array}$

(Table VII continued on next page.) 
TABLE VII (continued)

\begin{tabular}{lrrrrr}
$\begin{array}{l}\text { ITEM \# ON } \\
\text { QUESTIONNAIRE }\end{array}$ & MEAN X & SD X & MEAN Y & SD Y & $\begin{array}{l}\text { CORRELATION } \\
\text { COEFFICIENT }\end{array}$ \\
\hline 53. & 1.85 & .95 & 2.20 & .88 & .61 \\
54. & 2.32 & 1.47 & 2.70 & 1.40 & .73 \\
55. & 4.58 & 1.51 & 5.14 & 1.15 & .55 \\
56. & 5.26 & .89 & 5.17 & .79 & .35 \\
57. & 5.20 & 1.03 & 5.38 & .92 & .61 \\
\hline
\end{tabular}


TABLE VIII

RESULTS OF RELIABILITY TESTING OF BEHAVIOR ITEMS:

STUDENT--UNDERSTANDING AND LEARNING

ITEM \# ON

MEAN X

SD $\mathrm{X}$

MEAN Y

CORRELATION

QUESTIONNAIRE**

1.

5.13

1.10

5.26

SDY COEFICIENI

2.

4.51

1.09

4.67

1.03

.21

3.

4.41

1. 30

4.67

1.20

.48

4.

5.05

1.01

4.94

1.03

.54

5.

5.14

.80

5.20

.91

.26

6.

4.64

1.03

4.51

.83

.47

7.

1.60

.97

1.68

.98

.61

8.

1.79

.91

1.85

.90

.82

9.

3.80

1.54

4.02

.82

.68

10.

4.35

1.32

4.70

1.18

.75

11.

4.97

.96

5.08

.97

.27

12.

5.38

.81

5.11

.79

.71

13.

5.00

.92

5.23

1.06

.15

14.

4.51

1.26

4.77

.85

.69

15.

4.23

1.20

4.38

1.00

.41

16.

4.26

1.25

4.38

.98

.60

17.

4.94

1.07

4.94

1.01

.58

18.

4.76

.98

4.79

.81

.41

19.

3.44

1.15

3.73

.97

.51

20.

5.29

.97

5.41

1.08

.50

21.

5.14

.78

5.20

.98

.78

22.

4.02

1.15

4.31

.68

.44

23.

2.44

1.15

3.05

1.07

.51

24.

2. 70

1.19

3. 35

1. 32

.75

1.47

.65

**See Appendix B for copy of questionnaire.

KEY : $X=$ First generation of testing

$Y=$ Second generation of testing

$\mathrm{SD}=$ Standard deviation

(Table VIII continued on next page.) 
TABLE VIII (continued)

ITEM \# ON QUESTIONNAIRE

25.

26.

27.

28.

29.

30 .

31.

32 .

33.

34.

35.

36.

37.

38.

39.

40 .

41.

42.

43.

44.

45.

46.

47.

48.

49.

50 .

51.

52 .
MEAN X

3.25

5.29

3.82

5.32

4.11

3.88

3.62

4.14

4.85

3.14

3.73

2.74

2.32

3.97

4.02

4.58

2.47

3.97

5.05

5.11

4.05

4.29

4.67

5.11

4.26

4.97

3.97

3.85
1.50

.90

1.35

.84

1.47

1.10

1.80

1.04

1.03

1.24

1.44

1.29

1.14

1.35

1.33

1.25

1.05

1.26

.81

.80

1.47

1.19

1.19

.72

1.16

.90

1.40

1.41
3.54

5.32

4.26

5.50

4. 32

3.82

3.70

3.94

4.68

3.42

3.94

2.91

2.58

4.20

4.11

4.73

2.88

4.26

4.88

5.00

4.02

4.32

4.61

5.08

4.47

4.91

3.73

3.94
CORRELATION

SD Y COEFFICIENT

$1.31 \quad .61$

$.84 \quad .74$

$.96 \quad .49$

$.66 \quad .46$

$1.29 \quad .51$

$1.01 \quad .37$

$1.39 \quad .39$

$1.22 \quad .64$

$.93 \quad .59$

$1.19 \quad .57$

$1.20 \quad .70$

$1.17 \quad .78$

$1.23 \quad .67$

$1.32 \quad .08$

$1.03 \quad .45$

$1.05 \quad .50$

$1.27 \quad .13$

$1.13 \quad .23$

$.80 \quad .42$

$1.15 \quad .61$

$1.33 \quad .49$

$.91 \quad .55$

$1.23 \quad .34$

$.83 \quad .18$

$1.10 \quad .27$

$.99 \quad .40$

$1.13 \quad .57$

$1.25 \quad .69$

(Table VIII continued on next page.) 
TABLE VIII (continued)

\begin{tabular}{lrrrrr}
$\begin{array}{l}\text { ITEM \# ON } \\
\text { QUESTIONNAIRE }\end{array}$ & MEAN X & SD X & MEAN Y & SD Y & $\begin{array}{c}\text { CORRELATION } \\
\text { COEFFICIENT }\end{array}$ \\
\hline 53. & 2.08 & .86 & 2.17 & .99 & .47 \\
54. & 2.44 & 1.13 & 2.70 & 1.36 & .57 \\
55. & 2.47 & 1.37 & 2.97 & 1.56 & .63 \\
56. & 4.97 & .83 & 4.91 & 1.08 & .29 \\
57. & 5.58 & .60 & 5.41 & 1.04 & .55 \\
\hline
\end{tabular}


TARLE IX

RESULTS OF RELIABILITY TESTING OF BEHAVIOR ITEMS : PROFESSOR

ITEM \# ON MEAN

$\sin x$

MEAN $Y$

CORREIATION

QUESTIONNAIRE**

SD $\mathrm{X}$

1.

4.03

.78

3.84

1.01

COEFFICIENT

2 .

3.56

1.21

3.78

1.06

.53

3.

3.93

1.04

3.56

1.26

.76

4.

4.43

1.10

4.81

.93

.75

5.

5.53

.76

5.46

.67

.80

6.

4.21

1.09

4.40

.75

.19

7.

5.43

.66

5.53

.67

.47

8.

4.75

.70

4.66

.69

.54

9.

3.62

1.33

3.71

1.22

.59

10.

3.28

1. 39

3.50

1.13

.81

11.

2.68

.99

2.68

.85

.66

12.

4.96

.86

4.93

1.07

.29

13.

2.46

87

2.56

.94

.62

14.

4.56

1.34

4.59

1.24

.52

15.

5.21

.79

5.25

.80

.66

16.

5.15

1.05

5.31

.82

.62

17.

3.93

1.38

3. 78

1.21

.68

18.

4.15

1.22

4.43

.98

.66

19.

5.12

.79

5.12

.75

.58

20.

4.43

.80

4.53

1.16

.51

21.

3.18

1.10

3.39

.99

.53

22.

4.34

1.06

4.40

.35

23.

4.93

.84

4.65

.75

.58

24.

5.21

.79

5.21

.86

.67

.65

.27

** See Appendix B for copy of questionnaire.

KEY : $X=$ First generation of testing

$Y=$ Second generation of testing

$S D=$ Standard deviation

(Table IX continued on next page.) 
TABLE IX (continued)

ITEM \# ON QUESTIONNAIRE

25.

26.

27.

28.

29.

30 .

31.

32 .

33.

34.

35.

36.

37.

38.

39.

40.

41.

42 .

43.

44.

45.

46.

47.

48.

49.

50 .

51.

52.
MEAN X

4.62

4.25

4. 34

3.09

3.25

3.87

3.68

4.84

3.71

5.40

2.53

5.21

4.37

1. 31

1.65

3.78

5.40

4.03

4.18

4.43

4.43

5.45

4.56

5.50

4.71

5.19

2.87

2.74
SD X

.94

1.16

.93

1.25

1.27

1.31

1.44

.95

1.22

.75

1.04

.79

1.07

.64

.93

1.40

.55

1. 30

1.28

1.10

.91

.66

1.13

.76

1.05

.90

1.28

1.34
4.43

4.29

4.34

3.37

3.34

4.03

3.71

4.84

3.75

5.09

2.78

4.96

4.53

1.40

1.75

3.96

5.50

4.31

4.25

4.40

4.53

5.33

4.37

5.31

4.56

5.16

2.68

3.03
1.16

1.00

.93

1.09

1.09

1. 30

1.08

.84

1. 31

.68

1. 36

.59

.94

.71

.91

1.06

.56

1.40

1.10

.75

.84

.73

.87

.73

1.26

.73

1.40

.98

CORRELATION

COEFFICIENT

50

.54

.37

.32

.58

.60

.49

.68

.75

.41

.37

.49

.52

.41

.61

.44

.45

.54

.39

.47

.31

.57

.66

.74

.70

.79

.54

.76 
TABLE IX (continued)

\begin{tabular}{lrrrrr}
$\begin{array}{l}\text { ITEM \# ON } \\
\text { QUESTIONNAIRE }\end{array}$ & MEAN X & SD X & MEAN Y & SD Y $\begin{array}{l}\text { CORRELATION } \\
\text { COEFFICIENT }\end{array}$ \\
\hline 53. & 3.12 & 1.09 & 3.37 & .90 & .75 \\
54. & 4.31 & 1.28 & 4.28 & 1.14 & .62 \\
55. & 5.53 & .56 & 5.12 & .87 & .31 \\
56. & 3.37 & 1.07 & 3.50 & .95 & .31 \\
57. & 4.93 & 1.04 & 5.37 & .55 & .20 \\
58. & 5.18 & .85 & 5.50 & .62 & .42 \\
59. & 3.44 & 1.37 & 3.85 & 1.32 & .66 \\
60. & 3.94 & 1.25 & 4.08 & 1.02 & .54 \\
61. & 5.47 & .65 & 5.41 & .76 & .73 \\
\hline
\end{tabular}


TABLE X

CONDENSED RESULTS OF T-TESTS FOR COMPARISON OF INDEPENDENT SAMPLES :

SIGNIFICANCE LEVEL AND DIFFERENCE BETWEEN THE MEANS OF COMPARED SUBJECT GROUPS FOR EACH ITEM

\begin{tabular}{|c|c|c|c|c|}
\hline ITEM \# & NAME & $\begin{array}{l}\text { INT'L STUDENT } \\
\text { AMER STUDENT }\end{array}$ & $\begin{array}{l}\text { INT'L STUDENT } \\
\text { AMER PROFESSOR }\end{array}$ & $\begin{array}{l}\text { AMER STUDENT } \\
\text { AMER PROFESSOR } \\
\end{array}$ \\
\hline 1. & HGPPUR & $\begin{array}{l}.553 \\
.1017\end{array}$ & $\begin{array}{l}.306 \\
.1857\end{array}$ & $\begin{array}{l}.598 \\
.0840\end{array}$ \\
\hline 2. & HGPCON & $\begin{array}{l}.316 \\
.1764\end{array}$ & $\begin{array}{l}.446 \\
.1480\end{array}$ & $\begin{array}{l}.038 \\
.3244\end{array}$ \\
\hline 3. & HGPCRIT & $\begin{array}{l}.152 \\
.2488\end{array}$ & $\begin{array}{l}.100 \\
.2942\end{array}$ & $\begin{array}{l}.000 \\
.543\end{array}$ \\
\hline 4. & HGPREQ & $\begin{array}{l}.036 \\
.2876\end{array}$ & $\begin{array}{l}.797 \\
.0403\end{array}$ & $\begin{array}{l}.046 \\
.2473\end{array}$ \\
\hline 5. & HGPLIS & $\begin{array}{l}.013 \\
.5002\end{array}$ & $\begin{array}{l}.000 \\
.0938\end{array}$ & $\begin{array}{l}.002 \\
.4836\end{array}$ \\
\hline 6. & HGPMEM & $\begin{array}{l}.845 \\
.039\end{array}$ & $\begin{array}{l}.163 \\
.3229\end{array}$ & $\begin{array}{l}.120 \\
.2839\end{array}$ \\
\hline 7. & HGPTYPE & $\begin{array}{l}.000 \\
.8704\end{array}$ & $\begin{array}{l}.070 \\
.8799\end{array}$ & $\begin{array}{l}.954 \\
.0095\end{array}$ \\
\hline 8. & HGPABS & $\begin{array}{l}.219 \\
.2351\end{array}$ & $\begin{array}{l}.197 \\
.2794\end{array}$ & $\begin{array}{l}.789 \\
.0443\end{array}$ \\
\hline 9. & HGPINF & $\begin{array}{l}.804 \\
.0527\end{array}$ & $\begin{array}{l}.778 \\
.0672\end{array}$ & $\begin{array}{l}.937 \\
.0145\end{array}$ \\
\hline 10. & HGPIMAG & $\begin{array}{l}.000 \\
.6931\end{array}$ & $\begin{array}{l}.000 \\
.969\end{array}$ & $\begin{array}{l}.108 \\
.2759\end{array}$ \\
\hline 11. & HGPINT & $\begin{array}{l}.988 \\
.0023\end{array}$ & $\begin{array}{l}.446 \\
.1367\end{array}$ & $\begin{array}{l}.312 \\
.1393\end{array}$ \\
\hline 12. & HGPEXC & $\begin{array}{r}.000 \\
1.326\end{array}$ & $\begin{array}{c}.000 \\
1.6834\end{array}$ & $\begin{array}{l}.105 \\
.3574\end{array}$ \\
\hline
\end{tabular}

KEY: Top figure represents the level of significance of the calculated difference.

Lower figure represents the difference between the means of the two populations being compared.

(Table $X$ continued on next page.) 
TABLE X (continued)

\begin{tabular}{|c|c|c|c|c|}
\hline ITEM 非 & NAME & $\begin{array}{l}\text { INT'L STUDENT } \\
\text { AMER STUDENT }\end{array}$ & $\begin{array}{l}\text { INT'L STUDENT } \\
\text { AMER PROFESSOR }\end{array}$ & $\begin{array}{l}\text { AMER STUDENT } \\
\text { AMER PROFESSOR } \\
\end{array}$ \\
\hline 13. & HGPCOUR & $\begin{array}{l}.000 \\
.8546\end{array}$ & $\begin{array}{l}.000 \\
.9395\end{array}$ & $\begin{array}{l}.651 \\
.0849\end{array}$ \\
\hline 14. & UALCOUR2 & $\begin{array}{l}.000 \\
.9541\end{array}$ & $\begin{array}{l}.012 \\
.6383\end{array}$ & $\begin{array}{l}.071 \\
.3158\end{array}$ \\
\hline 15. & UALSMOKE & $\begin{array}{l}.422 \\
.1454\end{array}$ & $\begin{array}{l}.054 \\
.3757\end{array}$ & $\begin{array}{l}.158 \\
.2303\end{array}$ \\
\hline 16. & UALING & $\begin{array}{l}.189 \\
.2484\end{array}$ & $\begin{array}{l}.172 \\
.2838\end{array}$ & $\begin{array}{l}.826 \\
.0354\end{array}$ \\
\hline 17. & UALAUTH & $\begin{array}{l}.042 \\
.4337\end{array}$ & $\begin{array}{l}.006 \\
. .7097\end{array}$ & $\begin{array}{l}.243 \\
.1911\end{array}$ \\
\hline 18. & UALPART & $\begin{array}{l}.396 \\
.1213\end{array}$ & $\begin{array}{l}.504 \\
.1056\end{array}$ & $\begin{array}{l}.868 \\
.018\end{array}$ \\
\hline 19. & UALREAD & $\begin{array}{l}.231 \\
.204\end{array}$ & $\begin{array}{l}.000 \\
.6096\end{array}$ & $\begin{array}{l}.179 \\
.4056\end{array}$ \\
\hline 20 . & UALNOTE & $\begin{array}{l}.155 \\
.2285\end{array}$ & $\begin{array}{l}.887 \\
.024\end{array}$ & $\begin{array}{l}.090 \\
.2045\end{array}$ \\
\hline 21 & UALSLANT & $\begin{array}{l}.000 \\
1.1042\end{array}$ & $\begin{array}{l}.000 \\
.8756\end{array}$ & $\begin{array}{l}.179 \\
.2286\end{array}$ \\
\hline 22. & UALGRADE & $\begin{array}{l}.000 \\
.8114\end{array}$ & $\begin{array}{l}.001 \\
.8204\end{array}$ & $\begin{array}{l}.960 \\
.009\end{array}$ \\
\hline 23. & UALATTND & $\begin{array}{l}.283 \\
.1534\end{array}$ & $\begin{array}{l}.925 \\
.0144\end{array}$ & $\begin{array}{l}.189 \\
.1390\end{array}$ \\
\hline 24. & UALDIRCT & $\begin{array}{l}.000 \\
.902\end{array}$ & $\begin{array}{l}.000 \\
.9245\end{array}$ & $\begin{array}{l}.895 \\
.220\end{array}$ \\
\hline 25 . & UALCMPRE & $\begin{array}{l}.043 \\
.4351\end{array}$ & $\begin{array}{l}.070 \\
.4094\end{array}$ & $\begin{array}{l}.872 \\
.0257\end{array}$ \\
\hline 26. & UALRAISE & $\begin{array}{l}.000 \\
1.2202\end{array}$ & $\begin{array}{c}.000 \\
1.4073\end{array}$ & $\begin{array}{l}.246 \\
.1871\end{array}$ \\
\hline
\end{tabular}

(Table $\mathrm{X}$ continued on next page.) 
TABLE X (continued)

\begin{tabular}{|c|c|c|c|c|}
\hline ITEM 非 & NAME & $\begin{array}{l}\text { INT'L STUDENT } \\
\text { AMER STUDENT }\end{array}$ & $\begin{array}{l}\text { INT'L STUDENT } \\
\text { AMER PROFESSOR }\end{array}$ & $\begin{array}{l}\text { AMER STUDENT } \\
\text { AMER PROFESSOR }\end{array}$ \\
\hline 27. & PROFTEST & $\begin{array}{l}.040 \\
.3791\end{array}$ & $\begin{array}{l}.362 \\
.1905\end{array}$ & $\begin{array}{l}.001 \\
.5696\end{array}$ \\
\hline 28. & PROFPRFM & $\begin{array}{l}.000 \\
.7743\end{array}$ & $\begin{array}{l}.001 \\
.6575\end{array}$ & $\begin{array}{l}.468 \\
.1168\end{array}$ \\
\hline 29 . & PROFQUES & $\begin{array}{l}.024 \\
.4208\end{array}$ & $\begin{array}{l}.000 \\
.7927\end{array}$ & $\begin{array}{l}.030 \\
.3719\end{array}$ \\
\hline 30. & PROFQUT & $\begin{array}{l}.001 \\
.7401\end{array}$ & $\begin{array}{l}.000 \\
.9254\end{array}$ & $\begin{array}{l}.358 \\
.1853\end{array}$ \\
\hline 31. & PROFPERS & $\begin{array}{l}.011 \\
.5095\end{array}$ & $\begin{array}{l}.126 \\
.3528\end{array}$ & $\begin{array}{l}.391 \\
.1567\end{array}$ \\
\hline 32. & PROFFORM & $\begin{array}{l}.001 \\
.6309\end{array}$ & $\begin{array}{l}.000 \\
.6802\end{array}$ & $\begin{array}{l}.391 \\
.0493\end{array}$ \\
\hline 33. & PROFSPK & $\begin{array}{l}.071 \\
.2622\end{array}$ & $\begin{array}{l}.000 \\
.5787\end{array}$ & $\begin{array}{l}.671 \\
.3165\end{array}$ \\
\hline 34. & PROFRTRN & $\begin{array}{l}.769 \\
.0418\end{array}$ & $\begin{array}{l}.792 \\
.0387\end{array}$ & $\begin{array}{l}.981 \\
.0031\end{array}$ \\
\hline 35. & PROFOPIN & $\begin{array}{l}.120 \\
.1875\end{array}$ & $\begin{array}{l}.017 \\
.3149\end{array}$ & $\begin{array}{l}.192 \\
.1272\end{array}$ \\
\hline 36. & PROFMATR & $\begin{array}{l}.056 \\
.3886\end{array}$ & $\begin{array}{l}.007 \\
.5848\end{array}$ & $\begin{array}{l}.000 \\
.9734\end{array}$ \\
\hline 37. & PROFINVT & $\begin{array}{l}.383 \\
.17\end{array}$ & $\begin{array}{l}.896 \\
.0278\end{array}$ & $\begin{array}{l}.261 \\
.1978\end{array}$ \\
\hline 38. & PROFHRS & $\begin{array}{l}.000 \\
.6805\end{array}$ & $\begin{array}{l}.001 \\
.5542\end{array}$ & $\begin{array}{l}.164 \\
.1263\end{array}$ \\
\hline 39. & PROFAVLB & $\begin{array}{l}.242 \\
.2095\end{array}$ & $\begin{array}{l}.003 \\
.6347\end{array}$ & $\begin{array}{l}.013 \\
.4252\end{array}$ \\
\hline 40 & PROFNAME & $\begin{array}{l}.389 \\
.1444\end{array}$ & $\begin{array}{l}.666 \\
.0768\end{array}$ & $\begin{array}{l}.644 \\
.676\end{array}$ \\
\hline
\end{tabular}

(Table $X$ continued on next page.) 
TABLE X (continued)

\begin{tabular}{|c|c|c|c|c|}
\hline ITEM \# & NAME & $\begin{array}{l}\text { INT'I STUDENT } \\
\text { AMER STUDENT }\end{array}$ & $\begin{array}{l}\text { INT'L STUDENT } \\
\text { iMER PROFESSOR }\end{array}$ & $\begin{array}{l}\text { AMER STUDENT } \\
\text { AMER PROFESSOR }\end{array}$ \\
\hline 41. & PROFPERM & $\begin{array}{l}.014 \\
.4577\end{array}$ & $\begin{array}{l}.086 \\
.3792\end{array}$ & $\begin{array}{l}.658 \\
.785\end{array}$ \\
\hline 42. & PROFQUIZ & $\begin{array}{l}.080 \\
.3202\end{array}$ & $\begin{array}{l}.013 \\
.4953\end{array}$ & $\begin{array}{l}.242 \\
.1751\end{array}$ \\
\hline 43. & PROFLANG & $\begin{array}{l}.134 \\
.3249\end{array}$ & $\begin{array}{l}.015 \\
.5875\end{array}$ & $\begin{array}{l}.000 \\
.9169\end{array}$ \\
\hline 44. & PROFDED & $\begin{array}{l}.000 \\
.6737\end{array}$ & $\begin{array}{l}.000 \\
.9325\end{array}$ & $\begin{array}{l}.008 \\
.2588\end{array}$ \\
\hline 45. & PROFINFR & $\begin{array}{l}.010 \\
.5395\end{array}$ & $\begin{array}{l}.005 \\
.6839\end{array}$ & $\begin{array}{l}.000 \\
1.2235\end{array}$ \\
\hline
\end{tabular}


TABLE XI

T-TEST RESULTS FOR COMPARISON OF GROUPS :

INTERNATIONAL STUDENTS WITH

AMERI CAN STUDENTS

\begin{tabular}{|c|c|c|c|c|c|c|}
\hline ITEM & NAME & MEAN AS & MEAN IS & DIF. & VALUE $T$ & SIGNIFICANCE \\
\hline 1. & HGPPUR & 5.584 & 5.6857 & .1017 & -0.59 & .553 \\
\hline 2. & HGPCON & 4.9498 & 5.1262 & .1764 & -1.00 & .316 \\
\hline 3. & HGPCRIT & 4.9454 & 5.1942 & .2488 & -1.44 & .152 \\
\hline 4. & HG?REQ & 6.2395 & 5.9519 & .2876 & 2.11 & .036 \\
\hline 5. & HGPLIS & 5.3924 & 4.8922 & .5002 & 2.51 & .103 \\
\hline 6. & HGPMEM & 4.8745 & 4.9135 & .039 & -0.20 & .845 \\
\hline 7. & HGPTYPE & 4.3655 & 3.4951 & .8704 & 3.91 & .000 \\
\hline 8. & HGPABS & 5.0756 & 5.4107 & .2351 & -1.23 & .219 \\
\hline 9. & HGPINF & 4.4351 & 4.3824 & .0527 & 0.25 & .804 \\
\hline 10. & HGPIMAG & 4.8193 & 4.1262 & .6931 & 3.55 & .000 \\
\hline 11. & HGPINT & 5.4723 & 5.4700 & .0023 & 0.01 & .988 \\
\hline 12. & HGPEXC & 3.2954 & 4.1089 & 1.326 & -5.71 & .000 \\
\hline 13. & HGPCOUR & 3.2543 & 4.1089 & .8546 & -3.97 & .000 \\
\hline 14. & UALCOUR2 & 2.6842 & 3.6383 & .9541 & -3.95 & .000 \\
\hline 15. & UALSMOKE & 2.0217 & 1.8763 & .1454 & .80 & .422 \\
\hline 16. & UAIING & 2.6130 & 2.3646 & .2484 & 1.32 & .189 \\
\hline 17 . & UALAUTH & 3.8761 & 4.2947 & .4337 & -2.04 & .042 \\
\hline 18. & UALPART & 6.1653 & 6.0417 & .1213 & .85 & .396 \\
\hline 19. & UALREAD & 6.1525 & 5.9485 & .204 & 1.20 & .231 \\
\hline 20. & UALNOTE & 6.1660 & 5.9375 & .2285 & 1.43 & .155 \\
\hline 21. & UALSLANT & 2.9277 & 4.0319 & 1.1042 & -5.53 & .000 \\
\hline 22 & UALGRADE & 3.1574 & 3.9688 & .8114 & -3.86 & .000 \\
\hline 23. & UALATTND & 6.3390 & 6.1856 & .1534 & 1.08 & .283 \\
\hline 24. & UALDIRCT & 4.1709 & 5.0729 & .902 & -4.60 & .000 \\
\hline 25 . & UALCMPRE & 2.5128 & 2.9479 & .4351 & -2.04 & .043 \\
\hline
\end{tabular}

KEY $:$ AS = American Students (Table XI continued on next page.)

IS = International Students

$D I F=$ Difference between the mean scores 
TABLE XI (continued)

\begin{tabular}{|c|c|c|c|c|c|c|}
\hline ITEM 非 & NAME & MEAN AS & MEAN IS & $\mathrm{DIF}$. & VALUE $T$ & SIGNIFICANCE \\
\hline 26. & UALRAISE & 3.7179 & 4.9381 & 1.2202 & -5.87 & .000 \\
\hline 27. & PROFTEST & 3.4304 & 3.8095 & .3791 & -2.06 & .040 \\
\hline 28. & PROFPRFM & 3.6723 & 4.4466 & .7743 & -4.26 & .000 \\
\hline 29. & PROFQUES & 4.9578 & 5.3786 & .4208 & -2.26 & .024 \\
\hline 30. & PROFQUT & 3.3361 & 4.0762 & .7401 & -3.36 & .001 \\
\hline 31. & PROFPERS & 4.0714 & 3.5619 & .5095 & 2.55 & .011 \\
\hline 32. & PROFFORM & 5.8101 & 5.1792 & .6309 & 3.37 & .001 \\
\hline 33. & PROFSPK & 6.1757 & 5.9135 & .2622 & 1.82 & .071 \\
\hline 34. & PROFRTRN & 5.6766 & 5.7184 & .0418 & -0.29 & .769 \\
\hline 35. & PROFOPIN & 6.0837 & 5.8962 & .1875 & 1.56 & .120 \\
\hline 36. & PROFMATR & 3.9706 & 4.3592 & .3886 & -1.92 & .056 \\
\hline 37. & PROFINVT & 4.8494 & 5.0194 & .17 & -0.87 & .383 \\
\hline 38. & PROFHRS & 6.4519 & 5.7714 & .6805 & 4.42 & .000 \\
\hline 39. & PROFAVLB & 5.0000 & 5.2095 & .2095 & -1.17 & .242 \\
\hline 40. & PROFNAME & 5.3933 & 5.5377 & .1444 & -0.86 & .389 \\
\hline 41. & PROFPERM & 3.7731 & 4.2308 & .4577 & -2.47 & .014 \\
\hline 42. & PROFQUIZ & 3.5924 & 3.9126 & .3202 & -1.76 & .080 \\
\hline 43. & PROFLANG & 3.4958 & 3.8252 & .3294 & -1.50 & .134 \\
\hline 44. & PROFDED & 6.2218 & 5.5481 & .6737 & 4.52 & .000 \\
\hline 45. & PROFINFR & 4.7511 & 4.2115 & .5395 & 2.58 & .010 \\
\hline
\end{tabular}


TABLE XII

T-TEST RESULTS FOR COMPARISON OF GROUPS : INTERNATIONAL STUDENTS WITH AMERICAN PROFESSORS

\begin{tabular}{|c|c|c|c|c|c|c|}
\hline ITEM & NAME & MEAN IS & MEAN AP & DIF. & VALUE $\mathrm{T}$ & SIGNI FICANCE \\
\hline 1. & HGPPUR & 5.6857 & 5.5000 & .1857 & 1.03 & .306 \\
\hline 2. & HGPCON & 5.1262 & 5.2742 & .1480 & -0.76 & .446 \\
\hline 3. & HGPCRIT & 5.1942 & 5.4884 & .2942 & -1.65 & .100 \\
\hline 4. & HGPREQ & 5.9519 & 5.9922 & .0403 & -0.26 & .797 \\
\hline 5. & HGPIIS & 4.8922 & 5.8760 & .9838 & -4.71 & .000 \\
\hline 6. & HGPMEM & 4.9135 & 4.5906 & .3229 & 1.40 & .163 \\
\hline 7. & HGPTYPE & 3.4951 & 4.3750 & .8799 & -3.82 & .000 \\
\hline 8. & HGPABS & 5.3107 & 5.0313 & .2794 & 1.29 & .197 \\
\hline 9. & HGPINF & 4.3824 & 4.4496 & .0672 & -0.28 & .778 \\
\hline 10 & HGPIMAG & 4.126 .2 & 5.0952 & .969 & -4.48 & .000 \\
\hline 11. & HGPINT & 5.4700 & 5.3333 & .1376 & 0.76 & .445 \\
\hline 12. & HGPEXC & 4.6214 & 2.9380 & 1.6834 & 6.80 & .000 \\
\hline 13. & HGPCOUR & 4.1089 & 3.1694 & .9395 & 3.95 & .000 \\
\hline 14. & UAICOUR2 & 3.6383 & 3.0000 & .6383 & 2.53 & .012 \\
\hline 15. & UALSMOKE & 1.8763 & 2.2520 & .3757 & -1.94 & .054 \\
\hline 16. & UALING & 2.3646 & 2.6484 & .2838 & -1.37 & .172 \\
\hline 17. & UALAUTH & 4.2947 & 3.6850 & .7097 & 2.79 & .006 \\
\hline 18. & UALPART & 6.0417 & 4.1473 & .1056 & -0.67 & .504 \\
\hline 19. & UALREAD & 5.9485 & 5.4481 & .6096 & -3.76 & .000 \\
\hline 20. & UALNOTE & 5.9375 & 5.9615 & .042 & -0.14 & .887 \\
\hline 21. & UALSLANT & 4.0319 & 3.1563 & .8756 & 4.06 & .000 \\
\hline 22. & UALGRADE & 3.9611 & 3.1484 & .8204 & 3.48 & .001 \\
\hline 23. & UALATTND & 6.1856 & 6.2000 & .0144 & -0.09 & .925 \\
\hline 24. & UALDIRCT & 5.072 & 4.1484 & .9245 & 4.36 & .000 \\
\hline 25. & UALCMPRE & 2.9479 & 2.5385 & .4094 & 1.83 & .070 \\
\hline
\end{tabular}

KEY $:$ IS = International Students (Table XII continued on next page.) $\mathrm{AP}=$ American Professors DIF $=$ Difference between mean scores 
TABLE XII (continued)

\begin{tabular}{|c|c|c|c|c|c|c|}
\hline ITEM & NAME & MEAN IS & MEAN AP & DIF. & VALUE $T$ & SI GNI FI CANCE \\
\hline 26. & UALRAISE & 4.9381 & 3.5308 & 1.4073 & 6.43 & .000 \\
\hline 27. & PROFTEST & 3.8095 & 4.0000 & .1905 & -0.91 & .362 \\
\hline 28. & PROFPRFM & 4.4466 & 3.7891 & .6575 & 3.31 & .001 \\
\hline 29 . & PROFQUES & 5.3786 & 4.5859 & .7927 & 4.03 & .000 \\
\hline 30. & PROFQUT & 4.0762 & 3.1508 & .9254 & 3.81 & .000 \\
\hline 31. & PROFPERS & 3.5619 & 3.9147 & .3528 & -1.54 & .126 \\
\hline 32. & PROFFORM & 5.1792 & 5.8594 & .6802 & -3.62 & .000 \\
\hline 33. & PROFSPK & 5.9135 & 6.4922 & .5787 & -4.07 & .000 \\
\hline 34. & PROFRTRN & 5.7184 & 5.6797 & .0387 & 0.26 & .792 \\
\hline 35 . & PROFOPIN & 5.8962 & 6.2109 & .3194 & -2.40 & .017 \\
\hline 36. & PROFMATR & 4.3592 & 4.9440 & .5848 & -2.72 & .007 \\
\hline 37. & PROFINVT & 5.0194 & 5.0472 & .0278 & -0.13 & .896 \\
\hline 38. & PROFHRS & 5.7714 & 6.3256 & .5542 & -3.39 & .001 \\
\hline 39. & PROFAVLB & 5.2095 & 4.5748 & .6347 & 3.05 & .003 \\
\hline 40. & PROFNAME & 5.5377 & 5.4609 & .0768 & 0.43 & .666 \\
\hline 41. & PROFPERM & 4.2308 & 3.8516 & .3792 & 1.72 & .086 \\
\hline 42. & PROFQUIZ & 3.9126 & 3.4173 & .4953 & 2.51 & .013 \\
\hline 43. & PROFLANG & 3.8252 & 4.4127 & .5875 & -2.45 & .015 \\
\hline 44. & PROFDED & 5.5481 & 6.4806 & .9325 & -6.21 & .000 \\
\hline 45. & PROFINFR & 4.2115 & 3.5276 & .6839 & 2.87 & .005 \\
\hline
\end{tabular}


TABLE XIII

T-TEST RESULTS FOR COMPARISON OF GROUPS: AMERICAN STUDENTS WITH AMERI CAN PROFESSORS

\begin{tabular}{|c|c|c|c|c|c|c|}
\hline ITEM 非 & NAME & MEAN AS & MEAN AP & DIF. & VALUE $T$ & SIGNIFI CANCE \\
\hline 1. & HGPPUR & 5.5840 & 5.5000 & .0840 & 0.53 & .598 \\
\hline 2. & HGPCON & 4.9498 & 5.2742 & .3244 & -2.09 & .038 \\
\hline 3. & HGPCRIT & 4.9454 & 5.4884 & .543 & -3.80 & .000 \\
\hline 4. & HGPREQ & 6.2395 & 5.9922 & .2473 & 2.00 & .046 \\
\hline 5. & HGPLIS & 5.3924 & 5.8760 & .4836 & -3.15 & .002 \\
\hline 6. & HGPMEM & 4.8745 & 4.5906 & .2839 & 1.56 & .120 \\
\hline 7. & HGPTYPE & 4.3655 & 4.3750 & .0095 & -0.06 & .954 \\
\hline 8. & HGPABS & 5.0756 & 5.0313 & .0443 & 0.27 & .789 \\
\hline 9. & HGPINF & 4.4351 & 4.4496 & .0145 & -0.08 & .937 \\
\hline 10. & HGPIMAG & 4.8193 & 5.0952 & .2759 & -1.61 & .108 \\
\hline 11. & HGPINT & 5.4723 & 5.3333 & .1393 & 1.01 & .312 \\
\hline 12. & HGPEXC & 3.2954 & 2.9380 & .3574 & 1.63 & .105 \\
\hline 13. & HGP COUR & 3.2543 & 3.1694 & .0849 & 0.45 & .651 \\
\hline 14. & UALCOUR2 & 2.6842 & 3.0000 & .3158 & -1.81 & .071 \\
\hline 15. & UALSMOKE & 2.0217 & 2.2520 & .2303 & -1.41 & .158 \\
\hline 16. & UALING & 2.6130 & 2.6484 & .0354 & -0.22 & .826 \\
\hline 17. & UALAUTH & 3.8761 & 3.6850 & .1911 & 1.17 & .243 \\
\hline 18. & UALPART & 6.1653 & 6.1473 & .018 & 0.17 & .868 \\
\hline 19. & UALREAD & 6.1525 & 6.5581 & .4056 & -3.92 & .000 \\
\hline 20 . & UALNOTE & 6.1660 & 5.9615 & .2045 & 1.70 & .090 \\
\hline 21. & UALSLANT & 2.9277 & 3.1563 & .2286 & -1.35 & .179 \\
\hline 22 . & UALGRADE & 3.1574 & 3.1484 & .009 & 0.05 & .960 \\
\hline 23. & UAIATTND & 6.3390 & 6.2000 & .1390 & 1.32 & .189 \\
\hline 24. & UALDI RCT & 4.1709 & 4.1484 & .220 & 0.13 & .895 \\
\hline 25 . & UALCMPRE & 2.5128 & 2.5385 & .0257 & -0.16 & .872 \\
\hline
\end{tabular}


TABLE XIII (continued)

\begin{tabular}{|c|c|c|c|c|c|c|}
\hline ITEM \# & NAME & MEAN AS & MEAN AP & DIF. & VALUE T & SIGNIFICANCE \\
\hline 26. & UALRAISE & 3.7179 & 3.5308 & .1871 & 1.16 & .246 \\
\hline 27. & PROFTEST & 3.4304 & 4.0000 & .5696 & $-3,36$ & .001 \\
\hline 28. & PROFPRFM & 3.6723 & 3.7891 & .1168 & -0.73 & .468 \\
\hline 29. & PROFQUES & 4.9578 & 4.5859 & .3719 & 2.18 & .030 \\
\hline 30. & PROFQUT & 3.3361 & 3.1508 & .1853 & 0.92 & .358 \\
\hline 31. & PROFPERS & 4.0714 & 3.9147 & .1567 & 0.86 & .391 \\
\hline 32. & PROFFORM & 5.8101 & 5.8594 & .0493 & -0.43 & .671 \\
\hline 33. & PROFSPK & 6.1757 & 6.4922 & .3165 & -3.34 & .001 \\
\hline 34. & PROFRTRN & 5.6766 & 5.6797 & .0031 & -0.02 & .981 \\
\hline 35. & PROFOPIN & 6.0837 & 6.2109 & .1272 & -1.31 & .192 \\
\hline 36. & PROFMATR & 3.9706 & 4.9440 & .9734 & -5.95 & .000 \\
\hline 37. & PROFINVT & 4.8494 & 5.0472 & .1978 & -1.12 & .261 \\
\hline 38. & PROFHRS & 6.4519 & 6.3256 & .1263 & 1.39 & .164 \\
\hline 39. & PROFAVLB & 5.0000 & 4.5748 & .4252 & 2.49 & .013 \\
\hline 40. & PROFNAME & 5.3933 & 5.4609 & .676 & -0.49 & .626 \\
\hline 41. & PROFPERM & 3.7731 & 3.8516 & .785 & -0.44 & .658 \\
\hline 42. & PROFQUIZ & 3.5924 & 3.4173 & .1751 & 1.17 & .242 \\
\hline 43. & PROFLANG & 3.4958 & 4.4127 & .9169 & -4.51 & .000 \\
\hline 44. & PROFDED & 6.2218 & 6.4806 & .2588 & -2.68 & .008 \\
\hline 45. & PROFINFR & 4.7511 & 3.5276 & 1.2235 & 6.56 & .000 \\
\hline
\end{tabular}


TABLE XIV

NORMATIVE STRUCTURES OF ROLE BEHAVIOR ITEMS:

SUBJECT GROUPS' COLLAPSED EVALUATION

RATINGS OF EACH ITEM

ITEM \# NAME PROBABILITY GROUP UNDESIRABLE (\%) NEUTRAL (\%) DESIRABLE (\%)

\begin{tabular}{|c|c|c|c|c|c|}
\hline 1. & $\begin{array}{l}\text { HGPPUR } \\
p=.9618\end{array}$ & $\begin{array}{l}\text { AS } \\
\text { AP } \\
\text { IS }\end{array}$ & $\begin{array}{r}10.5 \\
7.8 \\
9.5\end{array}$ & $\begin{array}{l}10.9 \\
12.4 \\
13.3\end{array}$ & $\begin{array}{l}78.6 \\
78.1 \\
78.9\end{array}$ \\
\hline 2. & $\begin{array}{l}\text { HGPCON } \\
\mathrm{p}=.5542\end{array}$ & $\begin{array}{l}\text { AS } \\
\text { AP } \\
\text { IS }\end{array}$ & $\begin{array}{r}14.6 \\
8.1 \\
12.6\end{array}$ & $\begin{array}{l}20.9 \\
16.1 \\
17.5\end{array}$ & $\begin{array}{l}64.4 \\
75.8 \\
69.9\end{array}$ \\
\hline 3. & $\begin{array}{l}\text { HGPCRIT } \\
p=.0414\end{array}$ & $\begin{array}{l}\text { AS } \\
\mathrm{AP} \\
\text { IS }\end{array}$ & $\begin{array}{r}17.2 \\
3.9 \\
13.6\end{array}$ & $\begin{array}{r}17.6 \\
7.0 \\
14.6\end{array}$ & $\begin{array}{l}65.1 \\
89.1 \\
71.8\end{array}$ \\
\hline 4. & $\begin{array}{l}\text { HGPREQ } \\
\mathrm{p}=.0527\end{array}$ & $\begin{array}{l}\text { AS } \\
\text { AP } \\
\text { IS }\end{array}$ & $\begin{array}{l}2.9 \\
3.9 \\
5.8\end{array}$ & $\begin{array}{l}4.6 \\
7.0 \\
4.8\end{array}$ & $\begin{array}{l}92.4 \\
89.1 \\
89.4\end{array}$ \\
\hline 5. & $\begin{array}{l}\text { HGPLIS } \\
p=.0045\end{array}$ & $\begin{array}{l}\text { AS } \\
\text { AP } \\
\text { IS }\end{array}$ & $\begin{array}{r}11.0 \\
6.2 \\
22.5\end{array}$ & $\begin{array}{r}14.8 \\
8.5 \\
15.7\end{array}$ & $\begin{array}{l}74.3 \\
85.3 \\
61.8\end{array}$ \\
\hline 6. & $\begin{array}{l}\text { HGPMEM } \\
p=.1799\end{array}$ & $\begin{array}{l}\text { AS } \\
\text { AP } \\
\text { IS }\end{array}$ & $\begin{array}{l}20.1 \\
24.4 \\
24.0\end{array}$ & $\begin{array}{l}20.5 \\
22.0 \\
12.5\end{array}$ & $\begin{array}{l}59.4 \\
53.5 \\
63.5\end{array}$ \\
\hline 7. & $\begin{array}{l}\text { HGPTYPE } \\
p=.0000\end{array}$ & $\begin{array}{l}\text { AS } \\
A P \\
\text { IS }\end{array}$ & $\begin{array}{l}29.0 \\
19.5 \\
48.5\end{array}$ & $\begin{array}{l}26.1 \\
39.1 \\
20.4\end{array}$ & $\begin{array}{l}45.0 \\
41.4 \\
31.1\end{array}$ \\
\hline 8. & $\begin{array}{l}\text { HGPABS } \\
p=.0945\end{array}$ & $\begin{array}{l}\text { AS } \\
\text { AP } \\
\text { IS }\end{array}$ & $\begin{array}{l}14.7 \\
14.8 \\
17.5\end{array}$ & $\begin{array}{r}13.9 \\
10.2 \\
7.8\end{array}$ & $\begin{array}{l}71.4 \\
75.0 \\
74.8\end{array}$ \\
\hline
\end{tabular}


TABLE XIV (continued)

ITMM \# NAME

PROBABILITY GROUP UNDESIRABLE (\%) NEUTRAL (\%) DESIRABLE (\%)

\begin{tabular}{|c|c|c|c|c|c|}
\hline 9. & $\begin{array}{l}\text { HGPINF } \\
p=0410\end{array}$ & $\begin{array}{l}\text { AS } \\
\text { AP } \\
\text { IS }\end{array}$ & $\begin{array}{l}28.0 \\
21.7 \\
31.4\end{array}$ & $\begin{array}{l}17.6 \\
32.6 \\
14.7\end{array}$ & $\begin{array}{l}54.4 \\
45.7 \\
53.9\end{array}$ \\
\hline 10. & $\begin{array}{l}\text { HGPIMAG } \\
\mathrm{p}=.0006\end{array}$ & $\begin{array}{l}\text { AS } \\
\text { AP } \\
\text { IS }\end{array}$ & $\begin{array}{l}19.7 \\
11.1 \\
34.0\end{array}$ & $\begin{array}{l}22.3 \\
17.5 \\
23.3\end{array}$ & $\begin{array}{l}58.0 \\
71.4 \\
42.7\end{array}$ \\
\hline 11. & $\begin{array}{l}\text { HGPINT } \\
\mathrm{p}=.4379\end{array}$ & $\begin{array}{l}\text { AS } \\
\text { AP } \\
\text { IS }\end{array}$ & $\begin{array}{r}6.8 \\
7.0 \\
12.0\end{array}$ & $\begin{array}{l}13.6 \\
18.6 \\
15.0\end{array}$ & $\begin{array}{l}79.6 \\
74.4 \\
73.0\end{array}$ \\
\hline 12. & $\begin{array}{l}\text { HGPEXC } \\
p=.0000\end{array}$ & $\begin{array}{l}\text { AS } \\
A P \\
\text { IS }\end{array}$ & $\begin{array}{l}54.9 \\
65.9 \\
23.3\end{array}$ & $\begin{array}{l}16.0 \\
11.6 \\
17.5\end{array}$ & $\begin{array}{l}29.1 \\
22.5 \\
59.2\end{array}$ \\
\hline 13. & $\begin{array}{l}\text { HGPCOUR } \\
p=.0000\end{array}$ & $\begin{array}{l}\text { AS } \\
\text { AP } \\
\text { IS }\end{array}$ & $\begin{array}{l}49.6 \\
45.2 \\
35.6\end{array}$ & $\begin{array}{l}31.0 \\
45.2 \\
21.8\end{array}$ & $\begin{array}{r}19.4 \\
9.7 \\
42.6\end{array}$ \\
\hline 14. & $\begin{array}{l}\text { UALCOUR2 } \\
p=.0000\end{array}$ & $\begin{array}{l}\text { AS } \\
\text { AP } \\
\text { IS }\end{array}$ & $\begin{array}{l}61.0 \\
45.2 \\
46.8\end{array}$ & $\begin{array}{l}31.1 \\
48.4 \\
20.2\end{array}$ & $\begin{array}{r}7.9 \\
6.3 \\
33.0\end{array}$ \\
\hline 15. & $\begin{array}{l}\text { UALSMOKE } \\
p=.0038\end{array}$ & $\begin{array}{l}\text { AS } \\
\text { AP } \\
\text { IS }\end{array}$ & $\begin{array}{l}74.8 \\
65.9 \\
81.4\end{array}$ & $\begin{array}{l}21.3 \\
34.1 \\
12.4\end{array}$ & $\begin{array}{l}3.9 \\
0.0 \\
6.2\end{array}$ \\
\hline 16. & $\begin{array}{l}\text { UALING } \\
p=.0000\end{array}$ & $\begin{array}{l}\text { AS } \\
\text { AP } \\
\text { IS }\end{array}$ & $\begin{array}{l}63.0 \\
54.7 \\
79.2\end{array}$ & $\begin{array}{l}29.6 \\
45.3 \\
10.4\end{array}$ & $\begin{array}{r}7.4 \\
0.0 \\
10.4\end{array}$ \\
\hline 17. & $\begin{array}{l}\text { UALAUTH } \\
\mathrm{p}=.0005\end{array}$ & $\begin{array}{l}\text { AS } \\
\text { AP } \\
\text { IS }\end{array}$ & $\begin{array}{l}36.3 \\
33.1 \\
30.5\end{array}$ & $\begin{array}{l}27.4 \\
46.5 \\
23.2\end{array}$ & $\begin{array}{l}36.3 \\
20.5 \\
46.3\end{array}$ \\
\hline
\end{tabular}

(Table XIV continued on next page.) 
TABLE XIV (continued)

ITEM \#\# NAME

PROBABILITY GROUP UNDESIRABLE (\%) NEUTRAL $(\%)$ DESIRABLE(\%)

\begin{tabular}{|c|c|c|c|c|c|}
\hline 18. & $\begin{array}{l}\text { UALPART } \\
p=.2799\end{array}$ & $\begin{array}{l}\text { AS } \\
\text { AP } \\
\text { IS }\end{array}$ & $\begin{array}{l}1.7 \\
2.3 \\
6.3\end{array}$ & $\begin{array}{l}4.7 \\
3.9 \\
7.3\end{array}$ & $\begin{array}{l}93.6 \\
93.8 \\
86.5\end{array}$ \\
\hline 19. & $\begin{array}{l}\text { UALREAD } \\
p=.0727\end{array}$ & $\begin{array}{l}\text { AS } \\
\text { AP } \\
\text { IS }\end{array}$ & $\begin{array}{r}3.0 \\
.8 \\
6.2\end{array}$ & $\begin{array}{l}6.4 \\
1.6 \\
9.3\end{array}$ & $\begin{array}{l}90.7 \\
97.7 \\
84.5\end{array}$ \\
\hline 20 & $\begin{array}{l}\text { UALNOTE } \\
\mathrm{p}=.2732\end{array}$ & $\begin{array}{l}\text { AS } \\
\text { AP } \\
\text { IS }\end{array}$ & $\begin{array}{l}2.6 \\
1.5 \\
5.2\end{array}$ & $\begin{array}{r}5.5 \\
8.5 \\
11.5\end{array}$ & $\begin{array}{l}91.9 \\
90.0 \\
83.3\end{array}$ \\
\hline 21. & $\begin{array}{l}\text { UALSLANT } \\
\mathrm{p}=.0000\end{array}$ & $\begin{array}{l}\text { AS } \\
\text { AP } \\
\text { IS }\end{array}$ & $\begin{array}{l}59.1 \\
48.4 \\
31.9\end{array}$ & $\begin{array}{l}24.7 \\
38.3 \\
25.5\end{array}$ & $\begin{array}{l}16.2 \\
13.3 \\
42.6\end{array}$ \\
\hline 22. & $\begin{array}{l}\text { UALGRADE } \\
\mathrm{p}=.0001\end{array}$ & $\begin{array}{l}\text { AS } \\
\text { AP } \\
\text { IS }\end{array}$ & $\begin{array}{l}56.6 \\
47.7 \\
42.7\end{array}$ & $\begin{array}{l}26.4 \\
39.1 \\
19.8\end{array}$ & $\begin{array}{l}17.0 \\
13.3 \\
37.5\end{array}$ \\
\hline 23. & $\begin{array}{l}\text { UALATTND } \\
\mathrm{p}=.5994\end{array}$ & $\begin{array}{l}\text { AS } \\
\text { AP } \\
\text { IS }\end{array}$ & $\begin{array}{l}2.1 \\
1.5 \\
3.1\end{array}$ & $\begin{array}{r}4.2 \\
6.2 \\
10.3\end{array}$ & $\begin{array}{l}93.6 \\
92.3 \\
86.6\end{array}$ \\
\hline 24. & $\begin{array}{l}\text { UALDIRCT } \\
\mathrm{p}=.0015\end{array}$ & $\begin{array}{l}\text { AS } \\
\text { AP } \\
\text { IS }\end{array}$ & $\begin{array}{l}32.1 \\
26.6 \\
19.8\end{array}$ & $\begin{array}{l}23.5 \\
32.8 \\
12.5\end{array}$ & $\begin{array}{l}44.4 \\
40.6 \\
67.7\end{array}$ \\
\hline 25 & $\begin{array}{l}\text { UALCMPRE } \\
p=.0002\end{array}$ & $\begin{array}{l}\text { AS } \\
\text { AP } \\
\text { IS }\end{array}$ & $\begin{array}{l}73.5 \\
64.6 \\
58.3\end{array}$ & $\begin{array}{l}18.8 \\
32.3 \\
21.9\end{array}$ & $\begin{array}{r}7.7 \\
3.1 \\
19.8\end{array}$ \\
\hline 26. & $\begin{array}{l}\text { UALRAISE } \\
\mathrm{p}=.0000\end{array}$ & $\begin{array}{l}\text { AS } \\
\text { AP } \\
\text { IS }\end{array}$ & $\begin{array}{l}38.0 \\
35.4 \\
20.6\end{array}$ & $\begin{array}{l}34.6 \\
48.5 \\
20.6\end{array}$ & $\begin{array}{l}27.4 \\
16.2 \\
58.8\end{array}$ \\
\hline
\end{tabular}

(Table XIV continued on next page.) 
TABLE XIV (continued)

\begin{tabular}{|c|c|c|c|c|c|}
\hline PROB. & ILITY & GROUP & UNDESIRABLE (\%) & NEUTRAL (\%) & DESIRABLE (\%) \\
\hline 27. & $\begin{array}{l}\text { PROFTEST } \\
\mathrm{p}=.2063\end{array}$ & $\begin{array}{l}\text { AS } \\
\text { AP } \\
\text { IS }\end{array}$ & $\begin{array}{l}51.5 \\
37.0 \\
41.0\end{array}$ & $\begin{array}{l}20.3 \\
22.8 \\
24.8\end{array}$ & $\begin{array}{l}28.3 \\
40.2 \\
34.3\end{array}$ \\
\hline 28. & $\begin{array}{l}\text { PROFPRFM } \\
p=.0050\end{array}$ & $\begin{array}{l}\text { AS } \\
\text { AP } \\
\text { IS }\end{array}$ & $\begin{array}{l}45.4 \\
40.6 \\
24.3\end{array}$ & $\begin{array}{l}23.1 \\
31.3 \\
30.1\end{array}$ & $\begin{array}{l}31.5 \\
28.1 \\
45.6\end{array}$ \\
\hline 29. & $\begin{array}{l}\text { PROFQUES } \\
p=.0178\end{array}$ & $\begin{array}{l}\text { AS } \\
\text { AP } \\
\text { IS }\end{array}$ & $\begin{array}{l}16.9 \\
18.8 \\
13.6\end{array}$ & $\begin{array}{l}16.0 \\
29.7 \\
13.6\end{array}$ & $\begin{array}{l}67.1 \\
51.6 \\
72.8\end{array}$ \\
\hline 30. & $\begin{array}{l}\text { PROFQUT } \\
p=.0029\end{array}$ & $\begin{array}{l}\text { AS } \\
\text { AP } \\
\text { IS }\end{array}$ & $\begin{array}{l}55.5 \\
56.3 \\
35.2\end{array}$ & $\begin{array}{l}15.1 \\
23.8 \\
25.7\end{array}$ & $\begin{array}{l}29.4 \\
19.8 \\
39.0\end{array}$ \\
\hline 31. & $\begin{array}{l}\text { PROFPERS } \\
p=.0543\end{array}$ & $\begin{array}{l}\text { AS } \\
\text { AP } \\
\text { IS }\end{array}$ & $\begin{array}{l}37.4 \\
35.7 \\
44.8\end{array}$ & $\begin{array}{l}21.0 \\
27.1 \\
21.0\end{array}$ & $\begin{array}{l}41.6 \\
37.2 \\
34.3\end{array}$ \\
\hline 32 . & $\begin{array}{l}\text { PROFFORM } \\
p=.0004\end{array}$ & $\begin{array}{l}\text { AS } \\
\text { AP } \\
\text { IS }\end{array}$ & $\begin{array}{r}5.9 \\
1.6 \\
17.9\end{array}$ & $\begin{array}{l}6.3 \\
5.5 \\
5.7\end{array}$ & $\begin{array}{l}87.8 \\
93.0 \\
76.4\end{array}$ \\
\hline 33. & $\begin{array}{l}\text { PROFSPK } \\
\mathrm{P}=.1421\end{array}$ & $\begin{array}{l}\text { AS } \\
\text { AP } \\
\text { IS }\end{array}$ & $\begin{array}{l}2.9 \\
0.0 \\
6.7\end{array}$ & $\begin{array}{l}5.0 \\
3.9 \\
2.9\end{array}$ & $\begin{array}{l}92.1 \\
96.1 \\
90.4\end{array}$ \\
\hline 34. & $\begin{array}{l}\text { PROFRTRN } \\
\mathrm{p}=.9013\end{array}$ & $\begin{array}{l}\text { AS } \\
\text { AP } \\
\text { IS }\end{array}$ & $\begin{array}{l}4.3 \\
3.1 \\
1.9\end{array}$ & $\begin{array}{l}13.2 \\
14.1 \\
12.6\end{array}$ & $\begin{array}{l}82.6 \\
82.8 \\
85.4\end{array}$ \\
\hline 35. & $\begin{array}{l}\text { PROFOPIN } \\
\mathrm{p}=.7892\end{array}$ & $\begin{array}{l}\text { AS } \\
\text { AP } \\
\text { IS }\end{array}$ & $\begin{array}{l}1.3 \\
1.6 \\
1.9\end{array}$ & $\begin{array}{l}6.7 \\
2.3 \\
5.7\end{array}$ & $\begin{array}{l}92.1 \\
96.1 \\
92.5\end{array}$ \\
\hline
\end{tabular}


TABLE XIV (continued)

ITEM \# NAME

PROBABILITY

GROUP UNDESIRABLE

NEUTRAL

DESIRABLE

\begin{tabular}{|c|c|c|c|c|c|}
\hline 36. & $\begin{array}{l}\text { PROFMATR } \\
\mathrm{p}=.0005\end{array}$ & $\begin{array}{l}\text { AS } \\
\text { AP } \\
\text { IS }\end{array}$ & $\begin{array}{l}33.6 \\
11.2 \\
28.2\end{array}$ & $\begin{array}{l}25.6 \\
25.6 \\
18.4\end{array}$ & $\begin{array}{l}40.8 \\
63.2 \\
53.4\end{array}$ \\
\hline 37. & $\begin{array}{l}\text { PROFINVT } \\
\mathrm{p}=.8451\end{array}$ & $\begin{array}{l}\text { AS } \\
\text { AP } \\
\text { IS }\end{array}$ & $\begin{array}{l}19.2 \\
14.2 \\
15.5\end{array}$ & $\begin{array}{l}23.4 \\
21.3 \\
19.4\end{array}$ & $\begin{array}{l}57.3 \\
64.6 \\
65.0\end{array}$ \\
\hline 38. & $\begin{array}{l}\text { PROFHRS } \\
\mathrm{P}=.0120\end{array}$ & $\begin{array}{l}\text { AS } \\
\text { AP } \\
\text { IS }\end{array}$ & $\begin{array}{l}0.4 \\
0.8 \\
4.8\end{array}$ & $\begin{array}{l}2.5 \\
3.1 \\
9.5\end{array}$ & $\begin{array}{l}97.1 \\
96.1 \\
84.8\end{array}$ \\
\hline 39. & $\begin{array}{l}\text { PROFAVLB } \\
\mathrm{p}=.2131\end{array}$ & $\begin{array}{l}\mathrm{AS} \\
\mathrm{AP} \\
\mathrm{IS}\end{array}$ & $\begin{array}{l}16.3 \\
22.8 \\
11.4\end{array}$ & $\begin{array}{l}19.2 \\
23.6 \\
20.0\end{array}$ & $\begin{array}{l}64.4 \\
53.5 \\
68.6\end{array}$ \\
\hline 40 & $\begin{array}{l}\text { PROFNAME } \\
\mathrm{p}=.7923\end{array}$ & $\begin{array}{l}\text { AS } \\
\text { AP } \\
\text { IS }\end{array}$ & $\begin{array}{l}8.8 \\
6.3 \\
7.5\end{array}$ & $\begin{array}{l}13.4 \\
11.7 \\
17.9\end{array}$ & $\begin{array}{l}77.8 \\
82.0 \\
74.5\end{array}$ \\
\hline 41. & $\begin{array}{l}\text { PROFPERM } \\
\mathrm{p}=.3033\end{array}$ & $\begin{array}{l}\text { AS } \\
\text { AP } \\
\text { IS }\end{array}$ & $\begin{array}{l}37.8 \\
35.9 \\
26.0\end{array}$ & $\begin{array}{l}31.1 \\
26.6 \\
27.9\end{array}$ & $\begin{array}{l}31.1 \\
37.5 \\
46.2\end{array}$ \\
\hline 42. & $\begin{array}{l}\text { PROFQUIZ } \\
p=.0012\end{array}$ & $\begin{array}{l}\text { AS } \\
\text { AP } \\
\text { IS }\end{array}$ & $\begin{array}{l}42.0 \\
47.2 \\
37.9\end{array}$ & $\begin{array}{l}31.1 \\
39.4 \\
22.3\end{array}$ & $\begin{array}{l}26.9 \\
13.4 \\
39.8\end{array}$ \\
\hline 43. & $\begin{array}{l}\text { PROFLANG } \\
p=.0006\end{array}$ & $\begin{array}{l}\text { AS } \\
\text { AP } \\
\text { IS }\end{array}$ & $\begin{array}{l}52.9 \\
26.2 \\
46.6\end{array}$ & $\begin{array}{l}18.1 \\
20.6 \\
16.5\end{array}$ & $\begin{array}{l}29.0 \\
53.2 \\
36.9\end{array}$ \\
\hline 44. & $\begin{array}{l}\text { PROFDED } \\
\mathrm{p}=.0001\end{array}$ & $\begin{array}{l}\text { AS } \\
\text { AP } \\
\text { IS }\end{array}$ & $\begin{array}{l}2.5 \\
1.6 \\
7.7\end{array}$ & $\begin{array}{r}3.8 \\
0.8 \\
13.5\end{array}$ & $\begin{array}{l}93.7 \\
97.6 \\
78.8\end{array}$ \\
\hline
\end{tabular}

(Table XIV continued on next page.) 
TABLE XIV (continued)

\begin{tabular}{|c|c|c|c|c|c|}
\hline PROBA & ILITY & GROUP & UNDESIRABLE & NEUTRAL & DES IRABLE \\
\hline 45. & $\begin{array}{l}\text { PROFINFR } \\
\mathrm{p}=.0000\end{array}$ & $\begin{array}{l}\mathrm{AS} \\
\mathrm{AP} \\
\mathrm{IS}\end{array}$ & $\begin{array}{l}23.2 \\
48.8 \\
34.6\end{array}$ & $\begin{array}{l}21.9 \\
22.8 \\
12.5\end{array}$ & $\begin{array}{l}54.9 \\
28.3 \\
52.9\end{array}$ \\
\hline
\end{tabular}


TABLE XV

BREAKDOWN OF COUNTRIES REPRESENTED

BY CULTURE AREA DESIGNATIONS

American Professors:

American Students:

Asian Students (excluding Japan):

The Asian sample included students who declared their background or country as Chinese, Hong Kong, Indonesia, Micronesia, Oriental, Phillipines, Taiwan, Thailand, and Vietnam.

Japanese Students:

Middle Eastern Students (excluding Iran):

The Middle Eastern sample included students who declared their background or country as Arab, Iraq, Kuwait, Lebanon, Libya, Middle Eastern, Palestine, Qatar, Saudi Arabia, Turkey, United Arab Emirates.

Iranian Students:

African Students:

The African sample included students who declared their background or country as African, Ethiopia, Liberia, and Nigeria.

Latin American Students:

The Latin American sample included students who declared their background or country as Costs Rica, Mexico, South American, and Venezuela.

Western European Students:

The Western European sample included students who declared their background or country as England, European, The Netherlands, and Switzerland. 